\title{
ESTUDO DAS CARACTERÍSTICAS ELÉTRICAS E MICROESTRUTURAIS DE SUPERCAPACITORES PARA ARMAZENAMENTO DE ENERGIA
}

\author{
Antonio Paulo Rodrigues Fernandez
}

Dissertação apresentada como parte dos requisitos para obtenção do Grau de Mestre em Ciências na Área de Tecnologia Nuclear - Materiais

Orientador:

Prof. Dr. Rubens Nunes de Faria Junior

São Paulo

2016 


\title{
INSTITUTO DE PESQUISAS ENERGÉTICAS E NUCLEARES
}

Autarquia Associada à Universidade de São Paulo

\section{ESTUDO DAS CARACTERÍSTICAS ELÉTRICAS E MICROESTRUTURAIS DE SUPERCAPACITORES PARA ARMAZENAMENTO DE ENERGIA}

\author{
Antonio Paulo Rodrigues Fernandez
}

Dissertação apresentada como parte dos requisitos para obtenção do Grau de Mestre em Ciências na Área de Tecnologia Nuclear - Materiais

Orientador:

Prof. Dr. Rubens Nunes de Faria Junior

São Paulo

2016 
À minha mãe Anita, em seu descanso eterno. 


\section{AGRADECIMENTOS}

Agradeço imensamente ao meu Professor e Orientador Dr. Rubens Nunes de Faria Júnior, por me ensinar e conduzir, com paciência, conhecimento e sabedoria.

Agradeço ao Dr. Júlio César Serafim Casini pela amizade e participação no desenvolvimento e nas pesquisas dos supercapacitores à base de grafeno reduzido pelo processo HDDR.

Agradeço ao Dr. Eguiberto Galego pela amizade e pelo auxilio nas análises de fluorescência de raios $\mathrm{X}$ e de microscopia eletrônica de varredura.

Agradeço a Srta. Tayara Correia Gonsalves pelas curvas de voltametria cíclica.

Agradeço aos órgãos de fomento (FAPESP/CNPq) pelo suporte financeiro aos Laboratórios do Grupo de Baterias, Supercapacitores e Células Fotovoltaicas do IPENCCTM possibilitando a realização desta investigação.

Agradeço ao meu Pai de alma, Guines Martines Fernandez, pelo seu amor incondicional, a cada segundo, todos os dias.

Agradeço a minha irmã Saada Hachem Araji, por ter acreditado em mim, por me incentivar a explorar o mundo das ciências e, principalmente, por ser meu maior exemplo de perseverança e humildade.

Agradeço a minha filha Thais Saada Ferreira Fernandez, por ser a pessoa mais fascinante que conheço, por ser meu maior motivo de continuar tentando melhorar como pessoa, por me amar do fundo da alma, apesar de todos meus defeitos e ausências. Minha alma gêmea de polaridade invertida. Te amo Filha, sempre. 
"Um expert é uma pessoa que cometeu todos os erros possíveis em uma área específica."

Niels Bohr. 


\section{RESUMO}

Fernandez, Antonio Paulo Rodrigues. Estudo das Características Elétricas e Microestruturais de Supercapacitores para Armazenamento de Energia. 2016. 125 f. Dissertação (Mestrado) - Instituto de Pesquisas Energéticas e Nucleares - Autarquia Associada à Universidade de São Paulo, São Paulo, 2016.

Esta dissertação tem por objetivo reportar dados relativos às características elétricas e microestruturais de eletrodos aplicadas em dispositivos armazenadores de energia, especificamente supercapacitores constituídos por eletrodos de carvão ativado.

Os parâmetros elétricos estudados foram a resistência em série equivalente obtida pelo método da interrupção de corrente $\left(E S R_{(I n s t)}\right)$ (sendo que a sigla $E S R$ é oriunda do termo inglês Equivalent Series Resistance), a resistência em paralelo equivalente $\left(E P R_{(D e p)}\right)$ obtida pelo método do valor dependente (sendo que a sigla EPR é oriunda do termo inglês Equivalent Parallel Resistance) e a capacitância $\left(C_{(D C)}\right)$ obtida pelo método da corrente contínua (sendo que a sigla DC oriunda do termo inglês Direct Current).

Tais parâmetros foram escolhidos devido ao impacto que causam no tempo de vida útil, na capacidade de armazenamento de cargas elétricas, na velocidade de carga e descarga, na perda por efeito termoiônico nos processos de carga e descarga e na perda de cargas armazenadas devido à autodescarga em supercapacitores. Os dados microestruturais reportam por meio de imagens a homogeneidade da porosidade e por meio de valores correlacionados a composição química e eventuais contaminações presentes nos eletrodos. Os dados e valores coletados possuem a intenção de servir como referência comparativa de qualidade e apontar qual parâmetro afeta mais a qualidade do supercapacitor. Para tanto foram realizados testes a fim de coletar valores de $C_{(D C)}, E S R_{(I n s t)}$ e $E P R_{(D e p)}$ após a exposição de supercapacitores de $1 \mathrm{~F} / 5,5 \mathrm{~V}$ a temperaturas de $50^{\circ} \mathrm{C}, 75^{\circ} \mathrm{C}, 100^{\circ} \mathrm{C}$ e $125^{\circ} \mathrm{C}$ por 672 horas, sendo os dados coletados ao inicio dos testes, à temperatura ambiente, e posteriormente a cada 168 horas. Feitos os experimentos concluiu-se que o parâmetro que sofreu maior deterioração com o acréscimo de energia térmica foi a $E P R_{(D e p)}$, em seguida a $C_{(D C)}$, que de fato pouco sofreu alteração e a $E S R_{(I n s t)}$, em que a mudança dentro do erro de medição foi imperceptível.

Palavras chave: Supercapacitores. Resistência em série equivalente. Resistência em paralelo equivalente. Capacitância. Alteração dos parâmetros elétricos com o aumento da energia térmica. 


\begin{abstract}
Fernandez, Antonio Paulo Rodrigues. Study of Electrical and Microstructural Characteristics of Supercapacitors for Energy Storage. 2016. 125 f. Thesis (MA) Institute of Energy and Nuclear Research - linked to the University of São Paulo, São Paulo, 2016.

This paper aims to report information on electrical and microstructural characteristics of electrodes applied at devices that store energy, specifically supercapacitors made of activated carbon electrodes.

The studied electrical parameters were the equivalent series resistance obtained by the method of the instantaneous value of the voltage drop $\left(E S R_{(I n s t)}\right)$, where the acronym ESR has the meaning "Equivalent Series Resistance", the equivalent parallel resistance $\left(E P R_{(D e p)}\right)$ obtained by the method of dependent value, where the acronym EPR has the meaning "Equivalent Parallel Resistance", and the capacitance $\left(C_{(D C)}\right)$ obtained by the method of direct current.

These parameters were chosen because of the impact they have on lifetime, the storage capacity of electric charge, the speed of loading and unloading, the loss thermionic effect on the charge and discharge processes and loss of stored charge due to self-discharge in supercapacitors. The data given by microstructural images of the homogeneity and porosity values correlated by the chemical composition and possible contaminations present in the electrodes. The collected data and values are intended to serve as a comparative reference point and quality parameter which most affects the quality of the supercapacitor. For both tests were carried out in order to collect values of $C_{(D C)}, E S R_{(I n s t)}$ and $E P R_{(D e p)}$ after supercapacitors of the $1 F / 5.5 \mathrm{~V}$ are exposure at temperatures of 50,75, 100 and $125^{\circ} \mathrm{C}$ for 672 hours, and the data collected at the beginning of the tests (room temperature) and subsequently every 168 hours. Made experiments it was concluded that the parameter further deterioration suffered with the increase of thermal energy is $\operatorname{EPR}_{(D e p)}$, then $C_{(D C)}$, which in fact little changed and $\operatorname{ESR}_{(I n s t)}$, in which the change in the measurement error was are noticeable.
\end{abstract}

Keywords: Supercapacitors. Equivalent series resistance. Equivalent parallel resistance. Capacitance. Modification of the electrical parameters with increased thermal energy. 


\section{SUMÁRIO}

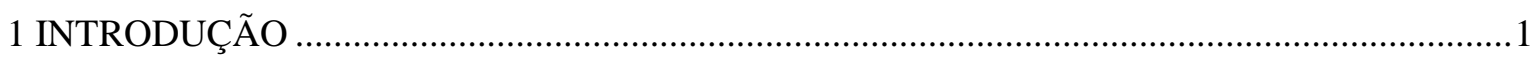

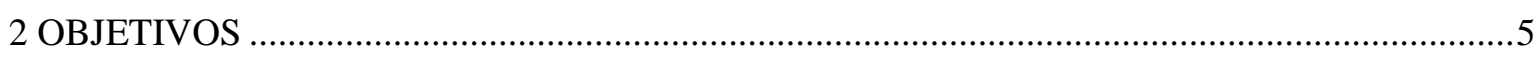

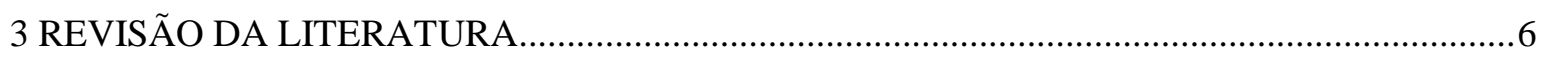

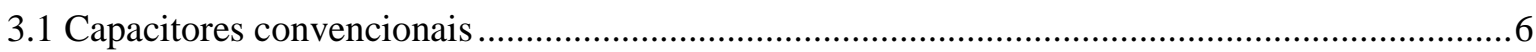

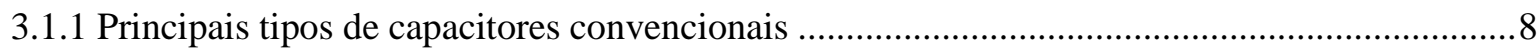

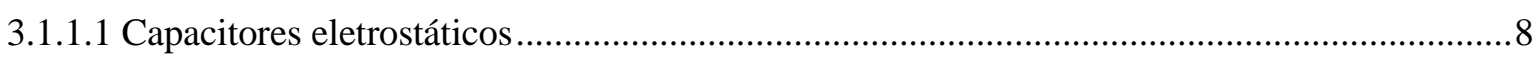

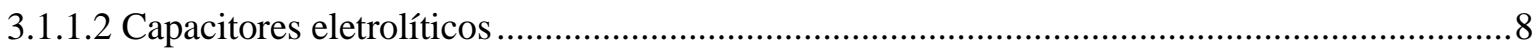

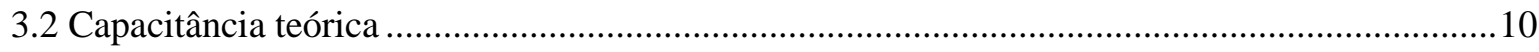

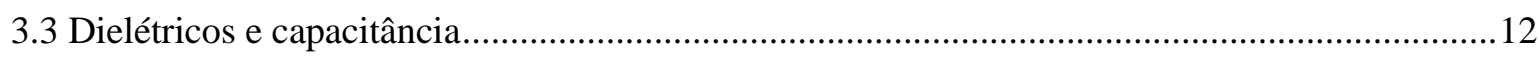

3.4 Modelos de armazenamento de energia para capacitores de dupla camada elétrica ....................18

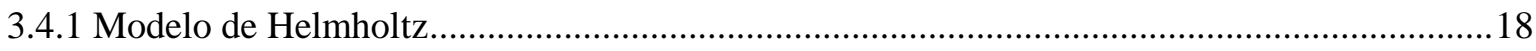

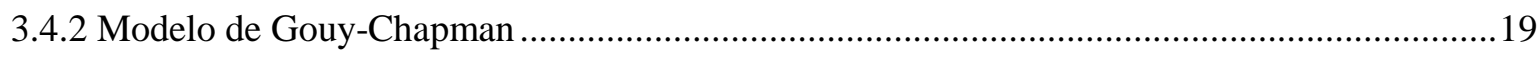

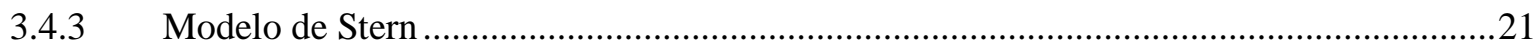

3.5 Supercapacitores - Capacitores de dupla camada elétrica ....................................................22

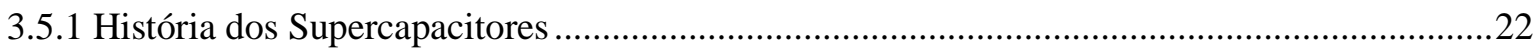

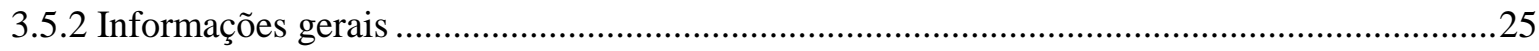

3.5.3 Princípios de armazenamento de energia correlacionado aos supercapacitores ........................30

3.5.4 Materiais empregados na produção de supercapacitores ........................................................36

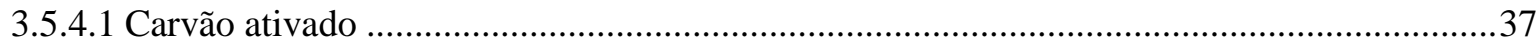

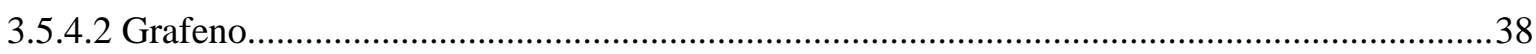

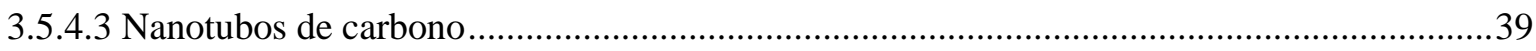

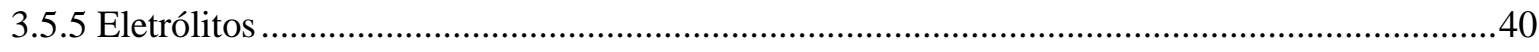

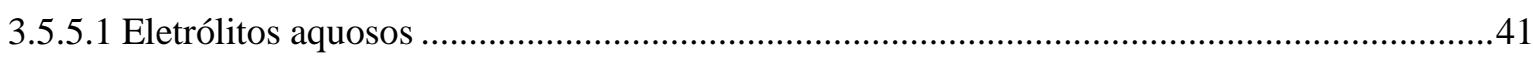

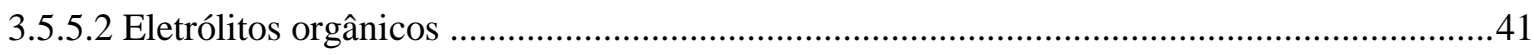

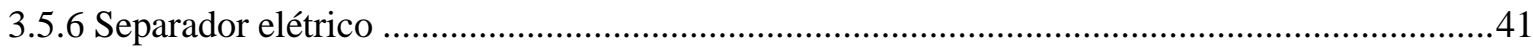

3.5.7 Circuito equivalente do supercapacitor tendo como base o modelo de Helmholtz...................42

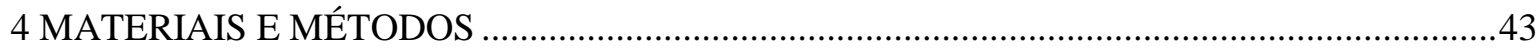


4.1 Considerações gerais

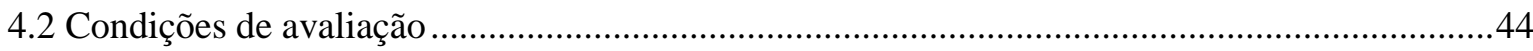

4.3 Equipamentos utilizados na avaliação dos parâmetros elétricos.

4.4 Equipamentos utilizados na avaliação da microestrutura e na composição química dos eletrodo

4.5 Resistência em paralelo equivalente obtida pelo método do valor dependente - $E P R_{(D e p)} \ldots \ldots \ldots . . . .46$

4.6 Resistência em série equivalente obtida pelo método da interrupção de corrente - $\operatorname{ESR}_{(I n s t) \cdots \cdots . . .49}$

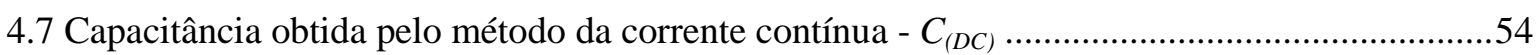

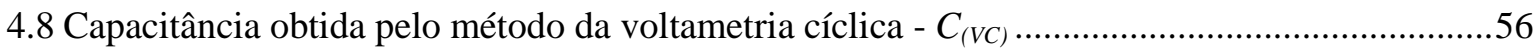

4.8.1 Capacitância obtida pelo método da área do voltamograma cíclico - $C_{(A V C)} \ldots \ldots \ldots \ldots \ldots \ldots \ldots \ldots \ldots \ldots . . . . . . . . . . . . . .62$

4.8.2 Capacitância obtida pelo método da média dos valores da corrente elétrica de resposta em módulo - $C_{(V C i M)}$

4.8.3 Capacitância obtida pelo método da média dos valores de corrente elétrica de resposta oriundos dos menores valores de potencial (potencial tendendo a zero) $-C_{(V C V \rightarrow 0)} \ldots \ldots \ldots \ldots \ldots \ldots \ldots \ldots \ldots . . . . . . . . . . . . . .64$

5 RESULTADOS .65

5.1 Considerações gerais

5.2 Avaliação da resistência em paralelo equivalente obtida pelo método do valor dependente $E P R_{(D e p)}$ .66

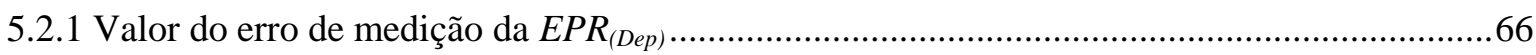

5.2.2 Valor da tolerância para a $E P R_{(D e p)}$

5.2.3 Valores de $E P R_{(D e p)}$ (a 80 horas de autodescarga) obtidos por meio da avaliação de quatro supercapacitores de referência em diferentes temperaturas e tempos de exposição

5.3 Avaliação da resistência em série equivalente obtida pelo método da interrupção de corrente -

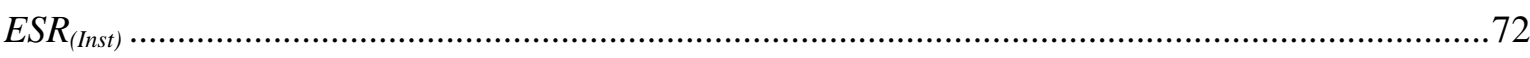

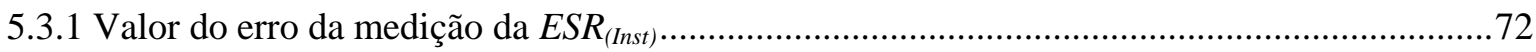

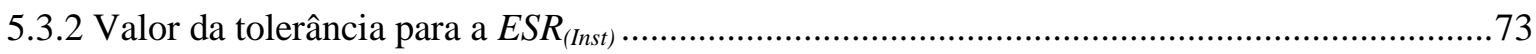

5.3.3 Valores de $E S R_{(I n s t)}$ obtidos pela avaliação de quatro supercapacitores de referência em diferentes temperaturas e diferentes tempos de exposição... .74

5.4 Avaliação da capacitância obtida pelo método da corrente contínua $\left(C_{(D C)}\right)$ à uma corrente

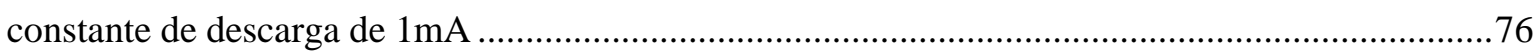

5.4.1 Valor do erro da medição da $C_{(D C)}$ a uma corrente constante de descarga de $1 m A$....................76 
5.4.2 Valor da tolerância para a $C_{(D C)}$ a uma corrente constante de descarga de $\operatorname{lm} A$

5.4.3 Valore da $C_{(D C)}$ a uma corrente constante de $1 \mathrm{~mA}$ obtidos por meio da avaliação de quatro supercapacitores de referência em diferentes temperaturas e diferentes tempos de exposição .........78

5.5 Avaliação da capacitância obtida pelo método da área do voltamograma cíclico - $C_{(A V C)} \ldots \ldots . . . . . .79$

5.5.1 Valor do erro da medição da $C_{(A V C)}$ para as velocidades de varredura de $25 \mathrm{mV} / \mathrm{s}, 50 \mathrm{mV} / \mathrm{s}$, $75 \mathrm{mV} / \mathrm{s}$ e $100 \mathrm{mV} / \mathrm{s}$

5.5.2 Valor da tolerância para a $C_{(A V C)}$.

5.5.3 Valores da $C_{(A V C)}$ obtidos por meio da avaliação de quatro supercapacitores de referência em diferentes temperaturas e diferentes tempos de exposição.

5.6 Avaliação da capacitância obtida pelo método da média dos valores da corrente elétrica de

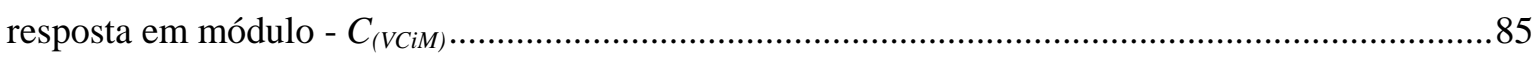

5.6.1 Valor do erro de medição da $C_{(V C i M)}$ para as velocidade de varredura de $25 \mathrm{mV} / \mathrm{s}, 50 \mathrm{mV} / \mathrm{s}$, $75 \mathrm{mV} / \mathrm{s}$ e $100 \mathrm{mV} / \mathrm{s}$ .85

5.6.2 Valor de tolerância para a $C_{(V C i M)}$

5.6.3 Valores da $C_{(V C i M)}$ obtidos pela avaliação de quatro supercapacitores de referência em diferentes temperaturas e diferentes tempos de exposição. .88

5.7 Avaliação da capacitância obtida pelo método da média dos valores de corrente elétrica de resposta oriundos dos menores valores de potencial (potencial tendendo a zero) - $C_{(V C V \rightarrow 0)}$

5.7.1 Valor do erro da medição da $C_{(V C V \rightarrow 0)}$ para velocidades de varredura de $25 \mathrm{mV} / \mathrm{s}, 50 \mathrm{mV} / \mathrm{s}$, $75 \mathrm{mV} / \mathrm{s}$ e $100 \mathrm{mV} / \mathrm{s}$

5.7.2 Valor da tolerância para a $C_{(V C V \rightarrow 0)}$

5.7.3 Valores da $C_{(V C V \rightarrow 0)}$ obtidos pela avaliação de quatro supercapacitores de referência em diferentes temperaturas e diferentes tempos de exposição .92

5.8 Análise química e caracterização dos materiais dos eletrodos .93

6 ANÁLISE E DISUCUSSÕES DOS RESULTADOS. .96

7 CONCLUSÕES. 102

8 REFERÊNCIAS BIBLIOGRÁFICAS 104 


\section{LISTA DE TABELAS}

Tabela 1 - Comparação entre a área específica superficial e capacitância específica de diferentes materiais baseados em carbono empregados na construção de capacitores que fazem uso de EDL (Panno, 2015; Schindall, Kassakian, Ku, \& Riccardo, 2016)

Tabela 2 - Dados utilizados na obtenção do valor do erro de medição da $E P R_{(D e p)}$

Tabela 3 - Dados utilizados na obtenção do valor da tolerância referente à $E P R_{(D e p)} \ldots \ldots . . .68$ Tabela 4 - Valores da $E P R_{(D e p)}$ para cada um dos supercapacitores de referência em diferentes temperatura e diferentes tempos de exposição.

Tabela 5 - Dados utilizados na obtenção do valor do erro de medição dos valores da

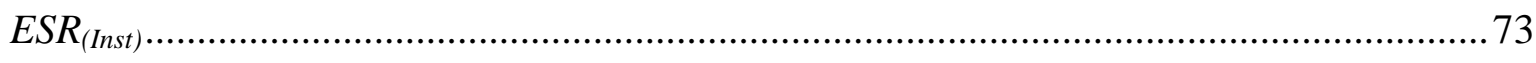

Tabela 6 - Dados utilizados na obtenção do valor da tolerância referente à $\operatorname{ESR}_{(\text {Inst) }} \ldots . . . . . . .74$ Tabela 7 - Valores da $\boldsymbol{E S R}_{(\text {Inst) }}$ para cada um dos supercapacitores de referência em diferentes temperatura e diferentes tempos de exposição .75

Tabela 8 - Dados utilizados na obtenção do valor do erro de medição da $C_{(D C)} a \operatorname{lmA} \ldots \ldots . .76$ Tabela 9 - Dados utilizados na obtenção do valor da tolerância referente à $C_{(D C)} a 1 m A \ldots 77$ Tabela 10 - Valores da $C_{(D C)}$, obtida com uma corrente constante de $1 \mathrm{~mA}$, para cada um dos supercapacitores de referência em diferentes tempos e temperaturas ............................78 Tabela 11 - Valores estimados da $C_{(D C)}$ específica, obtida com uma corrente constante de $1 \mathrm{~mA}$, em diferentes tempos e temperaturas de exposição para cada um dos supercapacitores de referência 78

Tabela 12 - Dados utilizados para determinar o valor do erro de medição da $C_{(A V C)}$ obtido por meio de dez medições de um único capacitor

Tabela 13 - Dados utilizados para determinar o valor da tolerância da $C_{(A V C)}$ para um lote de dez unidades de supercapacitores

Tabela 14 - Valores da $C_{(A V C)}$ em diferentes taxas de varredura para um supercapacitor não exposto (S0) e para os supercapacitores de referência S1, S2 e S3 expostos em diferentes temperatura e tempo de exposição de 672 horas 84

Tabela 15 - Valores estimados da $C_{(V C)}$ específica em diferentes taxas de varredura para um supercapacitor não exposto (S0) e para os supercapacitores de referência S1, S2 e S3 expostos em diferentes temperatura e tempo de exposição de 672 horas.

Tabela 16 - Dados utilizados para determinar o valor do erro de medição da $C_{(V C i M)} \ldots \ldots . . . .86$

Tabela 17 - Dados utilizados para determinar o valor da tolerância referente à $C_{(V C i M)} \ldots . . .87$ 
Tabela 18 - Valores da $C_{(V C i M)}$ para um supercapacitor não exposto (S0) e para os supercapacitores de referência S1, S2 e S3 expostos em diferentes temperatura e tempo de exposição de 672 horas

Tabela 19 - Valores estimados da $C_{(V C i M)}$ específica para um supercapacitor não exposto (S0) e para os supercapacitores de referência S1, S2 e S3 expostos em diferentes temperatura e tempo de exposição de 672 horas. 89

Tabela 20 - Dados utilizados para determinar o valor do erro de medição da $C_{(V C V \rightarrow 0)}$. .... 90

Tabela 21 - Dados utilizados para determinar o valor da tolerância da $C_{(V C V \rightarrow 0)} \ldots \ldots \ldots \ldots \ldots . . . . .91$

Tabela 22 - Valores da $C_{(V C V \rightarrow 0)}$ para um supercapacitor não exposto (S0) e para os supercapacitores de referência S1, S2 e S3 expostos em diferentes temperatura e tempo de exposição de 672 horas 92

Tabela 23 - Valores estimados da $C_{(V C V \rightarrow 0)}$ específica para um supercapacitor não exposto (S0) e para os supercapacitores de referência S1, S2 e S3 expostos em diferentes temperatura e tempo de exposição de 672 horas 92

Tabela 24 - Análise de fluorescência de Raios-X semiquantitativa do material do eletrodo

Tabela 25 - Valores percentuais do erro de medição da capacitância em acordo com o método adotado.

Tabela 26 - Valores da capacitância após 672 horas de exposição em acordo com o método adotado 98 


\section{LISTA DE FIGURAS}

Figura 1 - Gráfico de Ragone, relacionando energia específica e potência específica (Carvalho, 2014).

Figura 2 - Dois condutores próximos que estão isolados entre si formando um capacitor. ..7

Figura 3 - Capacitor de placas paralelas.

Figura 4 - Esquema de um capacitor eletrostático onde $D_{\text {diel }}$ representa a espessura do dielétrico que separa o catodo do anodo (Franco, 2014). .8

Figura 5 - Esquema de um capacitor eletrolítico, onde $\mathrm{D}_{\text {oxi }}$ representa a espessura do óxido que separa o catodo do anodo (Franco, 2014).

Figura 6 - (a) a configuração fundamental de um capacitor; (b) linhas de campo provenientes das placas do capacitor de placas paralelas. 10

Figura 7 - Polarização do dielétrico. 14

Figura 8 - Placas químicas. 16

Figura 9 - Variação linear da capacitância com a distância em relação a superfície do eletrodo (adaptado de Conway, 1999).

Figura 10 - Variação exponencial da capacitância com a distância em relação a superfície do eletrodo (adaptado de Conway, 1999).

Figura 11 - Variação da capacitância com a distância em relação à superfície do eletrodo em acordo com o modelo de Stern (adaptado de Conway, 1999). 21

Figura 12 - Alguns modelos de supercapacitores (Maxwell Technologies, 2015). 25

Figura 13 - Famílias de supercapacitores, EDLC, pseudocapacitores e híbridos, em acordo com o projeto dos eletrodos (adaptado de en.Wikipedia.org - Supercapacitor, 2016)........ 26 Figura 14 - Esquematização de um EDLC evidenciando a característica de porosidade dos eletrodos (Carvalho, 2014).

Figura 15 - Modelo da dupla camada formada na interface eletrodo-eletrólito, adaptado de Franco, 2014. 34

Figura 16 - Circuito equivalente de um supercapacitor (Adaptado de Conway, 1999)......42

Figura 17 - Circuito representando a autodescarga do supercapacitor. 48

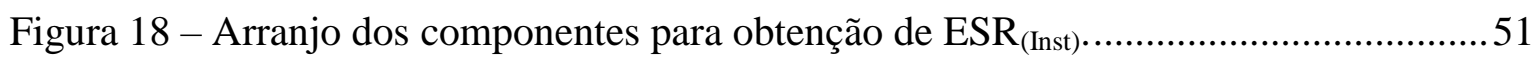

Figura 19 - Obtenção da $\operatorname{ESR}_{(\text {Inst) }}$ por meio da queda instantânea do potencial. .................51

Figura 20 - Processo de descarga livre do supercapacitor. ................................................52

Figura 21 - Circuito utilizado para determinar $\mathrm{v}_{\mathrm{C}}\left(\mathrm{tf}^{\prime}\right)$....................................................52 
Figura 22 - Circuito utilizado para determinar a capacitância do supercapacitor.

Figura 23 - Voltamograma cíclico de um supercapacitor ideal (a), da combinação entre um supercapacitor ideal e de um resistor em série (b), de um supercapacitor ideal em paralelo com um resistor (c) e de um resistor em série com um resistor em paralelo com um capacitor (d) (Huang, 2013).

Figura 24 - Comparação entre voltamogramas cíclicos de um capacitor ideal e de capacitores reais (Namisnyk, 2003).

Figura 25 - Comparação entre voltamogramas cíclicos de um supercapacitor com comportamento próximo ao ideal (Cortesia de Tayara Correia Gonsalves).

Figura 26 - Variação do valor da EPR(Dep) com o tempo para supercapacitores expostos à diferentes temperaturas.

Figura 27 - Variação do potencial durante o processo de auto descarga a $125^{\circ} \mathrm{C}$. 70

Figura 28 - Variação do valor da $\operatorname{EPR}_{(\text {Dep })}$ em acordo com o tempo de autodescarga.........71

Figura 29 - Avaliação de ESR pelo método da interrupção de corrente. .72

Figura 30 - Voltamogramas cíclicos do supercapacitor de referência - não exposto à energia térmica.

Figura 31 - Voltamogramas cíclicos do supercapacitor 1 exposto por quatro semanas a $50^{\circ} \mathrm{C}$.

Figura 32 - Voltamogramas cíclicos do supercapacitor 2 exposto por quatro semanas a $75^{\circ} \mathrm{C}$ 82

Figura 33 - Voltamogramas cíclicos do supercapacitor 3 exposto por quatro semanas a $100^{\circ} \mathrm{C}$.

Figura 34 - Microscopia eletrônica de varredura do material do eletrodo composto por carbono.

Figura 35 - Microscopia eletrônica de varredura do material do eletrodo com impurezas (pontos brancos).

Figura 36 - Espectro de Energia dispersiva de Raio-X das impurezas do material do eletrodo.

Figura 37 - Espectro de Fluorescência de Raios-X do material do eletrodo de um dos supercapacitores analisados.

Figura 38 - Valores da capacitância em acordo com o método e velocidade de varredura adotada ou intensidade de corrente de descarga $\left(\mathrm{C}_{(\mathrm{DC})}\right)$.

Figura 39 - Valores da capacitância em acordo com o método e velocidade de varredura adotada ou intensidade de corrente de descarga $\left(\mathrm{C}_{(\mathrm{DC})}\right)$. 


\section{LISTA DE ABREVIAÇÕES E SIGLAS}

$A$ - Ampère;

AC - $\quad$ Alternating Current (Corrente alternada);

C - Capacitância ou capacidade;

C- Coulomb;

$C_{(A V C)^{-}}$Capacitância obtida por voltametria cíclica pelo método da área do voltamograma cíclico;

$C_{(D C)}$ - $\quad$ Capacitância ou capacidade obtida pelo método da corrente contínua;

$C_{(V C i M)}{ }^{-} \quad$ Capacitância obtida por voltametria cíclica pelo método da média dos valores da corrente elétrica de resposta em módulo;

$C_{(V C V \rightarrow 0)}$ - Capacitância obtida pelo método da média dos valores de corrente elétrica oriundos de valores de potencial tendendo a zero;

$C_{p s}{ }^{-} \quad$ Pseudocapacitância

DC - Direct Current (Corrente contínua);

DRX - Difração de Raios-X;

E - Campo elétrico;

EDLC - Electric Double-Layer Capacitor (Capacitor de dupla camada elétrica);

EPR - Equivalent Parallel Resistance (Resistência em paralelo equivalente);

$E P R_{(D e p)}-$ Dependent Equivalent Parallel Ressitance (Resistência em paralelo equivalente dependente);

ESR - Equivalent Series Resistance (Resistência em série equivalente);

$E S R_{(I n s t)}$ - $E S R$ obtida pelo método da interrupção de corrente;

F - $\quad$ Farad;

FSR - $\quad$ Full Scale range (Fundo de escala)

$i-\quad$ Corrente elétrica; 
IEC - International Electrotechnical Commission (Comissão Internacional de Eletroquímica);

$i_{E P R}(t)$ - Corrente de fuga variável;

IPEN - Instituto de Pesquisas Energéticas e Nucleares.

$L$ - $\quad$ Indutância;

MEV - Microscópio Eletrônico de Varredura;

$Q-\quad$ Carga;

R - $\quad$ Resistência elétrica;

SEM - $\quad$ Scanning Electron Microscopy (Microscópio Eletrônico de Varredura);

SI - $\quad$ Sistema internacional de medidas;

U- Potencial;

$v$ - Velocidade de varredura, o mesmo que taxa de varredura, em Volts por segundo

$V-\quad$ Volt

VC - Voltametria cíclica (do inglês CV - Ciclic Voltametric); 


\section{LISTA DE SÍMBOLOS}

$\tau$ - $\quad T a u$, constante de tempo, sendo que $\tau=R C$;

$\varepsilon_{0}-\quad$ Permissividade do vácuo;

$\Omega-\quad \quad$ Ohm, unidade de resistência elétrica. 


\section{INTRODUÇÃO.}

Supercapacitores e baterias são empregados no armazenamento de energia elétrica e usam vários materiais especiais de modo a atender às especificações elétricas de uma ampla gama de aplicações. As baterias armazenam energia elétrica por meio de reações químicas e os supercapacitores de dupla camada elétrica por meio de cargas elétricas confinadas em um campo elétrico. Atualmente os supercapacitores são mais onerosos por unidade de energia do que as baterias. O supercapacitor utiliza materiais com elevada área superficial específica para fornecer alta densidade de energia e exibir baixa resistência em série equivalente. Combinando baixa indutância e baixa resistência em série equivalente os supercapacitores, comparados às baterias, conferem elevada densidade de potência com baixo tempo de recarga. (Carvalho, 2014; Chmiola, 2009; Diab, Venet, Gualous, \& Rojat, 2009).

$\mathrm{O}$ armazenamento eficiente de energia elétrica na forma de cargas elétricas torna-se cada vez mais necessário devido aos novos modelos de geração de energia elétrica. Dentre tais novos modelos de geração de energia elétrica destacam-se a produção por meio de células fotovoltaicas e sistemas eólicos. A energia provinda do movimento ondulatório das ondas do mar é outro exemplo de geração que faz parte do grande rol de possibilidades de produção de energia (Carvalho, 2014; Chmiola, 2009). O que todos os meios descritos anteriormente possuem em comum é o fato de não produzirem energia de forma constante ao longo do tempo. A corrente elétrica instantânea e, portanto o potencial instantâneo em tais mecanismos de produção varia, pois, como exemplo, no caso das células fotovoltaicas a intensidade da energia eletromagnética emanada pelo sol muda ao longo do dia, o que depende das condições meteorológicas, cessando a noite. No caso da geração de energia por sistemas eólicos tem-se que a força dos ventos muda ao longo do dia, sendo mais intensa à medida que a diferença de temperatura entre os meios seja maior (por exemplo, a terra e o mar), em que, novamente, a energia eletromagnética provinda do sol é fator preponderante. A intensidade e frequência das ondas do mar também dependem dos ventos, que por sua vez, novamente, dependem da energia eletromagnética emanada pelo sol. Devido ao fato da corrente elétrica não ser constante faz-se necessário o armazenamento da energia gerada nas condições de pico para que tal energia seja posteriormente consumida nos momentos em que as fontes geradoras de energia não se fazem presentes. 
Outro caso em que os sistemas de armazenamento de energia se fazem necessários ocorre quando se presencia a variação da intensidade máxima ou mínima do potencial, ou então onde ocorra mudança do valor de frequência e, ou, defasagem entre potencial e corrente. Nestes casos é absolutamente necessário que a energia seja armazenada e, no ato do consumo corrigida por retificadores para um fornecimento adequado em termos de taxa de corrente ofertada e frequência correta. Pontes retificadoras são empregadas para transformar a corrente alternada em corrente variável (semiciclo) ou então em corrente contínua e capacitores são empregados para armazenar a energia elétrica retificada. Conforme ocorre demanda, a energia elétrica armazenada nos capacitores é liberada na forma de corrente contínua ou alternada, esta última com valor de frequência e potencial de pico a pico adequada por meio de um circuito modulador (circuito gerador de função).

Baterias são exímias armazenadoras de energia e razoáveis fornecedoras de potência instantânea devido ao relativo elevado tempo das reações químicas que liberam cargas elétricas (Carvalho, 2014).

Quando se julga qualitativamente o que é bom ou mau armazenador de energia é necessário se ter em mente os conceitos do que é energia por volume e energia por massa. Um dispositivo " $A$ " será melhor armazenador de energia comparado a um dispositivo "B" se conseguir armazenar mais cargas (elétrons e lacunas) para um mesmo referencial de volume ou de massa. A princípio baterias armazenam mais energia que capacitores para um mesmo referencial de volume, contudo nota-se uma tendência tecnológica dos capacitores suplantarem as baterias no quesito armazenamento de energia. Enquanto isso não ocorre os capacitores estão sendo usados em parceria com baterias, principalmente quando o sistema consumidor necessitar eventualmente de altas taxas instantâneas de energia, que pode ser chamada de potência, como ocorre com veículos elétricos que são alimentados por meio da energia provinda diretamente de banco de baterias em condições normais de deslocamento empregando capacitores quando de uma ultrapassagem, ou rápidas acelerações (Mussoi \& Villaça, 2000).

Como até aqui exposto nota-se que pesquisas na área de armazenamento de energia são de suma importância, e, portanto desenvolver novos materiais que permitam armazenar energia por longos períodos de tempo com maior eficácia, com maior densidade de energia e com menor potencial de recarga é vital na redução de desperdícios. O armazenamento de energia na atualidade passou a ser dentro do âmbito da engenharia dos materiais assunto de primeira instância e atenção. A demanda por veículos elétricos, desde 
motos até caminhões passou a ser prioritária no mundo contemporâneo. Dado o fato que é necessário o uso de baterias e capacitores em comunhão de eficiência, os supercapacitores também chamados de ultracapacitores, passaram a ser item de interesse econômico e acadêmico (Kötz \& Carlen, 1999).

O armazenamento de energia pode ocorrer por três processos: químico, eletroquímico e elétrico. Para os três métodos conhece-se uma abundância de materiais que permitem o armazenamento de energia, contudo ao correlacionar os parâmetros potência com volume de armazenamento o rol de materiais acaba por reduzir drasticamente.

Reduzir volume e peso do sistema que provê energia e potência é de suma importância em várias aplicações, das quais se destaca a veicular e a aeronáutica. O carbono e suas formas alotrópicas, principalmente o grafeno, estão à frente dos materiais utilizados para armazenar potência ao relacionar potência com volume. As baterias possuem comportamento que favorece o alto armazenamento e fornecimento contínuo de energia a baixas taxas de entrega (Júnior, 2014). É possível inferir que baterias de forma geral possuem alta resistência em série, parâmetro este explicado mais à frente. As baterias não possuem alta taxa de entrega de energia (potência), pois a corrente ofertada depende de reações químicas, dentre as quais se destacam a oxidação e a redução que necessitam um tempo maior de ocorrência quando comparadas com capacitores que têm à disposição cargas elétricas para pronta entrega, de forma quase que instantânea, já que a oferta de tais cargas não depende da ocorrência de reações químicas, pois elas estão lá, livres na forma de ânions, cátions, elétrons e lacunas. Capacitores de forma geral são ótimos componentes para fornecer potência instantânea, contudo, comparados as bateria possuem baixa capacidade de armazenamento de energia, o que se traduz em uma baixa densidade de energia. A parceira bateria-capacitor é, portanto, a solução ideal a ser aplicada em sistemas que demandam baixas correntes por longos períodos de tempo e eventualmente necessitem de altas correntes por curtos períodos de tempo, como ocorre com veículos em ultrapassagens e acelerações positivas (Carvalho, 2014).

Desenvolver supercapacitores que necessitem de um menor potencial para obtenção de rápida e eficaz recarga, que possuam alta densidade de energia, que ofertem a menor resistência no processo de carga e na entrega da energia armazenada e que apresentem a menor perda de energia armazenada é neste momento da peculiar história da ciência dos materiais assunto de grande interesse.

Por meio da figura 1 é possível comparar a densidade de energia e a densidade de potência entre as famílias dos dispositivos de armazenamento de cargas elétricas. 


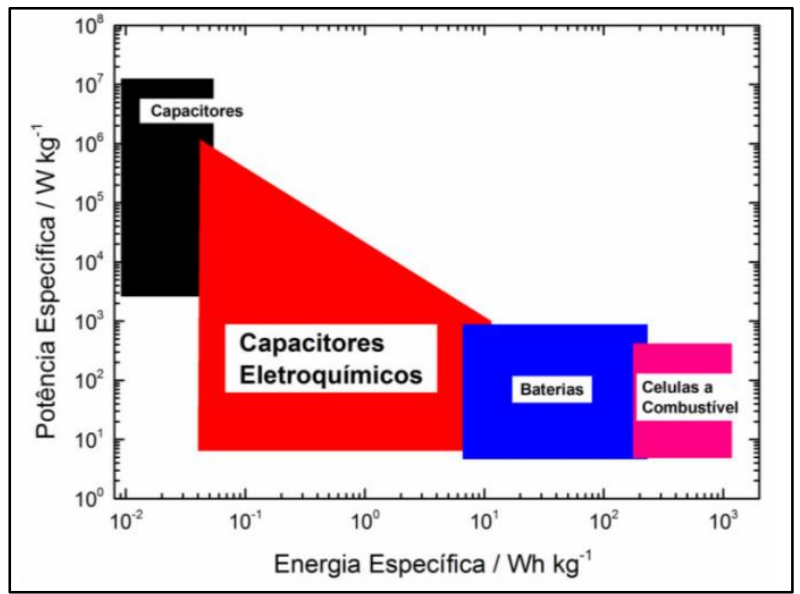

Figura 1 - Gráfico de Ragone, relacionando energia específica e potência específica (Carvalho, 2014).

Os supercapacitores também estão ganhando destaque no mundo onde as baterias são as estrelas; o mundo dos celulares e aparelhos que usam baterias recarregáveis. As baterias por vezes requerem minutos ou mesmo horas para serem recarregadas, ao passo que capacitores, dependendo do valor nominal de capacitância, de corrente máxima e de tensão a ser atingida, requerem minutos e, em alguns casos, segundos para a recarga. Este é outro motivo que impele a pesquisa de materiais para o desenvolvimento dos supercapacitores: baixíssimo tempo de recarga. Ao se pensar em baterias de celulares têmse em mente pequenos volumes com baixa densidade de carga, como por exemplo, 2000 $\mathrm{mAh}$, que requer algumas horas para recarga, contudo quando o assunto é veículo elétrico, onde a densidade de carga é de algumas dezenas de ampères hora, que requer muitas horas de recarga torna-se prioritário desenvolver sistemas de armazenamento de energia elétrica que requeiram minutos, se possível aqueles mesmos minutos que são usados para encher o tanque do veículo com combustível. Sendo assim o uso de supercapacitores passa a ser de vital importância no rápido armazenamento de energia.

As baterias, por mais ecologicamente corretas que sejam, acabam sempre contendo ácidos e metais ou óxidos metálicos que são prejudiciais ao meio ambiente quando incorretamente descartadas, enquanto que capacitores e supercapacitores são constituídos por eletrodos a base de carbono, ou cobre, ou alumínio, contendo uma camada separadora (dielétrico) que pode ser produzida com papel ou plástico inerte e tendo ainda um eletrólito composto por solução solvatada compostas por sais não tóxicos. Portanto do ponto de vista ecológico os supercapacitores são mais vantajosos que as baterias. 


\section{OBJETIVOS.}

Esta dissertação tem como objetivos:

- Dispor conhecimentos adquiridos ao longo da realização da etapa teórica do mestrado, sendo os mesmos correlatos ao estudo de supercapacitor do tipo dupla camada elétrica (sigla utilizada EDLC, oriunda do termo inglês Electric Double-Layer Capacitor);

- Apresentar resultados experimentais da influência da energia térmica sobre a resistência em série equivalente $(E S R)$, resistência em paralelo equivalente $(E P R)$, e capacitância $C$ por se tratarem de parâmetros que são tipicamente utilizados para qualificar comparativamente os supercapacitores;

- Relatar a caracterização da composição química dos materiais dos eletrodos por meio de microscopia eletrônica de varredura - SEM (Scanning Electron Microscopy) e difração de Raios X - DRX confrontando dados relativos à resistência em série e em paralelo e de autodescarga com a composição química verificada. 


\section{REVISÃO DA LITERATURA.}

\subsection{Capacitores convencionais.}

O capacitor, também chamado de condensador armazena energia elétrica por meio de um campo elétrico estabelecido entre seus principais elementos constituintes, as placas (Mussoi \& Villaça, 2000).

O capacitor armazena energia elétrica na forma de cargas estáticas em uma região restrita do espaço por meio do campo elétrico gerado por tais cargas, sendo que a quantidade de energia armazenada depende da geometria e do material que constituí as placas do capacitor (Franco, 2014).

As placas são os itens responsáveis pelo armazenamento das cargas. As placas também são chamadas no jargão da eletroeletrônica de armaduras ou eletrodos, e são constituídas por material condutor, como por exemplo, alumínio, cobre, formas alotrópicas do carbono (como grafite e grafeno) além de outros materiais condutores.

Os capacitores armazenam energia elétrica quando seus eletrodos são submetidos a um potencial.

Entre as placas do capacitor normalmente, porém não obrigatoriamente, existe um material dielétrico que recebe o nome de separador. $O$ separador tem a função de manter as placas separadas a certa distância e aumentar a capacitância (Mussoi \& Villaça, 2000).

O capacitor é empregado em circuitos elétricos principalmente como armazenador de energia e componente de circuitos de sintonia.

A carga elétrica armazenada em um capacitor pode ser mantida durante certo período, funcionando como uma bateria de baixa capacidade de armazenagem de energia por massa ou por volume. Capacitores são utilizados, por exemplo, para dar ignição em motores elétricos monofásicos, e bifásicos, para ionizar gases de lâmpadas além do muitos outros exemplos. Na área médica, os capacitores são requeridos em desfibriladores cardiovasculares. São também usados em fontes de alimentação, placas mãe, televisores e em inúmeros outros aparelhos eletrônicos (Kötz \& Carlen, 1999).

O capacitor dentro do aspecto físico trata-se de um conjunto de dois condutores próximos que estão galvanicamente isolados e podem ser carregados, cada qual, com carga positiva e carga negativa $(+Q$ e $-Q)$, conforme exemplificado por meio da figura 2 ( Brescansin, 2013). 


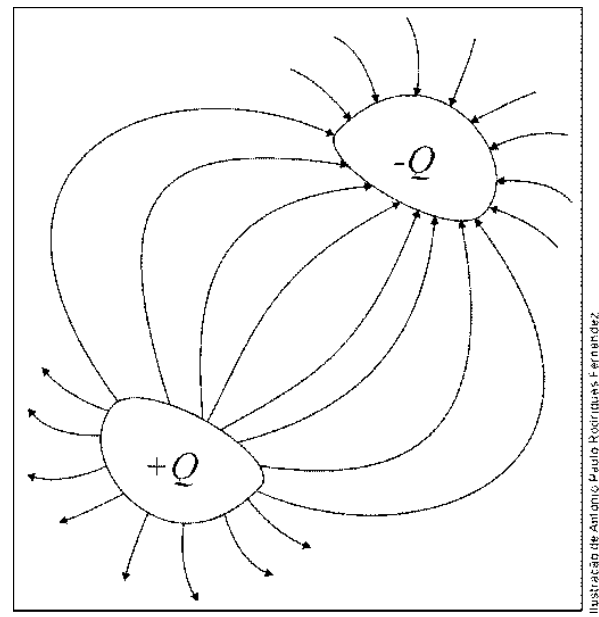

Figura 2 - Dois condutores próximos que estão isolados entre si formando um capacitor.

Existem várias formas, tamanhos e nomenclaturas de capacitores. Os mais usuais são os eletrolíticos, os de poliéster, os de cerâmica, os de tântalo e os de mica (MUSSOI \& VILLAÇA, 2000).

Apesar de existirem três formas notáveis para os capacitores, do ponto de vista da física, sendo estes a cilíndrica, a esférica, e a plano ( Brescansin, 2013), por questões de objetividade será tomado como modelo teórico de exemplificação o capacitor de forma plana (capacitor de placas planas ou simplesmente capacitor plano), conforme exemplificado por meio da figura 3.

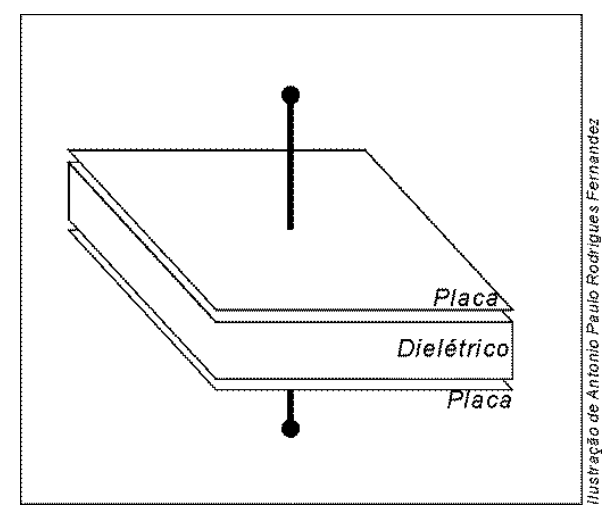

Figura 3 - Capacitor de placas paralelas. 


\subsubsection{Principais tipos de capacitores convencionais.}

\subsubsection{Capacitores eletrostáticos.}

O capacitor mais simples em termos de concepção é o plano mostrado na figura 4, sendo constituído por duas placas metálicas idênticas e paralelas entre si, separadas por um material dielétrico (mica, vidro, cerâmica, poliéster, polietileno ou papel).

Ao aplicar um potencial nos terminais do capacitor as placas acumulam cargas elétricas de sinais opostos. Os capacitores que fazem uso de dielétrico sólido são denominados capacitores eletrostáticos. Como apresentado na figura 4, de forma geral, capacitores eletrostáticos possuem um dielétrico inserido entre as placas, o que aumenta a sua capacidade de armazenar energia.

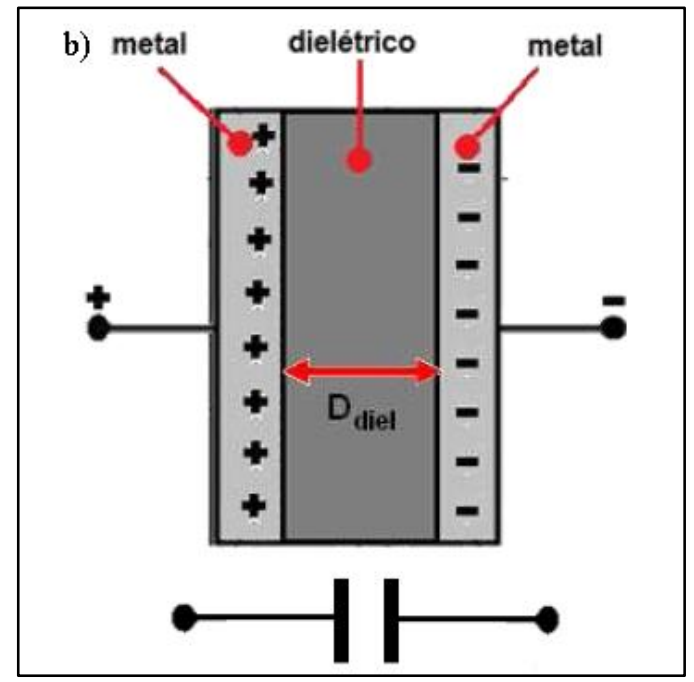

Figura 4 - Esquema de um capacitor eletrostático onde $\mathrm{D}_{\text {diel }}$ representa a espessura do dielétrico que separa o catodo do anodo (Franco, 2014).

\subsubsection{Capacitores eletrolíticos.}

Tal como os capacitores eletrostáticos os eletrolíticos acumulam cargas em dois eletrodos separados por um dielétrico sólido. A grande diferença está no fato do catodo do capacitor eletrolítico ser uma solução líquida eletrolítica (eletrólito), sendo o anodo uma placa metálica, normalmente alumínio revestido por uma finíssima camada de óxido de alumínio. O óxido de alumínio é um isolante elétrico, atuando, portanto como dielétrico. O eletrólito fica em contato com uma folha de alumínio não oxidada e durante o 
processo de carregamento as cargas positivas (lacunas) acumulam-se na folha de alumínio revestida com óxido de alumínio enquanto as cargas negativas (elétrons) acumulam no eletrólito na interface formada entre a folha de alumínio não oxidada e o eletrólito. Essas cargas são mantidas separadas devido à fina camada de óxido isolante (Franco, 2014). Por meio da figura 5 exemplifica-se esquematicamente como é um capacitor eletroquímico.

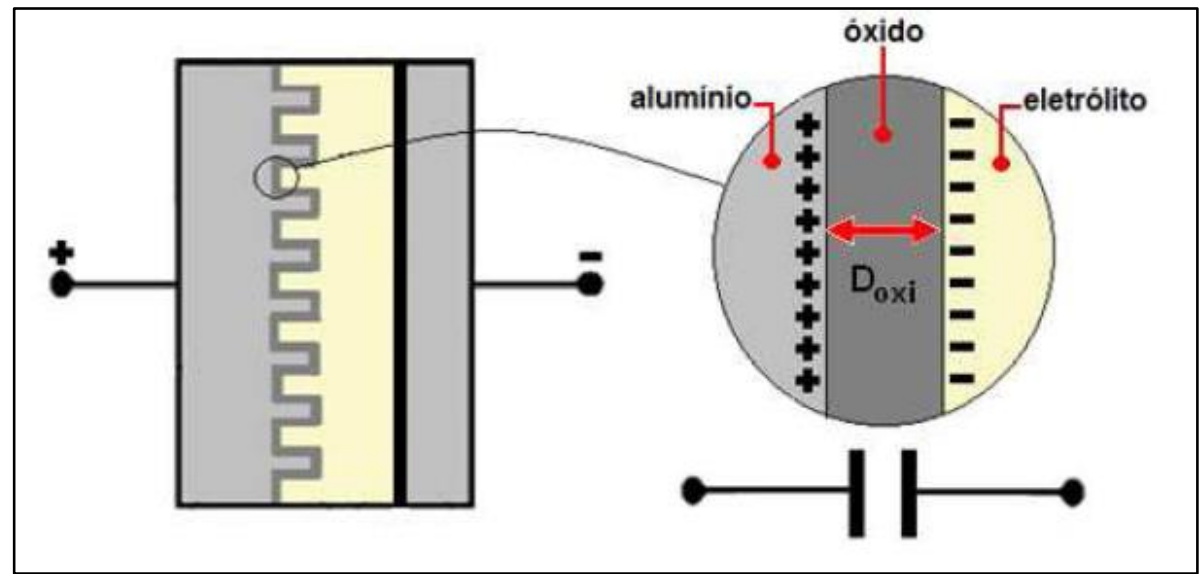

Figura 5 - Esquema de um capacitor eletrolítico, onde $\mathrm{D}_{\text {oxi }}$ representa a espessura do óxido que separa o catodo do anodo (Franco, 2014).

A placa (ou eletrodo), ou interface líquida iônica carregada positivamente é chamada de anodo, pois atrai cargas negativas e a placa, ou interface iônica carregada negativamente é chamada de catodo, pois atrai cargas positivas (Edminister, 1991; Kötz \& Carlen, 1999). 


\subsection{Capacitância teórica.}

Entre as placas do capacitor há tipicamente um material dielétrico, como ar, papel e poliéster.

Por meio da figura 6 (a) é possível verificar a configuração fundamental de um capacitor, e por meio da figura 6 (b) verifica-se como seriam as linhas de campo provenientes das placas do capacitor de placas paralelas.

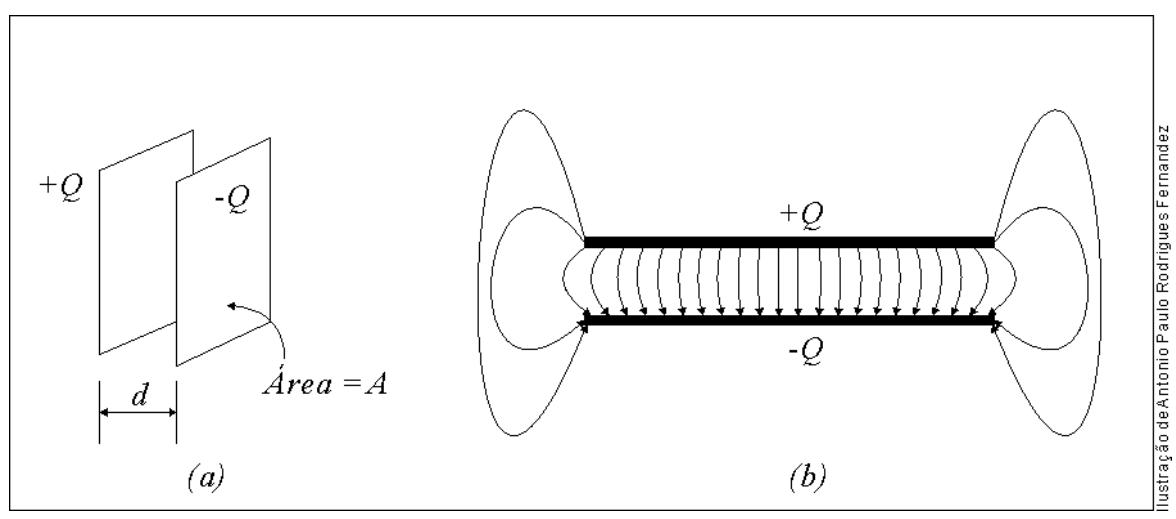

Figura 6 - (a) a configuração fundamental de um capacitor; (b) linhas de campo provenientes das placas do capacitor de placas paralelas.

Os efeitos das linhas de campo que se espalham além do capacitor (figura 6 (b)) podem ser desprezados se a área das placas do capacitor for muito grande ou se a distância entre as placas for ínfima, pois as linhas de campo podem ser consideradas paralelas na parte mais interna do capacitor ( Brescansin, 2013).

A capacitância simbolizada pela letra $C$ é o quociente entre a carga total simbolizada pela letra $Q$ armazenada e o potencial simbolizado pela letra $U$ aplicado no armazenamento de tal carga total (Brescansin, 2013), portanto a equação (1) exprime a capacitância de um capacitor.

$$
C=\frac{Q}{U}
$$

Sendo a capacitância $C$ o quociente de $Q$ sobre $U$, as unidades da capacitância no SI serão Coulomb por Volt $(C / V)$ ou $\operatorname{Farad}(F)$.

O processo de carregamento elétrico ou simplesmente processo de carga do capacitor pode ocorrer por meio da conexão de seus terminais a um componente que forneça corrente contínua ( $D C$ - Direct Current), tal como uma pilha, uma bateria ou uma fonte $D C$. Ao conectar a fonte de $D C$ ao capacitor será estabelecido um potencial entre as placas do mesmo, assim em função do fato estabelecido de que 


$$
Q=U C
$$

cargas $+Q$ e $-Q$ irão acumular nas placas do capacitor estabelecendo um potencial inicial de valor $V_{0}$ entre as placas.

Quando a fonte de $D C$ é conectada ao capacitor a mesma retira elétrons de uma das placas e deposita na outra. Se o capacitor estiver descarregado ao início do processo de carregamento a corrente de carga será máxima, decaindo à medida que o capacitor vai sendo carregado. O potencial entre as placas irá aumentar a cada instante até o momento em que a mesma seja igual ao potencial existente entre os polos da fonte $D C$, sendo que neste instante a corrente de carga irá cessar estando o capacitor carregado.

Na prática o tempo para que um capacitor carregue completamente pode tender a infinito, o que pode ser comprovado pelo fato de que em alguns casos, mesmo tendo passado muito tempo desde que o capacitor atingiu o potencial da fonte, pois verifica-se que ainda há uma tênue e decrescente circulação de corrente entre os circuitos que ligam os terminais da fonte aos terminais do capacitor.

A capacitância também depende de questões geométricas (Brescansin, 2013), como pode ser observado por meio da equação (3)

$$
C=\varepsilon_{0} \frac{A}{d}
$$

Sendo que A é a área de cada armadura, d a distância entre elas e $\varepsilon_{0}$ a permissividade do vácuo.

É possível notar que a capacitância é proporcional à permissividade do meio e a uma distância $d$ ', pois a área de cada armadura, indicada por $A$, dividida pela distância $d$ que separa as armaduras resulta em uma distância $d^{\prime}$ ( Brescansin, 2013).

Portanto a capacitância, grosso modo, é o produto entre a permissividade de um meio qualquer e uma distância d' (Brescansin, 2013).

A capacitância tem, portanto, dois parâmetros, um que depende de fatores elétricos explicitados por meio da equação (1) e outro que depende de fatores geométricos, que são explicitados pela equação (3).

As duas expressões podem ser unidas para determinar, por exemplo, a permissividade de um meio e a condutividade de um material. 


\subsection{Dielétricos e capacitância.}

Faraday foi quem observou experimentalmente que a capacitância mudava quando era introduzido algum tipo de dielétrico entre as placas do capacitor (Brescansin, 2013).

Faraday verificou que se fosse inserido um dielétrico entre as placas de um capacitor após o mesmo ter sido carregado o potencial entre as placas reduzia e, no processo de carga, se fosse mantido um potencial entre as placas, já estando o dielétrico inserido entre as mesmas, o número de cargas armazenadas aumentava para um mesmo potencial e tempo de referência de carga em relação a um capacitor sem dielétrico.

Resumidamente Faraday descobriu que a introdução de um dielétrico entre as placas do capacitor acarreta no aumento da capacitância do mesmo desde que o dielétrico preencha completamente o volume entre as placas do capacitor (Brescansin, 2013; Mussoi \& Villaça, 2000).

Como anteriormente explicado a capacitância é proporcional a um comprimento $d$ ' e a permissividade de um meio qualquer, que no caso foi adotado por conveniência como sendo a do vácuo $\left(\varepsilon_{0}\right)$, assim para identificar a capacitância (ou capacidade) do capacitor estando o volume entre as placas sobre vácuo a capacitância será escrita como sendo $C_{0}$, portanto:

$$
C_{0}=\varepsilon_{0} d^{\prime}
$$

Ao inserir um dielétrico entre as placas do capacitor a capacitância do mesmo passará a ser $C_{d}$

$$
C_{d}=k \varepsilon_{0} d^{\prime}(k>1),
$$

onde $C_{d}$ refere-se a capacitância do dielétrico e $k$ alude-se a uma constate que depende do tipo de dielétrico, chamada de constante dielétrica.

É possível também afirmar que

$$
C_{d}=k C_{0} \quad(k>1)
$$


Com base em uma visão atômica do dielétrico é possível entender o que gera o aumento da capacitância. Os dielétricos são materiais isolantes que podem ser polares ou apolares. Os materiais polares são compostos por moléculas que podem ser orientadas sobre a ação de um campo elétrico e, portanto sendo sucintos ao momento de dipolo elétrico (Brescansin, 2013). Como exemplo de material dielétrico polar tem-se a água, sendo que no caso da mesma ocorre momento de dipolo permanente. Nos materiais apolares as moléculas não possuem polaridade ou a somatória dos momentos de dipolo elétrico de cada molécula resulta em um campo em que a intensidade é zero e portando não podem ser orientadas sobre a ação de um campo elétrico. Nos materiais apolares as moléculas ao serem submetidas a um campo elétrico podem acabar sofrendo um deslocamento momentâneo do centro de cargas se tornando momentaneamente polares, sendo assim poderá ocorrer momento de dipolo instantâneo ou não permanente, também chamado de dipolo induzido em materiais apolares (Brescansin, 2013).

Quando é inserido um dielétrico entre as placas do capacitor e aplicado um potencial entre as placas ocorre das moléculas do dielétrico, quer sejam estas polares ou apolares, sofrerem uma orientação que por sua vez faz com que surja uma densidade superficial de carga positiva na interface da placa do capacitor que está carregada com cargas negativas e, ao mesmo tempo surja uma densidade de carga positiva na interface da placa que está carregada com cargas negativas (Brescansin, 2013), conforme exemplificado por meio da figura 7. 


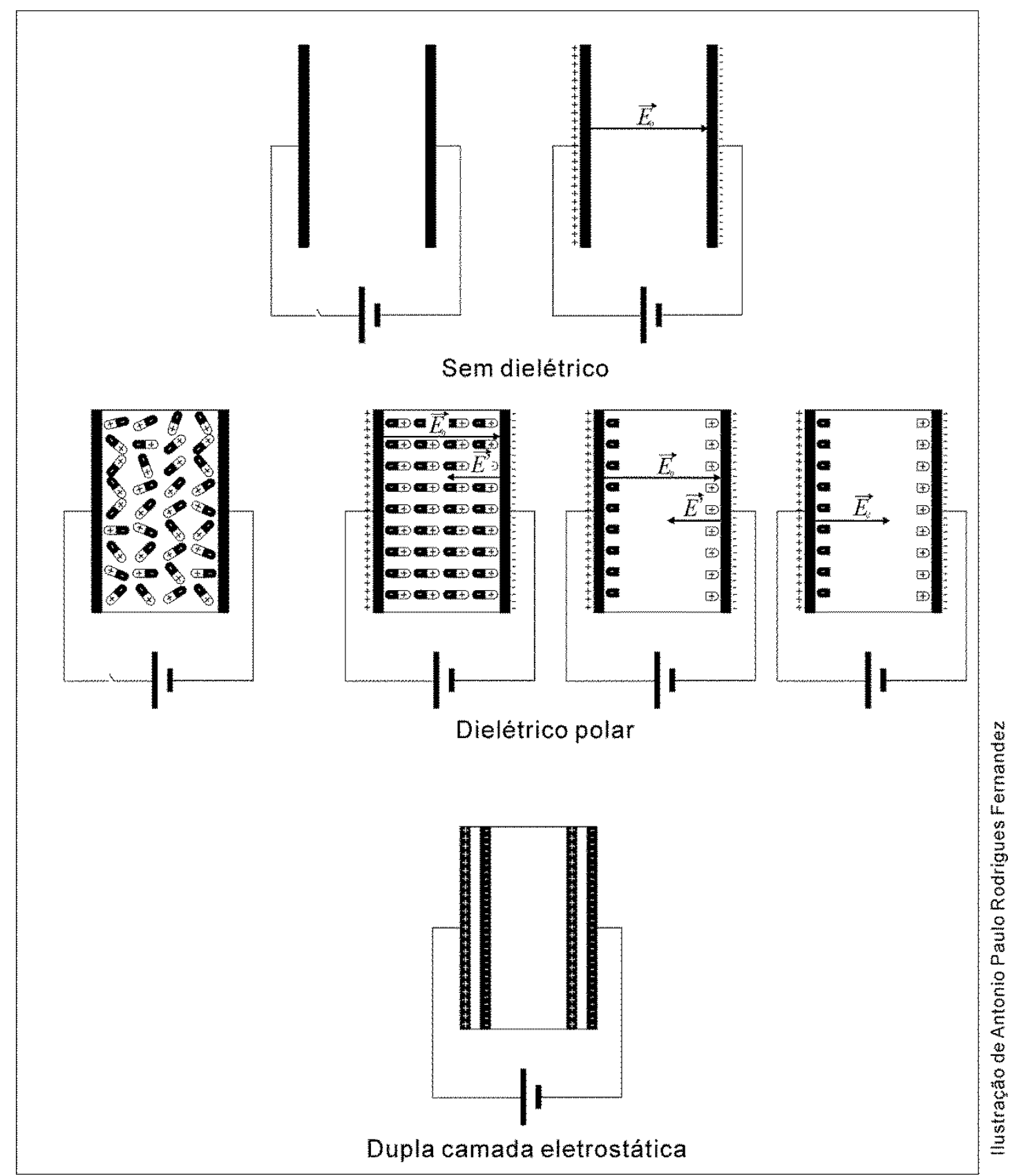

Figura 7 - Polarização do dielétrico.

As cargas que estão no centro do dielétrico acabam por se anular, já que ocorre de coincidir polo positivo com negativo entre as moléculas do dielétrico, o que faz com que a resultante de carga seja nula.

A densidade superficial de carga que se formou na interface entre dielétrico e placa acaba agindo como uma placa fictícia que possui uma densidade de carga $+\sigma^{\prime}$ e $-\sigma$ '. 
As placas fictícias com densidade de carga $+\sigma^{\prime}$ e $-\sigma^{\prime}$ acabam por gerar um campo $E^{\prime}$ que se opõe ao campo $E_{0}$ gerado pelas cargas contidas nas placas do capacitor, e como resultado ocorrerá do campo total $E_{d}$ dentro do dielétrico ser menor que o campo $E_{0}$, pois

$$
E_{d}=E_{0}-E^{\prime}
$$

Desta maneira, em módulo, o campo $E_{d}$ será menor que o campo $E_{0}$, e com base neste fato e tendo o fato experimental de que

$$
k=\frac{C_{d}}{C_{0}}(k>1)
$$

o que torna possível afirmar que

$$
E_{d}=\frac{E_{0}}{k} \quad(k>1) \Rightarrow k=\frac{E_{0}}{E_{d}}\left(\frac{E_{0}}{E_{d}}>1\right)
$$

Assim tem-se que a introdução de um dielétrico em um capacitor produz a redução da intensidade do campo elétrico tendo como resultado final o aumento da capacitância, pois em acordo com a equação (5) é possível escrever que

$$
\begin{gathered}
C_{d}=k \varepsilon_{0} \frac{A}{d}, \\
C_{d}=\frac{E_{0}}{E_{d}} \varepsilon_{0} \frac{A}{d}\left(\frac{E_{0}}{E_{d}}>1\right), \\
C_{d}=\varepsilon_{d} \varepsilon_{0} \frac{A}{d} \quad\left(\varepsilon_{d}>1\right) .
\end{gathered}
$$


Outra forma de "enxergar" a causa do aumento da capacitância do capacitor quando o dielétrico é inserido entre as placas é pensar que foram criadas duas novas placas fictícias, ou "placas eletrostáticas". As placas eletrostáticas fazem surgir então dois conjuntos de armaduras, como pode ser verificado por meio da figura 8.

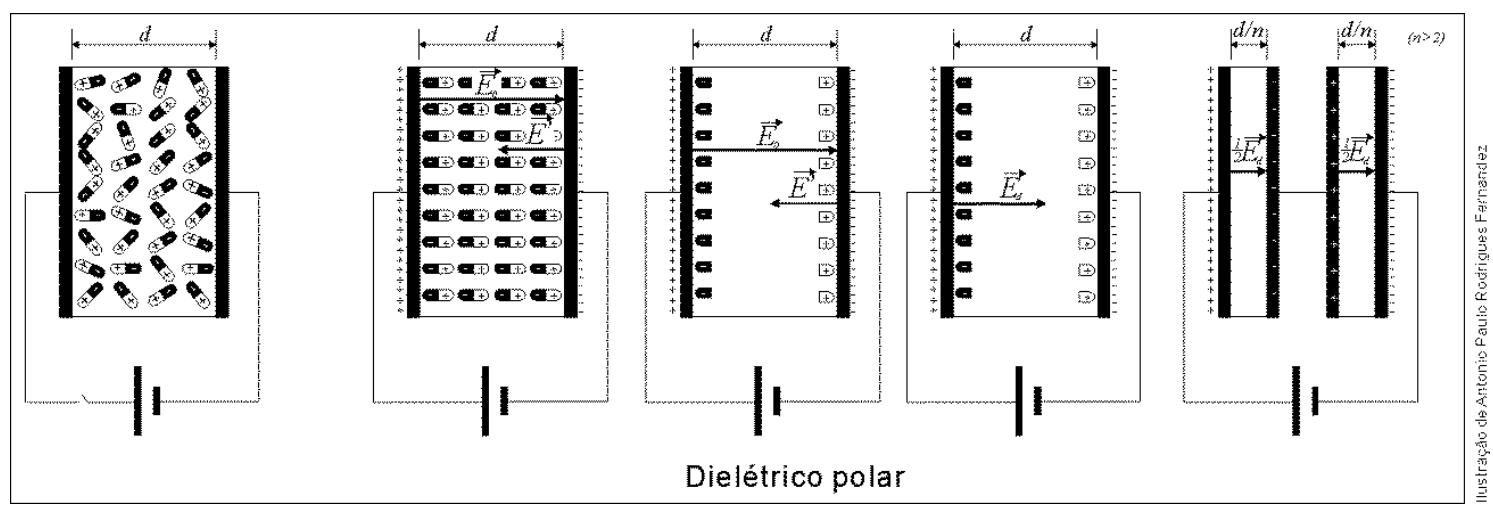

Figura 8 - Placas químicas.

Devido ao efeito da dupla camada (camada elétrica ou eletrostática) a capacitância aumentará na proporção de

$$
\frac{1}{C_{\text {Total }}}=\frac{1}{C_{a}}+\frac{1}{C_{b}}
$$

pois a capacitância é oriunda da soma de duas capacitâncias em série, conforme exemplificado por meio da figura 8 .

Normalmente

$$
\frac{1}{C_{a}}=\frac{1}{C_{b}} \Rightarrow C_{\text {Total }}=\frac{1}{2} C_{a}
$$


A permissividade do meio, denominada de forma genérica por $\varepsilon_{d}$ pode ser determinada na prática pela avaliação do potencial do capacitor com e sem a presença de um dielétrico. Para tanto o capacitor é carregado sem dielétrico, medindo-se o potencial entre seus terminais ao final do processo de carga, e posteriormente introduzindo-se um dielétrico entre as placas e medindo-se novamente o potencial entre seus terminais. A seguir divide-se o valor do potencial sem dielétrico $\left(U_{0}\right)$ pelo valor do potencial com dielétrico $\left(U_{d}\right)$, obtendo-se o valor da permissividade do meio, como exemplificado pelas equações (15), (16) e (17).

$$
\begin{gathered}
Q=U_{0} C_{0}, \\
Q=U_{d} C_{d}, \\
\frac{U_{0}}{U_{d}}=\frac{C_{d}}{C_{0}}=\varepsilon_{d},
\end{gathered}
$$




\subsection{Modelos de armazenamento de energia para capacitores de dupla camada elétrica.}

\subsubsection{Modelo de Helmholtz.}

O modelo de interface de Helmholtz considera que uma placa é a superfície do eletrodo metálico, rígido, e a outra placa é formada por íons de carga oposta na solução, rigidamente ligados (eletricamente adsorvidos) ao eletrodo.

Por analogia com um capacitor convencional (o que pode ser feito no modelo de Helmholtz), tem-se que a capacitância $C_{H}$ do modelo de Helmholtz é:

$$
C_{H}=\frac{\varepsilon_{R} \varepsilon_{0}}{x_{H}},
$$

Sendo que:

$C_{H}=$ Capacitância do modelo de Helmholtz por unidade de área;

$x_{H}=$ Raio iônico da molécula solvatada;

$\varepsilon_{R}=$ Permissividade relativa (do meio); e

$\varepsilon_{0}=$ Permissividade do vácuo.

Valores típicos de $\varepsilon_{R}$ das soluções de solvatação estão entre 6 e 7, o que conduz a um valor de $C_{H}$ da ordem de $10 \mathrm{~F} / \mathrm{cm}^{2}$.

- O modelo de Helmholtz prevê um decaimento linear do potencial eletrostático entre a superfície metálica e os íons adjacentes, assim como considera que a capacitância $C_{H}$ não varia com o potencial aplicado no eletrodo.

O modelo de Helmholtz não considera:

- as interações que ocorrem entre o eletrodo e espécies em solução, além das espécies adsorvidas na primeira camada;

- qualquer dependência com relação à concentração do eletrólito;

- a adsorção específica de outras espécies junto ao metal; e

- a variação de $C_{H}$ com o potencial.

O modelo de Helmholtz é válido para a região dos íons idealmente adsorvidos, conforme exemplificado por meio da figura 9. 


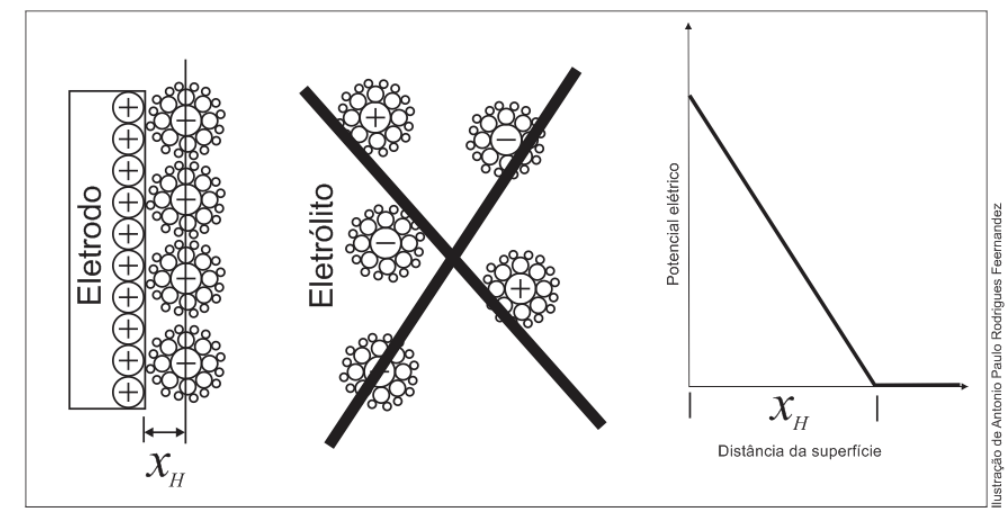

Figura 9 - Variação linear da capacitância com a distância em relação a superfície do eletrodo (adaptado de Conway, 1999).

Portanto: No modelo de Helmholtz a capacitância varia linearmente com o potencial aplicada.

\subsubsection{Modelo de Gouy-Chapman.}

O modelo de Gouy e Chapman considera que o potencial e a concentração do eletrólito influenciam no valor da capacitância da dupla camada.

No modelo de Gouy e Chapman a dupla camada não é considerada compacta como no modelo de Helmholtz, mas possui uma concentração iônica variável, sendo mais concentrada na interface com o eletrodo metálico e reduzindo tal concentração na medida em que se afasta de tal interface (Conway, 1999).

No modelo de Gouy e Charpman os íons são livres para se movimentar.

O modelo de Gouy e Charpman também é chamado modelo da Dupla Camada Difusa, pois assume que não há adsorção específica.

O potencial na dupla camada difusa decai por meio da interface existente entre eletrodo e solução, sendo uma função de característica exponencial, conforme exemplificado por meio da figura 10 . 


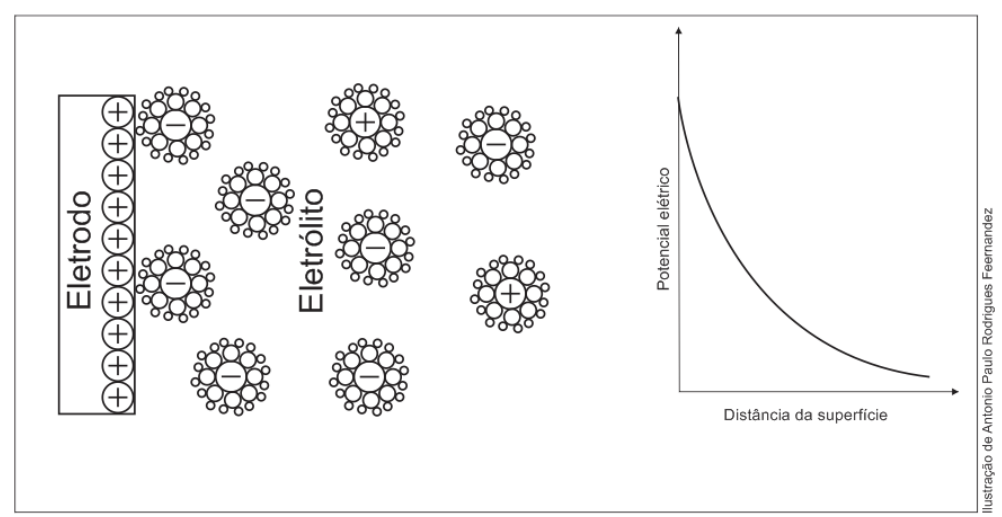

Figura 10 - Variação exponencial da capacitância com a distância em relação a superfície do eletrodo (adaptado de Conway, 1999).

Portanto no modelo de Gouy-Chapman a capacitância varia exponencialmente com o potencial, independentemente da região avaliada.

O modelo de Gouy-Charpman não pode ser visto como uma teoria completa, e a principal discrepância é o fato da capacitância calculada para a dupla camada variar bruscamente com a variação do potencial na camada interna de Helmholtz. No entanto, tal modelo não pode ser descartado, pois pode ser aplicado para os íons que não estão alinhados na superfície de eletrodo. Para o tratamento da parte difusa ou inteiramente eletrostática da dupla camada elétrica de supercapacitores, este modelo é adequado (Conway, 1999).

Em acordo com o modelo de Gouy-Chapman o valor da capacitância poderá ser obtido pela equação (19).

$$
C_{G C}=\frac{\partial \sigma^{m}}{\partial \phi_{0}}=\left(\frac{2 \varepsilon_{r} \varepsilon_{0} n(\infty) z^{2} e^{\prime 2}}{k T}\right) \cosh \left(\frac{z e^{\prime} \phi_{\Delta, 0}}{2 k T}\right)
$$

Sendo que:

$C_{G C}=$ Capacitância do modelo de Gouy-Chapman;

$k=$ Constante de Boltzmann $\left(1,3805.10^{-6} \mathrm{erg} / \mathrm{K}\right)\left(1 \mathrm{erg}=6.2416 .10^{11} \mathrm{eV}\right)$;

$T=$ Temperatura absoluta do eletrólito em Kelvin;

$z$ = Valência (carga) da espécie do íon (adimensional inteiro);

$e^{\prime}=$ Carga do elétron $\left(\approx 1,602.10^{-19} \mathrm{C}\right)$;

$\phi_{0}=$ Potencial no ponto de interesse;

$\varepsilon_{r}=$ Permissividade elétrica do vácuo $\left(\approx 8,85 \cdot 10^{-12} \cdot C^{2} \cdot N^{-1} \cdot m^{-2}\right)$;

$\varepsilon_{0}=$ Permissividade relativa do meio, no caso do eletrólito $\left(\approx a \cdot 10^{-12} \cdot C^{2} \cdot N^{-1} \cdot m\right.$

2) e $(0 \leq a<\infty)$. 


\subsubsection{Modelo de Stern.}

O modelo de Stern combina o Modelo de Helmholtz com o Modelo de GouyChapman, considerando que a dupla camada elétrica é formada por uma camada compacta de íons adsorvidos (próximos ao eletrodo), seguida por uma camada difusa que se estende para dentro do seio da solução (Conway, 1999).

O modelo de Stern é válido, pois potenciais muito intensos presentes na superfície do eletrodo exercem uma forte atração sobre os íons mais próximos e, portanto os torna rigidamente ligados a superfície do eletrodo. Toda queda de potencial é restrita a uma distância que corresponde à primeira camada de íons (camada compacta ou camada interna de Helmholtz) (Conway, 1999).

Para potenciais além da camada compacta, existe uma distribuição difusa de íons.

$\mathrm{Na}$ figura 11 é possível verificar o comportamento do potencial e consequentemente da capacitância em função da distância em acordo com o modelo de Stern, onde para a camada compacta o decaimento é linear e além desta é exponencial.

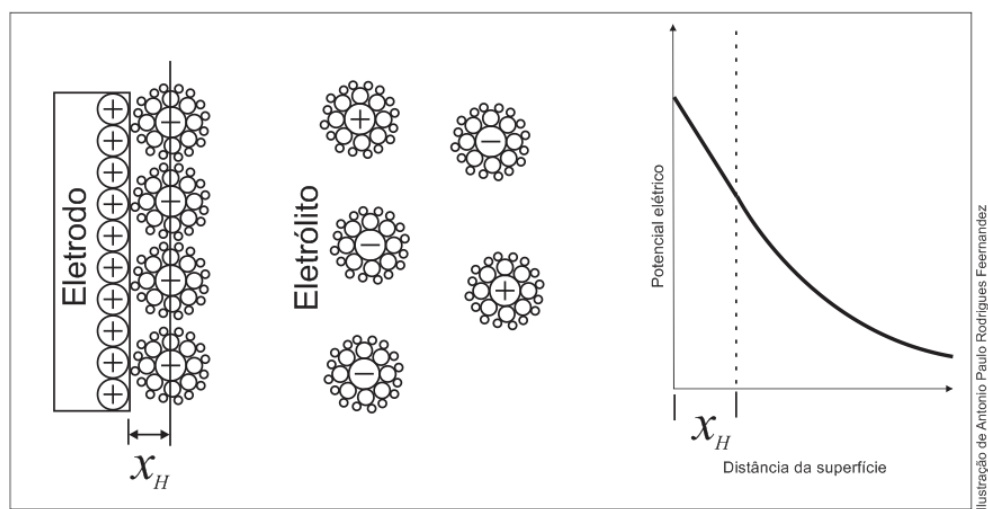

Figura 11 - Variação da capacitância com a distância em relação à superfície do eletrodo em acordo com o modelo de Stern (adaptado de Conway, 1999).

A capacitância da dupla camada em acordo com o modelo de Stern pode ser representada por meio da associação em série entre a capacitância do modelo de Helmholtz e a capacitância do modelo de Gouy-Chapman.

Em acordo com o modelo de Stern o valor da capacitância poderá ser obtido pela equação (20).

$$
\frac{1}{C_{S}}=\frac{1}{C_{H}}+\frac{1}{C_{G C}}
$$




\subsection{Supercapacitores - Capacitores de dupla camada elétrica.}

\subsubsection{História dos Supercapacitores.}

A história dos supercapacitores está intimamente correlacionada ao desenvolvimento das teorias de dupla camada e camadas interfaciais que iniciaram por volta de 1853 com o modelo Helmholtz.

Entre 1910 e 1913 Louis Georges Gouy David e Leonard Chapman observam que a capacitância dos supercapacitores não é constante como a dos capacitores convencionais, sendo independente do potencial aplicado nos terminais, tendo o supercapacitor um comportamento muito próximo ao observado na adsorção de gases introduzindo o modelo Gouy-Chapman (Namisnyk , 2003; Panno, 2015; Franco, 2014)

Em 1942 Otto Stern observou que o modelo Gouy-Chapman falhava para altos valores de carga em duplas camadas, sugerindo a união entre os modelos de Helmholtz e Gouy-Chapman (Namisnyk, 2003; Panno, 2015).

Em 1947 David C. Grahame modificou o modelo proposto por Stern, propondo que algumas espécies iônicas ou sem carga podem penetrar na camada de Stern, apesar da superfície do eletrodo ser ocupada por moléculas do solvente (Namisnyk, 2003; Panno, 2015).

Em meados de 1963 Bernhardt Patrick John O’Mara Bockris, Michael Angelo Vincent Devanathan e Karl Alexander Müller propuseram o modelo BMD de dupla camada que incluiu a ação do solvente na interface, sugerindo que moléculas atreladas (ligadas) do solvente, como as da água, teriam um alinhamento fixo a superfície (Namisnyk, 2003).

Em 1971 Sergio Trasatti e Giovanni Buzzanca demonstraram por meio de pesquisas com camadas duplas em filme de dióxido de rutênio submetidos a baixo valor de potencial com adsorção específica de íons apresentaram comportamento igual à de um supercapacitor, propiciando a compreensão da pseudocapacitância (Namisnyk, 2003)

Por volta de 1951 engenheiros da General Electric (GE) começaram experimentos com eletrodos de carvão poroso. O projeto de supercapacitores teve inicio a partir do projeto de células de combustível e baterias recarregáveis, incluindo o carvão ativado que é um condutor elétrico extremamente poroso, como uma esponja formada de carbono, tendo uma altíssima área superficial específica. Em 1957 H. Becker desenvolveu capacitor à baixo valor de potencial com eletrodos de carvão poroso. Ele acreditava que a 
energia era armazenada como uma carga nos poros do carvão como nos poros das lâminas que constituem os eletrodos de capacitores eletrolíticos. Devido à dupla camada mecanismos ainda não conhecidos por H. Becker à época lhe impeliram a escrever na patente a seguinte frase: "Não se sabe exatamente o que está ocorrendo com o componente, se ele é usado para armazenar energia, porém leva a uma capacidade extremamente alta" (Namisnyk, 2003).

A GE não quis dar andamento às pesquisas dos supercapacitores e em 1966 pesquisadores da Standard Oil of Ohio (SOHIO) desenvolveram outra versão do componente como sendo "um aparato de armazenamento de energia elétrica", enquanto trabalhavam em projetos de células de combustíveis. A natureza do armazenamento de energia não foi descrito nesta patente. Em 1970 o capacitor eletroquímico patenteado por Donald L. Boos foi registrado como um capacitor eletrolítico com eletrodos de carvão ativado. A SOHIO não quis comercializar sua invenção, licenciando a tecnologia para a NEC, que finalmente comercializou os resultados como um supercapacitor em 1971, para prover energia de backup para a memória de computadores (Namisnyk, 2003; Kötz \& Carlen, 1999; Panno, 2015).

Inicialmente capacitores eletroquímicos usavam duas lâminas de alumínio revestidas com carvão ativado (sendo os eletrodos), que eram impregnadas com um eletrólito e separadas por uma fina camada de isolante poroso. Tal projeto gerava um capacitor com capacitância na ordem de um Farad, significativamente maior que os capacitores eletrolíticos convencionais de mesmas dimensões. Este projeto mecânico básico permanece à base da maioria dos capacitores eletroquímicos (Namisnyk, 2003).

Entre 1975 e 1980 Brian Evans Conway conduziu um trabalho de base e desenvolvimento em capacitores eletroquímicos de óxido de rutênio. Em 1991 ele descreveu a diferença de comportamento entre supercapacitor e bateria no armazenamento eletroquímico de energia. Em 1999 ele cunhou o termo "supercapacitor" para explicar o aumento da capacitância por meio das reações redox superficiais com transferência faradaica de cargas entre eletrodos e íons. Seus Supercapacitores armazenavam cargas elétricas parcialmente em uma dupla camada de Helmholtz e parcialmente como resultado de reações faradaicas com "pseudocapaciância". O mecanismo atuante da pseudocapaciância são reações redox, intercalações e eletrossorção (adsorção sobre uma superfície). Com suas pesquisas Conway expandiu os conhecimentos dos capacitores eletroquímicos (Conway, 1999; Namisnyk, 2003). 
A venda de supercapacitores expandiu vagarosamente até 1978, quando a Panasonic iniciou a comercialização da marca "Goldcaps". Esse produto teve grande sucesso como backup de energia para memórias. Até 1987 a marca Panasonic não sofria competição até que a empresa ELNA entrou no mercado lançando a marca "Dynacaps". A primeira geração de EDLCs possuía resistência interna relativamente alta que limitava a velocidade da corrente de descarga, sendo usada para aplicações de baixa corrente como a potencialização de processadores SRAM ou para armazenamento de dados (Conway, 1999)

No final da década de 80 melhorias nos materiais dos eletrodos aumentaram os valores de capacitância. Ao mesmo tempo, o desenvolvimento de eletrólitos com melhor condutividade reduziu a resistência em série equivalente aumentando as correntes de carga e descarga. O primeiro supercapacitor com baixa resistência interna foi desenvolvido em 1982 para aplicações militares por meio do instituto de pesquisas Pinnacle, e foram comercializados sob a marcar "PRI Ultracapacitor". Em 1992 os laboratórios Maxwell (Posteriormente recebendo o nome de Maxwell Technologies) assumiu o desenvolvimento da marca PRI Ultracapacitors. A empresa Maxwell adotou o termo ultracapacitor da PRI e o chamou então de "Boost Caps" para delinear seu uso para aplicações de potência (Conway, 1999).

Como a energia contida nos capacitores aumenta com o quadrado do potencial, pesquisadores procuram uma forma de aumentar o valor do potencial de ruptura do eletrólito. David A. Evans desenvolveu um "Capacitor híbrido eletrolítico-eletroquímico". Este capacitor combina propriedades dos capacitores eletrolíticos e eletroquímicos. Ele combina a alta resistência dielétrica de um anodo de um capacitor eletrolítico com a alta capacitância de um catodo de óxido metálico (rutênio) pseudocapacitivo de um capacitor eletroquímico, produzindo um capacitor eletroquímico híbrido. Capacitores Evans, chamados Capaterry, possuíam um conteúdo de energia cinco vezes maior que capacitores eletrolíticos de tântalo para um mesmo tamanho. Seu alto custo os limitou para aplicações militares específicas (Conway, 1999). 


\subsubsection{Informações gerais.}

Um supercapacitor, às vezes chamado de ultracapacitor e tecnicamente de capacitor de dupla camada elétrica (sigla do inglês EDLC - Electric Double-Layer Capacitor), é um capacitor eletroquímico que possui valores de capacidade (o mesmo que capacitância) muito elevados em comparação aos capacitores convencionais para um mesmo referencial de volume, tendo em contrapartida baixo limite de potencial, fazendo uma ponte entre os capacitores eletrolíticos e baterias recarregáveis. Tipicamente os supercapacitores armazenam de 10 a 100 vezes mais energia por unidade de volume ou massa que capacitores eletrolíticos, podendo receber e doar cargas muito mais rápido que baterias, e tolerando muitos mais ciclos de carga e descarga que baterias recarregáveis. No entanto eles são dez vezes maiores que uma bateria convencional para uma dada carga (Conway, 1999; Namisnyk, 2003; Kötz \& Carlen, 1999; Panno, 2015).

Supercapacitores são usados em aplicações que requerem velocidades de carga e descarga muito rápidas ao invés de armazenamento compacto de energia, como por exemplo, carros elétricos, guindastes elétricos, elevadores, onde são usados para ações regenerativas, fornecendo potência instantânea, a qual, por questões de tempo de reação, as baterias não conseguem ofertar (Panno, 2015).

Alguns supercapacitores são usados como backup de memória para memórias de acesso randômico (Namisnyk, 2003).

Existe uma série de modelos (cores, volumes, massas de supercapacitores), conforme exemplificado na figura 12.

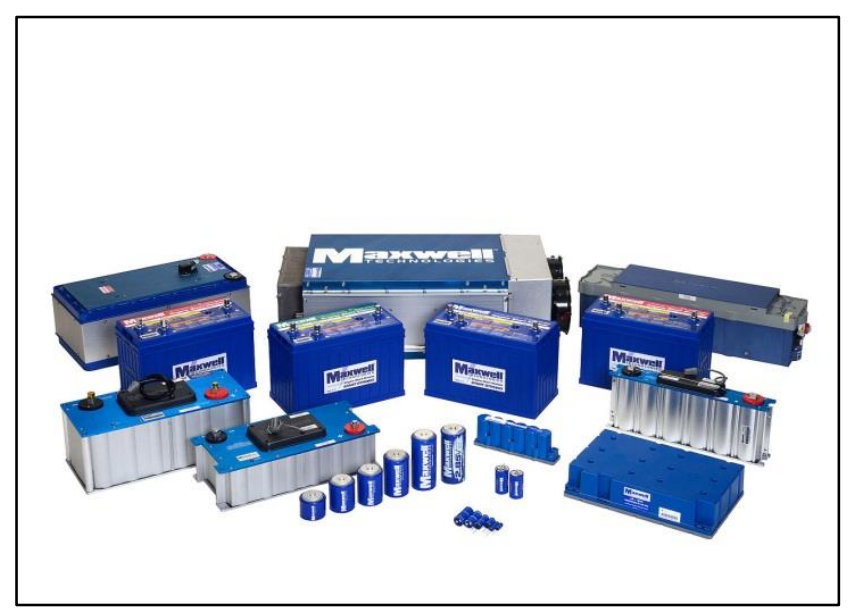

Figura 12 - Alguns modelos de supercapacitores (Maxwell Technologies, 2015). 
Supercapacitores não usam dielétrico sólido como os capacitores convencionais eletrolíticos, ao invés disso usam uma substância solvatada que forma uma dupla camada eletrostática, também chamada de dupla camada elétrica. Os supercapacitores fazem uso da capacitância eletrostática e da pseudocapacitância eletroquímica ou uma combinação de ambas (Namisnyk, 2003; Conway, 1999). Por meio da figura 13 apresenta-se quadro analítico das principais famílias de capacitores na sua concepção de armazenamento de energia.

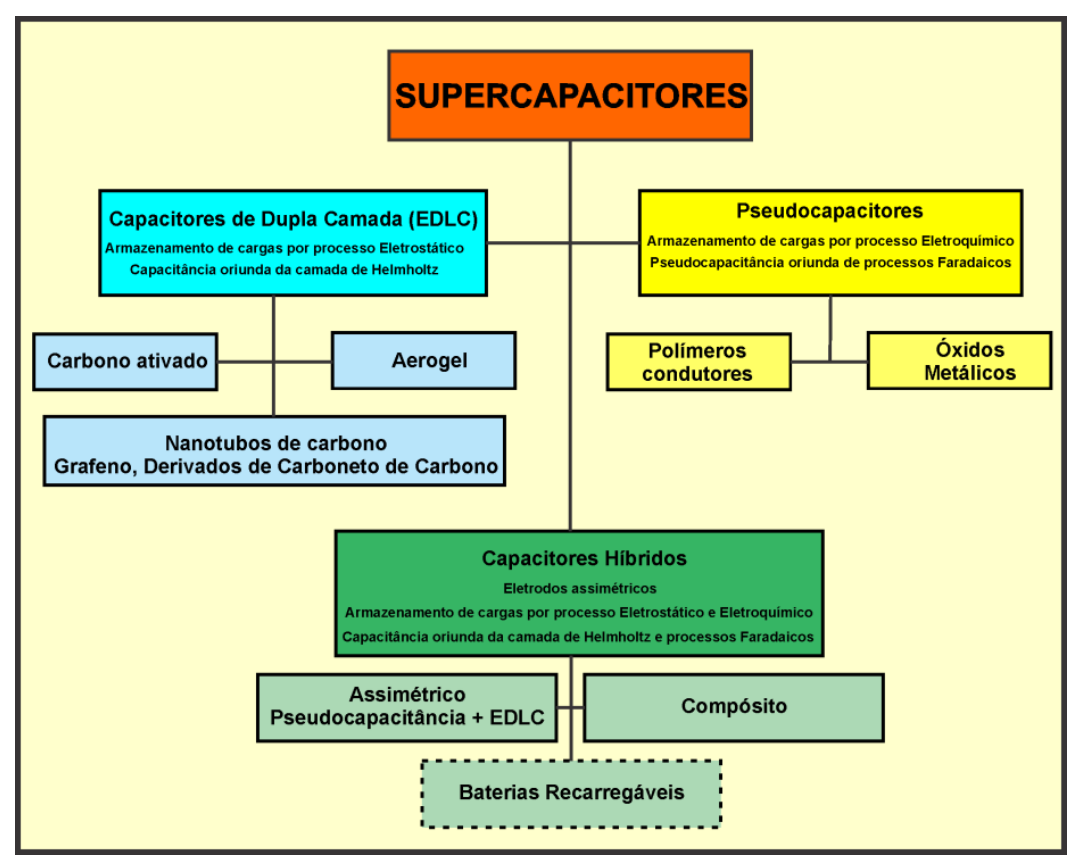

Figura 13 - Famílias de supercapacitores, EDLC, pseudocapacitores e híbridos, em acordo com o projeto dos eletrodos (adaptado de en.Wikipedia.org - Supercapacitor, 2016).

Capacitores de dupla camada elétrica usam eletrodos de carvão ativado, ou grafeno (que é uma das formas alotrópicas do carbono) que aumenta em muitas vezes a capacitância de dupla camada, pois a área específica chega a atingir centenas de metros quadrados por grama, apresentando muito maior capacitância que os capacitores que utilizam princípios eletroquímicos. A alta capacitância dos capacitores de dupla camada elétrica é obtida devido à ínfima distância existente entre a superfície da armadura fixa (superfície do carvão ativado ou do grafeno) e a camada eletrostática que é formada por íons envoltos por uma tênue camada do solvente, cuja espessura da camada de solvente é da ordem de décimos de nanômetros (tipicamente 0,3 a 0,8nm). A espessura do dielétrico de um supercapacitor é, sem dúvida, muitas vezes menor que a de um capacitor convencional (Chmiola, 2009; Kötz \& Carlen, 1999; Namisnyk, 2003; Conway, 1999). 
Pseudocapacitores eletroquímicos usam eletrodos revestidos por óxidos metálicos ou polímeros condutores que propiciam a alta pseudocapaciância. A Pseudocapacitância é obtida por processos faradaicos de transferência eletrônica de cargas por meio de reações de redução e oxidação (redox), intercalação ou eletrossorção (Conway, 1999).

Capacitores híbridos, como os capacitores a base de íons de lítio usam eletrodos com diferentes características: um exibe maior capacitância eletrostática e o outro maior capacitância eletroquímica (Conway, 1999). Trata-se de um capacitor que tenta obter um maior acúmulo de cargas que os EDLCs e maior velocidade de carga ou descarga que os capacitores eletroquímicos.

O supercapacitor pode ser caracterizado pelos seus mecanismos de armazenamento de energia, que são a dupla camada elétrica e a pseudocapacitância. Na prática estes dois mecanismos ocorrem simultaneamente e são inseparáveis em sistemas reais (Carvalho, 2014).

Os Supercapacitores utilizam a capacitância decorrente da separação de carga na interface eletrodo-eletrólito. Esse arranjo de cargas na interface origina a dupla camada elétrica. Um eletrodo polarizável é aquele onde não ocorre transferência de carga quando seu potencial é variado. Portanto, todo aumento de potencial leva a um aumento de capacitância de dupla camada elétrica, e este conjunto constitui um exemplo de capacitor de dupla camada elétrica. Se a área eletródica é aumentada através de poros, grandes quantidades de carga podem ser armazenadas, e o capacitor de dupla camada elétrica constitui um supercapacitor (Schindall, Kassakian, Ku, \& Riccardo, 2016; Chmiola, 2009; Carvalho, 2014).

Supercapacitores são dispositivos capazes de armazenar energia em um curto intervalo de tempo com uma alta capacidade de potência e razoável densidade de energia. Supercapacitores também possuem alta propagação de energia, pequeno tamanho e altíssima capacidade de ciclagem, suportando grande número de manobras de carga e descarga entes de ter suas propriedades de armazenamento de energia, de resistência em série e em paralelo alteradas permanentemente para pior. Já foi provado que os supercapacitores atuam de forma perfeita quando usados como complemento às baterias, e o emprego de suas performances são consideradas promissoras quando combinadas no fornecimento de energia para várias aplicações como nos veículos ecologicamente corretos, eletrônicos portáteis. Alguns supercapacitores já possuem capacitância que lhes 
dão densidade de energia igual à de baterias para um mesmo referencial de volume de armazenamento, mantendo rápida recarga de energia (Kötz \& Carlen, 1999).

Para construção de um capacitor de dupla camada elétrica, o material dos eletrodos deve ser estável em relação à solução eletrolítica, portanto, processos faradaicos como oxidação, corrosão e formação de filme de óxido não devem ocorrer. Para isso, pesquisas buscam materiais eletródicos não corroentes, tais como o carvão ativado (Kötz \& Carlen, 1999), que apresenta ampla aplicação em capacitores eletroquímicos devido ao seu baixo custo, alta área específica e alta estabilidade para aplicações tecnológicas (Carvalho, 2014).

A capacitância do EDLC é produzida pelo acúmulo eletrostático no limite da interface entre eletrodo e eletrólito. Além da alta área superficial do eletrodo outros parâmetros são importantes para os supercapacitores, dos quais se destacam: alta performance de potência (alto fornecimento de corrente instantânea) através da baixa resistência em série, alta persistência de carga devido a alta resistência em paralelo, onde as cargas armazenadas assim permanecem por longos períodos de tempo, alta ciclagem, mantendo suas características iniciais ao longo de muitas manobras de carga e descarga, baixa variação de comportamento mediante alterações de temperatura, alta estabilidade química que é afetada pela alteração de temperatura em conjunto com o armazenamento de energia por longos períodos de tempo. Os capacitores também devem ser considerados seguros no que se refere ao isolamento elétrico da carcaça e devem apresentar baixo aquecimento no processo de carga ou durante o fornecimento de corrente, além de serem atrativos na relação custo $\mathrm{x}$ eficiência.

Atendendo as condições de melhor armazenamento de energia por volume e por custo de volume os materiais a base de carbono são os mais adequados quando comparados a grande oferta existente de materiais, pois apresentam boas propriedades capacitivas, facilidade na produção dos eletrodos e abundância, tudo isso levando ao baixo custo produtivo dos supercapacitores (Schindall, Kassakian, Ku, \& Riccardo, 2016; Chmiola, 2009; Carvalho, 2014).

Na Tabela 1 apresenta-se a comparativa pontual entre a área superficial específica e a capacitância específica de diferentes derivados do carbono. 
Tabela 1 - Comparação entre a área específica superficial e capacitância específica de diferentes materiais baseados em carbono empregados na construção de capacitores que fazem uso de EDL (Panno, 2015; Schindall, Kassakian, $\mathrm{Ku}, \&$ Riccardo, 2016)

\begin{tabular}{lcc}
\hline $\begin{array}{c}\text { EDLC }- \text { Materiais } \\
\text { baseados em carbono }\end{array}$ & $\begin{array}{c}\text { Área superficial específica } \\
\left(\mathrm{m}^{2} \mathrm{~g}^{-1}\right)\end{array}$ & $\begin{array}{c}\text { Capacitância específica } \\
\mathrm{C}_{\mathrm{m}}\left(\mathrm{F} \mathrm{g}^{-1}\right)\end{array}$ \\
\hline Carvão ativado & $1000 \sim 3500$ & $<200$ \\
Fibra de carbono & $1000 \sim 3000$ & $120 \sim 370$ \\
Lâmina de carbono & $500 \sim 3000$ & $100 \sim 350$ \\
Carbono em aerogel & $400 \sim 1000$ & $100 \sim 125$ \\
Nanotubos de carbono & $120 \sim 500$ & $15 \sim 135$ \\
\hline
\end{tabular}

Em acordo com a Tabela 1 a capacitância por massa específica do grafeno é maior que a dos nanotubos de carbono e o potencial do grafeno é mais atrativo, pois o mesmo possui maior área específica e pode ser fabricado em alto volume com baixo custo. O grafeno é inerentemente poroso, e todos os poros no material baseado em grafeno podem ser produzidos pelo controle de sua microestrutura sendo ainda que o grafeno um excelente meio de mobilidade eletrônica.

Nos supercapacitores, a fim de manter um determinado valor de capacitância e ao mesmo tempo atingir um determinado valor máximo de potencial entre seus terminais sem que ocorra ruptura do separador ou desassociação do eletrólito, faz-se uso da associação em paralelo de capacitores, obtendo-se desta maneira como resultado final um capacitor encapsulado que pode conter de dois até vários capacitores associados, com valores de potencial tipicamente na ordem de volts e dezenas de Farads. 


\subsubsection{Princípios de armazenamento de energia correlacionado aos supercapacitores.}

Todos capacitores eletroquímicos possuem, dentro de uma concepção convencional dois eletrodos (alguns possuem três ou mais, servindo os eletrodos adicionais como eletrodos de controle), que são fisicamente separados por um separador elétrico (membrada de separação elétrica). A membrana de separação elétrica propicia o isolamento galvânico, porém permite o trânsito livre de íons, portanto mantendo os eletrodos conectados via eletrólito.

O eletrólito é um líquido que possui uma mistura de íons positivos e negativos oriundos normalmente de um sal atóxico, solvatados por um solvente polar, como por exemplo, a água.

Em cada superfície dos eletrodos origina-se uma área em que o eletrólito líquido faz contato com a superfície metálica condutiva do eletrodo, formando uma interface comum entre as duas diferentes fases da matéria. Tal interface comporta-se como um revestimento insolúvel do eletrodo e do eletrólito líquido adjacente, ocorrendo então um fenômeno muito especial que é a formação, ou efeito, da dupla camada (Franco, 2014; Panno, 2015)

Portanto os capacitores eletroquímicos usam o efeito da dupla camada para armazenar energia elétrica, sendo que, apesar de se comportar tal como na condição de máximo carregamento, esta dupla camada não é um dielétrico sólido convencional que separa as cargas como ocorre nos capacitores eletrostáticos ou eletrolíticos (Franco, 2014; Panno, 2015)

A aplicação de um potencial em um capacitor eletroquímico produz em ambos os eletrodos do capacitor uma dupla camada elétrica, sendo que a mesma consiste de duas camadas: uma trata-se de uma superfície líquida iônica oriunda de íons dissolvidos e solvatados no eletrólito, que é formada pelos íons de polaridade oposta a das cargas internas ao eletrodo físico, e a outra é formada pelas cargas elétricas (elétrons ou lacunas) que se emparelham na estrutura cristalina do eletrodo condutor. As duas camadas são separadas por uma monocamada de moléculas do solvente, isto é, pelas moléculas polares da água como solvente. Tal camada é chamada de plano interno de Helmholtz (IPH) (Conway, 1999).

Quando o potencial é aplicado, moléculas do solvente aderem à superfície do eletrodo por processo físico de adsorção, separando os íons de polaridade oposta uns dos 
outros no seio da solução eletrolítica. Neste processo forma-se, pensando-se em uma condição ideal, uma camada dielétrica líquida por parte do solvente polar. Em tal condição não há transferência de cargas entre eletrodo e eletrólito, apenas forças de coesão interfacial (momento de dipolo elétrico e atração eletrostática) que causam a adesão, não havendo ligação química permanente. As moléculas adsorvidas são polarizadas, porém devido à falta de transferência de cargas entre eletrólito e eletrodo não ocorrem mudanças químicas na superfície do eletrodo, isto é, para uma condição ideal de temperatura e potencial, assim como para uma quantia razoável de manobras de carga e descarga. Um dos principais motivos de deterioração dos capacitores eletroquímicos está na absorção e ligação química dos íons do solvente por parte do eletrodo (Kötz \& Carlen, 1999; Kurzweil, Chwistek, \& Gallay, 2006; Panno, 2015; Carvalho, 2014; Conway, 1999).

Os supercapacitores possuem dois modos de armazenar energia na dupla camada que contribuem para a capacitância total. A primeira baseia-se no princípio da capacitância de dupla camada que é essencialmente eletrostática, armazenando energia pela separação das cargas na dupla camada de Helmholtz. A outra faz uso da pseudocapacitância que utiliza princípios eletroquímicos, armazenando energia elétrica por reações faradaicas de redox com transferência de cargas. Ambas as capacitâncias são separáveis apenas por técnicas de medição. A quantia de cargas armazenadas por unidade de potencial em um capacitor eletroquímico é basicamente uma função do tamanho do eletrodo, embora a quantia de capacitância de cada princípio de armazenamento possa variar muito. Praticamente esses princípios de armazenamento produzem um capacitor com um valor de capacitância que varia entre 1 e 100 Farads (Franco, 2014).

Em supercapacitores a quantia de carga no eletrodo é correspondente à magnitude de cargas contrárias existentes no plano externo de Helmholtz. O fenômeno de dupla camada armazena cargas elétricas como em um capacitor convencional. As cargas da dupla camada formam um campo elétrico na camada molecular das moléculas do solvente no plano interno de Helmholtz que correspondem ao potencial aplicado (Conway, 1999).

A dupla camada serve como uma camada dielétrica em um capacitor convencional, contendo espessura de algumas moléculas do solvente. Então, a fórmula padrão para determinar a capacitância de capacitores convencionais de placas planas e paralelas pode ser usada nos supercapacitores (Conway, 1999; Namisnyk, 2003). 
A fórmula padrão para determinar a capacitância oriunda do uso de um dielétrico em acordo com a equação (12) é:

$$
C_{d}=\varepsilon_{d} \varepsilon_{0} \frac{A}{d}
$$

Em acordo com a equação (12) é possível notar que a capacitância crescerá se a constante de permissividade do meio for alta, se a área superficial dos eletrodos for grande e se a distância entre as placas for ínfima. Na prática mudar a permissividade do meio é complicado, já que a maior permissividade conhecida é a do vácuo e pode chegar a 1. Portanto resta a quem fabrica o supercapacitor aumentar a área da superfície das armaduras e reduzir a distância entre as mesmas. O aumento da área da superfície é obtido pelo uso do carvão ativado. A ínfima distância entre as placas é obtida pelo subterfúgio químico da dupla camada eletroquímica que faz com que a distância entre a armadura sólida e a armadura líquida formada pelos íons solvatados seja da ordem de angstrons elevando a capacitância à ordem dezenas, ou mesmo centenas de Farads (Conway, 1999; Panno, 2015).

Capacitores eletroquímicos consistem de dois eletrodos separados por um separador permeável aos íons chamada de separador elétrico ou membrana de separação elétrica, e um eletrólito que impregna os dois eletrodos, normalmente constituídos por material condutor extremamente poroso, como carvão ativado por exemplo (Kötz \& Carlen, 1999; Franco, 2014).

Quando os eletrodos são polarizados pela aplicação de um potencial, íons no eletrólito formam uma dupla camada de polaridade oposta ao do potencial aplicado. Por exemplo, se o eletrodo for polarizado positivamente será formada uma camada de íons de carga líquida negativa, ou seja: ocorrerá uma adsorção de cargas positivas na superfície do eletrodo polarizado negativamente. O oposto é verdade para o eletrodo polarizado negativamente. Além disso, dependendo do material do eletrodo e forma da superfície, alguns íons poderão permear a dupla camada tornando-se íons especificamente adsorvidos e contribuindo para a pseudocapacitância do supercapacitor. Por meio da figura 14 exemplifica-se a estrutura de um supercapacitor. 


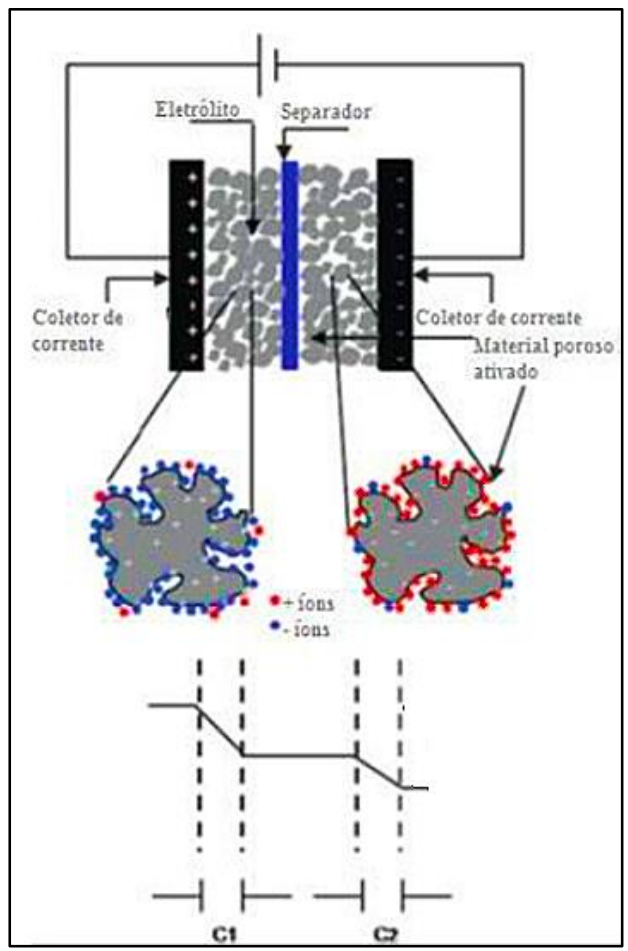

Figura 14 - Esquematização de um EDLC evidenciando a característica de porosidade dos eletrodos (Carvalho, 2014).

Por meio da figura 15 apresenta-se o modelo de dupla camada mais utilizado na literatura técnica, sendo que no mesmo os íons na interface encontram-se divididos em três regiões que são: a região dos íons dessolvatados ou adsorvidos (íons mais próximos ao eletrodo na cor verde); a região dos íons solvatados e não especificamente adsorvidos e a região difusa. Tais regiões são delimitadas pela superfície do eletrodo, pelo plano interno de Helmholtz (IPH), pelo plano externo de Helmholtz (PEH) e pelo plano de Gouy. O PIH passa pelo centro dos íons especificamente adsorvidos e o PEH passa pelo centro dos íons solvatados e não especificamente adsorvidos. O plano de Gouy delimita a região, a partir da qual a concentração de íons solvatados passa a ser constante, isto é, passa a ser igual ao interior da solução. A região de cisalhamento limita a região, dentro da dupla camada, onde a fixação de íons devido à carga do eletrodo deixa de acontecer, podendo coincidir ou não com o PEH (Franco, 2014). 


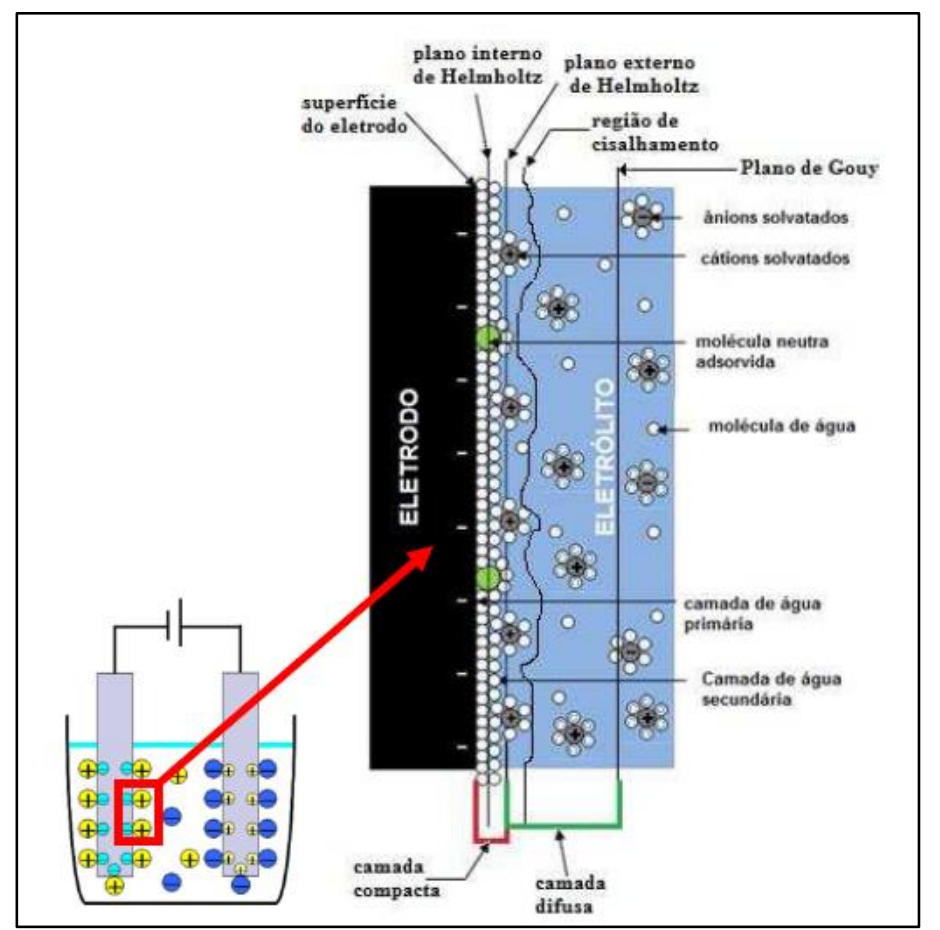

Figura 15 - Modelo da dupla camada formada na interface eletrodo-eletrólito, adaptado de Franco, 2014.

A interface situada entre a superfície do eletrodo e o PEH é conhecida por camada de Helmholtz ou ainda camada interna ou camada de compactação. A interface situada entre o PEH e o plano de Gouy, é chamada de camada difusa ou camada de difusão. Para o caso de soluções suficientemente concentradas (próximas à saturação) temse que a maior parte das cargas elétricas acumuladas no eletrólito está compactada dentro do plano PEH, ou seja: poucas cargas tendem a dispersar na camada difusa. Em tal condição, a dupla camada elétrica, que se forma na interface eletrodo/eletrólito, pode ser grosso modo, representada por um único capacitor plano em que a espessura da camada compacta pode ser tomada como distância de um dielétrico que separa dois planos de cargas elétricas opostas; um plano na superfície do eletrodo e o outro no PEH. Desta maneira a espessura da separação entre os planos de cargas em um capacitor eletroquímico é muitas vezes menor em relação aos demais capacitores (Franco, 2014; Kötz \& Carlen, 1999; Panno, 2015). 
A capacitância específica (capacitância por área ou por volume) de um capacitor eletroquímico pode superar em dezenas de milhares de vezes a capacitância específica de capacitores eletrostáticos e eletrolíticos, pois a distância de separação entre as cargas num capacitor eletroquímico é da ordem de décimos de nanômetros, ou seja: é muito menor se comparada com a espessura típica de uma camada de óxido de alumínio presente em capacitores eletrolíticos que é da ordem de centenas de nanômetros, ou a de um dielétrico cerâmico ou plástico presente em capacitores eletrostáticos que é da ordem de micrometros. Há ainda o fato de o capacitor eletroquímico poder armazenar uma energia extra por meio de sua propriedade de pseudocapacitância. Os capacitores eletroquímicos possuem menor energia específica que baterias, mas afinal de contas supercapacitores não foram, até agora, destinados a armazenar energia, mas sim potência. Os capacitores eletroquímicos possuem a vantagem de ter um longo tempo de vida útil sofrendo milhares de manobras de carga e descarga sem que ocorra degradação de suas propriedades de potência e de armazenamento de energia, o que nem sempre ocorre com as baterias recarregáveis (Franco, 2014; Panno, 2015).

Nos capacitores eletroquímicos a energia também pode ser armazenada eletroquimicamente por meio de processos que envolvem transferência de carga elétrica entre o material ativo e o eletrólito (ditos processos faradaicos). Existe uma diferença fundamental entre o comportamento eletroquímico destes capacitores em relação ao de baterias. A forma como uma bateria e um capacitor eletroquímico armazena energia química e a reverte em energia elétrica são diferentes. Pelo menos idealmente, o armazenamento de energia eletroquímica em um capacitor eletroquímico ocorre localmente numa região bidimensional, na interface eletrodo/eletrólito, através de reações rápidas e reversíveis, e, portanto, não envolvem mudanças de densidade no interior do eletrólito ou eletrodo. Já nas baterias, o armazenamento da energia eletroquímica envolve uma região no volume tridimensional, no interior do eletrólito e eletrodos, onde ocorrem mudanças de densidade através de reações químicas reversíveis, porém mais lentas. Por ocorrer numa interface e ter rápida reversibilidade, assemelhando-se muito a um armazenamento de energia eletrostática, o armazenamento de energia eletroquímico em capacitores eletroquímicos é denominado pseudocapacitância $C_{p s}$. 
A pseudocapacitância $C_{p s}$ está associada à relação entre a corrente que flui pela dupla camada elétrica, devido a uma transferência de carga elétrica e a variação do potencial $\Delta V_{d c}$ da dupla camada, sendo expressa por meio da equação (21)

$$
C_{p s}=\frac{\partial(Q)}{\partial\left(V_{d C}\right)}=\frac{\partial(I d t)}{\partial\left(V_{d C}\right)}
$$

A pseudocapacitância está relacionada com processos faradaicos altamente reversíveis tais como: eletrossorção de hidrogênio ou de átomos metálicos e/ou reações de oxirredução de espécies eletroativas. Os capacitores eletroquímicos cujo armazenamento de energia é principalmente eletroquímico são chamados pseudocapacitores. Os capacitores eletroquímicos híbridos têm ambas as contribuições de armazenamento de energia expressivas (Franco, 2014).

\subsubsection{Materiais empregados na produção de supercapacitores.}

As propriedades dos supercapacitores advêm da interação entre o material que compõe os eletrodos (ando e catodo sólido) e os elétrons que são movidos pelo trabalho proposto pela fonte entre os eletrodos por meio do potencial e os íons presentes no eletrólito. A combinação do tipo material do eletrodo e do eletrólito determina a funcionalidade e as características elétricas e de calor dos supercapacitores (Franco, 2014; Conway, 1999; Kötz \& Carlen, 1999).

Os eletrodos dos supercapacitores devem: possuir alta condutividade elétrica, apresentar alta estabilidade térmica, serem quimicamente inertes, terem altíssima resistência a redução e oxidação (altamente resistentes a corrosão) e possuir altíssima área superficial específica. Temos ainda que os mesmos devam ser amigáveis à natureza e apresentarem baixo custo (Conway, 1999; Namisnyk, 2003).

A intensidade da dupla camada assim como a pseudocapacitância armazenadas por Volt em um supercapacitor é predominantemente uma função da área superficial do eletrodo, portanto os eletrodos dos supercapacitores são tipicamente feitos de material microporoso, tal como um material esponjoso, que apresentam grande área superficial específica, como por exemplo o carvão ativado.

Geralmente quanto menor o tamanho dos poros maior será a capacitância e densidade de energia. Contudo, pequenos poros aumentam a resistência em série equivalente (ESR) e reduzem a densidade de potência. Aplicações que requerem altos 
picos de corrente necessitam de poros grandes e baixa perda interna, enquanto que aplicações que requerem alta densidade de energia necessitam de poros pequenos.

O material mais comumente usado como eletrodo para supercapacitores é o carbono em várias formas como o carvão ativado, tecido de fibra de carbono, carboneto derivado de carbono, aerogel de carbono, grafite em estrutura tridimensional, grafite em estrutura bidimensional (conhecido como grafeno) e nanotubos de carbono. Todos os itens descritos derivam de formas alotrópicas do carbono.

Eletrodos baseados em carbono exibem capacitância predominantemente estática por meio de dupla camada eletroquímica, ainda que uma pequena quantia de pseudocapacitância possa estar presente dependendo da distribuição dos poros. O tamanho dos poros no carvão ativado está tipicamente em uma faixa que parte dos microporos, menores que $2 \mathrm{~nm}$, até mesoporos, que atingem de 2 a $50 \mathrm{~nm}$, porém os microporos contribuem para a pseudocapacitância. Na medida em que o diâmetro (ou algo próximo a isto) dos poros se aproxima ao dos cátions solvatados ou dos ânions solvatados ocorre de tais moléculas serem impedidas de adentrar ou continuar penetrando no interior dos poros, e somente íons livres (não solvatados) conseguem penetrar nos poros de menor diâmetro, aumentando a densidade de empacotamento iônico e a capacidade de armazenamento (capacitância).

\subsubsection{Carvão ativado.}

Carvão ativado foi o primeiro material escolhido para eletrodos de EDLCs. Ainda que sua condutividade elétrica seja aproximadamente de $0,003 \%$ dos metais, que está entre 1,250 e 2,000 Siemens por metro, é suficiente para aplicações em supercapacitores. O carvão ativado é uma forma de carvão extremamente porosa que possui uma área superficial específica, em que em uma aproximação grosseira tem-se que em um grama há (algo próximo à ponta de um lápis) há uma área entre 1000 e 3000 metros quadrados, o que equivale de 4 a 12 quadras de tênis. Eletrodos devem ser de baixa densidade com muitos poros, fornecendo alta capacitância de dupla camada (Conway, 1999; Chmiola, 2009; Franco, 2014).

Carvão sólido ativado, também conhecido por carbono amorfo consolidado, é o material mais utilizado para eletrodos de supercapacitores e pode ser mais barato que outros derivados de carbono. Ele é produzido a partir de pó de carvão ativado prensado 
dentro de uma forma desejada, formando um bloco com uma larga distribuição de tamanho de poros. Um eletrodo com uma área superficial acima de $1000 \mathrm{~m}^{2} / \mathrm{g}$ resulta em uma capacitância de dupla camada com mais de $10 \mu \mathrm{F} / \mathrm{cm}^{2}$ e uma capacitância específica de $100 \mathrm{~F} / \mathrm{g}$.

A partir de 2010 praticamente todos supercapacitores comercializados são de pó de carvão ativado feito de casca de coco, que produz carvão ativado com mais microporos que carvão feito de madeira.

Fibras de carvão ativado são produzidas a partir de carvão ativado e possuem um diâmetro típico de $10 \mu \mathrm{m}$. Elas podem ter microporos com uma faixa de distribuição de tamanho que pode ser controlada. A área superficial das fibras de carvão ativado pode urdir um tecido com mais de $2500 \mathrm{~m}^{2} / \mathrm{g}$. Vantagens dos eletrodos de fibras de carvão ativado incluem a baixa resistência elétrica ao longo do eixo longitudinal da fibra e bom contato com o coletor (Conway, 1999; Chmiola, 2009; Franco, 2014).

Referente aos eletrodos de tecido de fibra de carbono tem-se que os mesmos apresentam predominantemente capacitância de dupla camada devido aos seus microporos.

\subsubsection{Grafeno.}

O grafeno é como uma folha com espessura de um átomo de grafite, com átomos arranjados em um padrão hexagonal regular, também chamado de "papel nanocompósito". O grafeno possui uma área superficial específica de $2630 \mathrm{~m}^{2} / \mathrm{g}$ que teoricamente leva a uma capacitância de 550F/g. Adicionalmente, uma vantagem do grafeno sobre o carvão ativado é sua alta condutividade elétrica. A partir de 2012 um novo desenvolvimento usando folhas de grafeno diretamente como eletrodos sem coletores pra aplicações portáteis foi iniciado.

Em uma personificação, um supercapacitor baseado em grafeno usando folhas curvadas de grafeno que não se acumulam face a face, formando mesoporos que são acessíveis para, e molháveis pelos eletrólitos iônicos em potencial superior a $4 \mathrm{~V}$. Uma densidade específica de energia de $85,6 \mathrm{Wh} / \mathrm{kg}(308 \mathrm{~kJ} / \mathrm{kg})$ foi obtida em temperatura ambiente igualando-se a uma bateria convencional de hidreto metálico de níquel, porém com densidade de potencia 1001000 vezes maior. A estrutura bidimensional do grafeno melhora a carga e descarga em termos de tempo e quantidade de ciclos (aumento da quantidade de ciclos). Portadores de carga em folhas orientadas verticalmente podem 
migrar rapidamente dentro ou fora das estruturas mais profundas dos eletrodos, então aumentando as correntes elétricas. Tal como capacitores eletrostáticos pode ser aplicado em aplicações de sistemas de filtro entre 100 e 120Hz, que são impróprios (inacessíveis) para supercapacitores que usam materiais a base de carbono (Conway, 1999; Chmiola, 2009; Franco, 2014).

\subsubsection{Nanotubos de carbono.}

Nanotubos de carbono (Carbon nanotubes - CNTs) são moléculas de carbono que formam uma nanoestrutura cilíndrica. Eles possuem uma estrutura oca com paredes formadas por folhas de um átomo de espessura de grafeno. Essas folhas são enroladas com um ângulo discreto e específico e a combinação do raio e ângulo controlam propriedades como a condutividade elétrica, molhabilidade eletrolítica e acesso iônico. Nanotubos são categorizados (classificados) como nanotubos de única parede (singlewalled nanotubes SWNTs) ou nanotubos de múltiplas paredes (multiwalled nanotubes - MWNTs). Este último possui um ou mais tubos sucessivamente inseridos (envelopados) uns nos outros, tal como uma boneca matryoshka russa; aquela que possui várias bonecas inseridas umas nas outras. Os nanotubos de múltiplas paredes possuem faixa de diâmetro entre 1 e $3 \mathrm{~nm}$. Os nanotubos de múltiplas paredes possuem distância coaxial de separação de paredes de $0,34 \mathrm{~nm}$ que está perto da distância de intercalar do grafeno.

Nanotubos de carbono podem crescer verticalmente no substrato do coletor, como uma bolacha de silicone. Os tamanhos típicos ficam entre 20 e $100 \mu \mathrm{m}$.

Nanotubos de carbono podem melhorar enormemente a performance de capacitores, gerando superfícies altamente molháveis e altamente condutoras.

Um supercapacitor baseado em nanotubos de parede única com eletrólito aquoso foi sistematicamente estudado na Universidade de Delaware pelo Professor Bingqing Wei e seu grupo. Li e colaboradores descobriram pela primeira vez que o efeito "tamanho de íon" e a molhabilidade eletrodo-eletrólito são fatores dominantes, pois afetam

o comportamento eletroquímico dos supercapacitores flexíveis a base de nanotubos de parede única imersos em eletrólitos aquosos com um mol de diferença entre ânions e cátions. Os resultados experimentais também mostraram que para os supercapacitores flexíveis é recomendável aplicar pressão entre os dois eletrodos para melhorar a molhabilidade do eletrólito. 
Nanotubos de parede única possuem uma grande área superficial específica teórica de $1315 \mathrm{~m}^{2} / \mathrm{g}$, enquanto que para os nanotubos de múltiplas paredes tal parâmetro é pequeno comparada com a área superficial específica de $3000 \mathrm{~m}^{2} / \mathrm{g}$ do carvão ativado. A área superficial específica é determinada pelo diâmetro dos tubos e ângulo de nidificação. Mesmo assim nanotubos de carbono possuem maior capacitância que eletrodos de carvão ativado, isto é, $102 \mathrm{~F} / \mathrm{g}$ para os nanotubos de múltiplas paredes e $180 \mathrm{~F} / \mathrm{g}$ para os nanotubos de parede única.

Nanotubos de múltiplas paredes possuem mesoporos que permitem fácil acesso dos íons na interface eletrodo-eletrólito. Como o tamanho dos poros se aproxima do tamanho dos íons da camada de solvatação, as moléculas do solvente são parcialmente desnudadas (o solvente é removido do entorno do íon), resultando em uma alta densidade de empacotamento e aumento da capacidade de armazenamento faradaico (Conway, 1999) (Chmiola, 2009) (Franco, 2014).

\subsubsection{Eletrólitos.}

Eletrólitos consistem de um solvente e um soluto que estão desassociados em cátions e ânions, sendo, portanto os eletrólitos eletricamente condutivos. Quanto mais íons o eletrólito conter, melhor será sua condutividade. Nos eletrodos dos supercapacitores há uma conexão condutiva iônica entre os dois eletrodos, embora os eletrodos estejam isolados galvanicamente (Carvalho, 2014).

Adicionalmente, nos supercapacitores o eletrólito provém moléculas para a separação monocamada na dupla camada de Helmholtz e entrega os íons para pseudocapacitância. Os eletrólitos determinam as algumas características dos supercapacitores: seu potencial de operação, faixa de temperatura de trabalho, resistência em série equivalente e capacitância. Com eletrodos de carvão ativado um eletrólito aquoso atinge valores de capacitância de $160 \mathrm{~F} / \mathrm{g}$, enquanto um eletrólito orgânico atinge apenas 100 F/g (Conway, 1999; Kurzweil, Chwistek, \& Gallay, 2006).

O eletrólito deve ser quimicamente inerte e não atacar quimicamente outros materiais no capacitor para oferecer longo tempo de vida e comportamento estável dos parâmetros elétricos do supercapacitor. A viscosidade do eletrólito deve ser suficientemente baixa para permitir a umectação dos poros que fazem parte da estrutura 
esponjosa dos eletrodos. Um eletrólito ideal não existe, forçando um comprometimento entre desempenho e outros requisitos (Conway, 1999).

\subsubsection{Eletrólitos aquosos.}

A água é um solvente relativamente bom para substâncias inorgânicas. Tratada com ácidos como o sulfúrico, álcalis como hidróxido de potássio, ou sais como os percloreto de sódio, percloreto de lítio ou arseneto hexafluorídrico de lítio, a água oferece relativos altos valores de condutividade, que ficam entre 100 e $1000 \mathrm{mS} / \mathrm{cm}$. Eletrólitos aquosos possuem um valor de potencial de dissociação de $1,15 \mathrm{~V}$ por eletrodo (potencial máximo de $2,3 \mathrm{~V}$ por célula) e uma relativa pequena faixa de temperatura de operação. A água é usada em supercapacitores com baixa densidade de energia e alta densidade de potência.

\subsubsection{Eletrólitos orgânicos.}

Eletrólitos com solventes orgânicos como o acetato nitrílico, carbonato de propileno, carbonato de dietil, e soluções com sais quartenários de amônia ou sais álcalis de amônia são mais caros que eletrólitos aquosos, porém possuem um maior potencial de desassociação de tipicamente $1,35 \mathrm{~V}$ por eletrodo (2,7 por capacitor), e uma alta faixa de temperatura. A baixa condutividade elétrica dos solventes orgânicos (de 10 a $60 \mathrm{mS} / \mathrm{cm}$ ) conduz a uma baixa densidade de potência, porém sendo que a densidade de energia aumenta com o quadrado do potencial, sendo que a densidade de energia aumenta com o quadrado do potencial (Schindall, Kassakian, Ku, \& Riccardo, 2016; Franco, 2014; Kötz \& Carlen, 1999).

\subsubsection{Separador elétrico.}

O separador elétrico (membrana de separação elétrica) proporciona uma separação física entre os eletrodos para evitar curtos circuitos devido ao contato direto entre os mesmos. Ele deve ser muito fino (alguns centésimos de milímetros) e deve ser muito poroso para permitir a fácil passagem dos íons solvatados, e assim reduzir a resistência em série equivalente. Os separadores elétricos também devem ser 
quimicamente inertes para preservar a estabilidade dos eletrodos e a condição de condutividade. Para reduzir os custos de processo de fabricação utiliza-se papel como separador elétrico em alguns modelos de capacitores e supercapacitores. Projetos mais sofisticados utilizam TNT (tecido-não-tecido) poroso obtido a partir de polímeros como o poliacrilatonitrílico, ou então fibra de vidro tecida, ou tecido cerâmico poroso (Conway, 1999; Kötz \& Carlen, 1999).

\subsubsection{Circuito equivalente do supercapacitor tendo como base o modelo de Helmholtz.}

O supercapacitor real, além de possuir comportamento predominantemente capacitivo, também apresenta comportamento indutivo, o que é percebido nos processos de carga e descarga por meio de potencial AC onde se verifica defasagem entre potencial e corrente diferente daquela proposta apenas por um componente apenas capacitivo, tal como se o capacitor tivesse um componente indutivo em série com seus eletrodos. $\mathrm{O}$ supercapacitor nos processos de carga e descarga apresenta maior lentidão (menor valor de corrente) de entrega ou recebimento de cargas do que o teoricamente esperado, tal como se possuísse um componente resistivo em série com os eletrodos. E por fim o potencial de armazenamento acaba por diminuir mesmo que o supercapacitor esteja eletricamente isolado de qualquer carga, tal como se possuísse um componente resistivo em paralelo com o capacitor. Por conta de tais anomalias um dos modelos elétricos utilizados para análise do supercapacitor contém um indutor ideal $(L)$ em série que permite simular e analisar a indutância em regime de corrente alternada, um resistor ideal em série com o indutor chamado de ESR que permite simular a redução de corrente de carga e descarga e um uma resistência ideal $E P R$ em paralelo com o capacitor ideal $C$ que permite simular a fuga de carga, conforme exemplificado por meio da figura 16.

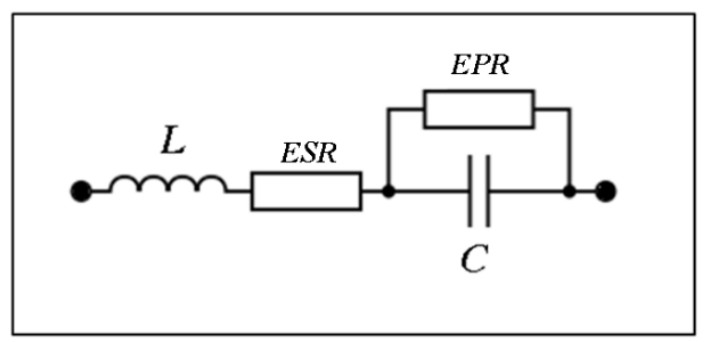

Figura 16 - Circuito equivalente de um supercapacitor (Adaptado de Conway, 1999). 


\section{MATERIAIS E MÉTODOS.}

\subsection{Considerações gerais.}

Nesta dissertação apenas o modelo de Helmholtz foi considerado para avaliar os parâmetros elétricos dos supercapacitores por ser o mais simplista dentre os três modelos de armazenamento de energia anteriormente apresentados. O modelo de Helmholtz torna possível avaliar alguns parâmetros elétricos dos supercapacitores por meio de instrumentos e procedimentos triviais, contudo por tal modelo não ser aquele que de fato expressa o comportamento de variação da capacitância ou da resistência em paralelo de um supercapacitor é necessário que todos os parâmetros sejam diferenciados em relação a um parâmetro conhecido e de fácil interpretação, sendo o tempo escolhido como parâmetro diferençável para esta dissertação.

Existem alguns parâmetros elétricos que permitem, a partir de seus valores obtidos por cálculos, ou de forma direta, chegar a algumas conclusões sobre a qualidade dos supercapacitores e com isso prever o comportamento dos mesmos. Dentre tais parâmetros elétricos se destacam a capacitância obtida pelo método da corrente continua $\left(C_{(D C)}\right)$, a capacitância obtida pelo método da corrente alternada, a capacitância obtida por voltametria cíclica pelo método da área do voltamograma cíclico $\left(C_{(A V C)}\right)$, a capacitância obtida por voltametria cíclica pelo método da média dos valores da corrente elétrica de resposta em módulo $\left(C_{(V C i M)}\right)$, a capacitância obtida pelo método da média dos valores de corrente elétrica oriundos de valores de potencial tendendo a zero $\left(C_{(V C V \rightarrow 0)}\right)$, a $E S R$ obtida pelo método da interrupção de corrente $\left(E S R_{(I n s t)}\right)$, a $E S R$ obtida pelo método da interrupção de corrente e interseção entre retas, a capacitância obtida pelo método da área do voltamograma cíclico $\left(C_{(A V C)}\right)$, a $E P R$ pelo método absoluto, a $E P R$ pelo método dependente $\left(E P R_{(D e p)}\right)$, a EPR por voltametria cíclica $E P R_{(V C)}$, a corrente de carga e descarga, o ciclo de estabilidade, a capacidade de energia, a densidade de potência, a densidade de energia e o tempo de vida.

Em virtude dos objetivos traçados ao início do mestrado foram avaliados os valores dos seguintes parâmetros elétricos:

- Resistência em paralelo equivalente obtida pelo método do valor dependente $\left(E P R_{(D e p)}\right)$; 
- Resistência em série equivalente obtida pelo método da interrupção de corrente - $E S R_{(I n s t)}$; e

- Capacitância obtida pelo método da corrente continua - $C_{(D C)}$;

- Capacitância obtida por voltametria cíclica pelo método da área do voltamograma cíclico $\left(C_{(A V C)}\right)$;

- Capacitância obtida por voltametria cíclica pelo método da média dos valores da corrente elétrica de resposta em módulo $\left(C_{(V C i M)}\right)$; e

- Capacitância obtida pelo método da média dos valores de corrente elétrica oriundos de valores de potencial tendendo a zero $\left(C_{(V C V \rightarrow 0)}\right)$.

Tais parâmetros elétricos foram escolhidos por serem possíveis de avaliação em acordo com o modelo de Helmholtz, e pelo fato de seus valores poderem ser obtidos pelo uso de equipamentos e procedimentos triviais na área de eletroeletrônica, a menos da capacitância obtida por voltametria cíclica, que exige o uso de equipamento específico.

É possível afirmar que tais parâmetros elétricos são os mais comumente utilizados quando da comparativa de qualidade entre supercapacitores de mesmas características construtivas.

\subsection{Condições de avaliação.}

Para a realização da etapa experimental foram adotadas as seguintes condições de avaliação:

- Potencial de carga de 5,1 Volts;

- Tempo mínimo de carga de 30 minutos após o capacitor atingir 5,1 Volts no processo de carga;

- Corrente de carga ou descarga controlada de 0,2mA/VF, o que equivale a um valor líquido de corrente de $1 \mathrm{~mA}$ em função do potencial de carga ser de 5,1 Volts e da capacitância nominal do supercapacitor ser de 1Farad. 


\subsection{Equipamentos utilizados na avaliação dos parâmetros elétricos.}

- Sistema de teste digital programável de baterias, capacitores, células combustíveis, células fotovoltaicas e reações eletroquímicas controlado por computador com interface via software MitsPro Versão 4 para caracterização de dispositivos elétricos Arbin BT-4 com as seguintes características: resistência interna de $10 \mathrm{G} \Omega$; corrente de saída (resposta) de $\pm 2 \mathrm{~A} / 100 \mathrm{~mA} / 1 \mathrm{~mA}$; potencial de saída de 2 até $10 \mathrm{~V}$; termistor de entrada de -80 até $150^{\circ} \mathrm{C}$; potência de saída de $40 \mathrm{~W}$; estabilizador para controle de variação do potencial externo de até $\pm 10 \mathrm{~V}$; tempo de resposta $100 \mu \mathrm{s}$; acuracidade de $0.1 \%$ FSR, resolução de 0,006\% FSR; com interface RS 232.

- Multímetro ICEL modelo MD 6680 na função voltímetro com resistência interna de $10,02 \pm 0,14 \mathrm{M} \Omega$;

- Multímetro ICEL modelo MD 6680 na função amperímetro com resistência interna de 540,15 $\pm 0,77 \Omega$, com saída RS 232 para interface com computador e coleta de dados;

- Fonte de tensão $D C$ com controle de corrente máxima marca ICEL, modelo OS 1500 com resistência interna de 2,63 $\pm 0,03 \mathrm{k} \Omega$ para potencial de $5,1 \mathrm{~V}$; e

- Osciloscópio marca BK Precision, modelo 2530B de 25Mhz com atenuação de sonda de $10 \mathrm{X}$ com resistência interna $10,02 \pm 0,02 \mathrm{M} \Omega$ e com saída USB 2.0 para interface com computador e coleta de dados;

\subsection{Equipamentos utilizados na avaliação da microestrutura e na composição química dos eletrodos.}

- Microscópio eletrônico de varredura marca Philips, modelo XL30, com microanálise química por meio de análise de energia dispersiva de Raios-X;

- Espectrômetro de Fluorescência de Raios-X fabricado pela SHIMADZU modelo EDX-720;

- Bomba mecânica de dois estágios e bomba difusora Edwards - vácuo (10${ }^{6}$ mbar); 


\subsection{Resistência em paralelo equivalente obtida pelo método do valor dependente - $\operatorname{EPR}_{(D e p)}$.}

O armazenamento de energia elétrica na dupla camada elétrica de supercapacitores faz com que os portadores de carga (íons solvatados) sejam separados por uma distância na ordem de moléculas da superfície dos poros. Acima desta curta distância irregularidades podem ocorrer, fazendo com que tais portadores, de polaridade oposta, se atraiam mutuamente gerando uma gradual descarga do supercapacitor (Franco, 2014). A autodescarga é oriunda da corrente de fuga variável $i_{E P R}(t)$ que depende da capacitância, potencial de carga, temperatura, estabilidade química dos eletrodos, estabilidade química do eletrólito e de possíveis reações entre eletrodos e eletrólito (Kötz \& Carlen, 1999). À temperatura ambiente $i_{E P R}(t)$ é tão baixa que sua variação (redução no caso da auto descarga) pode ser verificada a cada hora, a cada dia ou mesmo a cada semana (Ban, Zhang, Lei, Tsay, Song, \& Zou, 2013).

É costume avaliar $i_{E P R}(t)$ indiretamente por meio do valor do potencial do capacitor a cada intervalo de tempo.

O objetivo de avaliar $i_{E P R}(t)$, é determinar, o que será chamado nesta dissertação de valor de resistência em paralelo equivalente dependente (Dependent Equivalent Parallel Ressitance $\left.-E P R_{(D e p)}\right)$.

O valor da $E P R_{(D e p)}$ pode ser considerado um parâmetro que qualifica o supercapacitor. Quanto maior o valor de $E P R_{(D e p)}$ mais tempo o supercapacitor irá demorar para descarregar uma certa quantia de cargas em um determinado intervalo de tempo. Portanto mais rentável em termos de economia o supercapacitor será a medida $E P R_{(D e p)}$ seja comparativamente maior, assim, por exemplo, se um supercapacitor tem valor de $E P R_{(D e p)}$ de $30 \mathrm{M} \Omega$ obtido em 80 horas de auto descarga e outro supercapacitor tem valor de $E P R_{(D e p)}$ de $15 \mathrm{M} \Omega$ obtido em 80 horas de auto descarga, significa que o primeiro supercapacitor apresenta melhor qualidade comparativa em relação ao segundo supercapacitor, pois consegue, para um intervalo de 80 horas, que foi a referência absoluta de comparação, reter o dobro de cargas. Portanto o primeiro supercapacitor, em termos de qualificação de $E P R_{(D e p)}$ para 80 horas, é melhor que o segundo, obviamente considerandose na comparativa valores idênticos de capacitância e potencial de carga inicial.

A autodescarga consiste em carregar o capacitor com certa quantia de cargas, o que é possível de se verificar por meio do potencial e corrente ao final do processo de carga, e posteriormente medir a variação do potencial do capacitor ao longo de um 
intervalo de tempo onde o mesmo é mantido isolado de qualquer meio de descarga. A medição de $E P R_{(D e p)}$ pode ser feita de tal forma que a mesma retire o mínimo possível de cargas do capacitor, o que pode ser realizado com um voltímetro de alto valor de resistência interna juntamente com o uso de resistores em série em uma das, ou em ambas, pontas de provas utilizadas para coletar o valor do potencial do supercapacitor. É necessário saber o valor de tais resistências para inseri-lo nas equações que determinam o valor de $E P R_{(D e p)}$. A quantia de cargas transportadas de uma armadura à outra por meio do voltímetro no ato da medição é determinada pelo tempo que cada medição demora a ser realizada e da corrente que circula pelo equipamento, sendo a corrente que circula pelo equipamento determinada pelo potencial obtido no ato da leitura dividido pelo valor da resistência interna do voltímetro. Quanto menor o intervalo tempo de medida e maior o valor da resistência interna menos se interfere no valor da medida (Mussoi \& Villaça, 2000; Edminister, 1991).

Pode ocorrer de um supercapacitor ter valor de $E P R_{(D e p)}$ maior que de outro supercapacitor para um comparativo onde se faz uso de um curto tempo de auto descarga, porém esta condição pode mudar conforme ocorre aumento do tempo de auto descarga, sendo assim é interessante criar parâmetros investigativos e comparativos ao obter o valor de $\operatorname{EPR}_{(\text {Dep })}$.

O valor da $\operatorname{EPR}_{(D e p)}$ muda com a temperatura, portanto é de se esperar oscilações na coleta de dados para este parâmetro caso o ambiente não seja controlado. Devido a alta resistência interna do voltímetro qualquer pequena oscilação de potencial da rede elétrica acaba por inserir variações na leitura do valor da $E P R_{(D e p)}$. Campos eletromagnéticos também podem produzir ruídos no sinal coletado pelo voltímetro ou osciloscópio durante a avaliação do valor da $\operatorname{EPR}_{(D e p)}$.

O circuito que representa um capacitor real é obtido pelo uso de um capacitor ideal em paralelo com a $E P R_{(D e p)}$ e ambos estando em série com a resistência equivalente em série, por onde flui $i_{E P R}(t)$. Na figura 16 verifica-se um supercapacitor real, a menos do indutor em série com a $E S R$, que para os experimentos relatados nesta dissertação não foi considerado, pois os parâmetros elétricos do supercapacitor forma avaliados em corrente contínua.

A resistência em paralelo equivalente é posta em paralelo com o capacitor ideal, pois simula um resistor, que deveria ter altíssimo valor ôhmico, fazendo contato entre os terminais do capacitor, por onde a corrente de fuga variável $i_{E P R}(t)$ flui, sendo portanto por meio de EPR que ocorre a autodescarga do supercapacitor. 
Um dos métodos para avaliar o valor de $i_{E P R}(t)$ ocorre por meio da autodescarga, onde se aplica um potencial de teste por 30 minutos a fim de carregar o capacitor, deixado posteriormente o mesmo descarregando naturalmente. $\mathrm{O}$ potencial de carga deve ser igual ou ligeiramente menor que o máximo potencial recomendado pelo fabricante.

A cada hora, em média, realiza-se a avaliação do potencial do capacitor por meio de um voltímetro que deve ter valor de resistência interna bem alta, se possível com valor acima de $10 \mathrm{M} \Omega$ e, complementarmente recomenda-se o uso de ponteiras com atenuação de 10X, o que pode ser obtido fazendo-se uso de resistores de alto valor ôhmico em série com uma das pontas de prova do voltímetro, lembrando que a inserção de resistência em série em uma das ponteiras (ou em ambas) acarreta na redução do valor real do potencial, o qual deve ser corrigido posteriormente.

Deve-se ter cuidado na escolha das resistências, pois as mesmas dever ter absoluto comportamento ôhmico. Todo esse cuidado visa evitar a inserção de erros de medida devido ao sistema de medição.

A avaliação do valor da $i_{E P R}(t)$ durante a etapa experimental desta dissertação foi feita em 80 horas.

$\mathrm{Na}$ figura 17 apresenta-se o circuito (diagrama elétrico) utilizado para avaliar $i_{E P R}(t)$ durante as etapas experimentais.

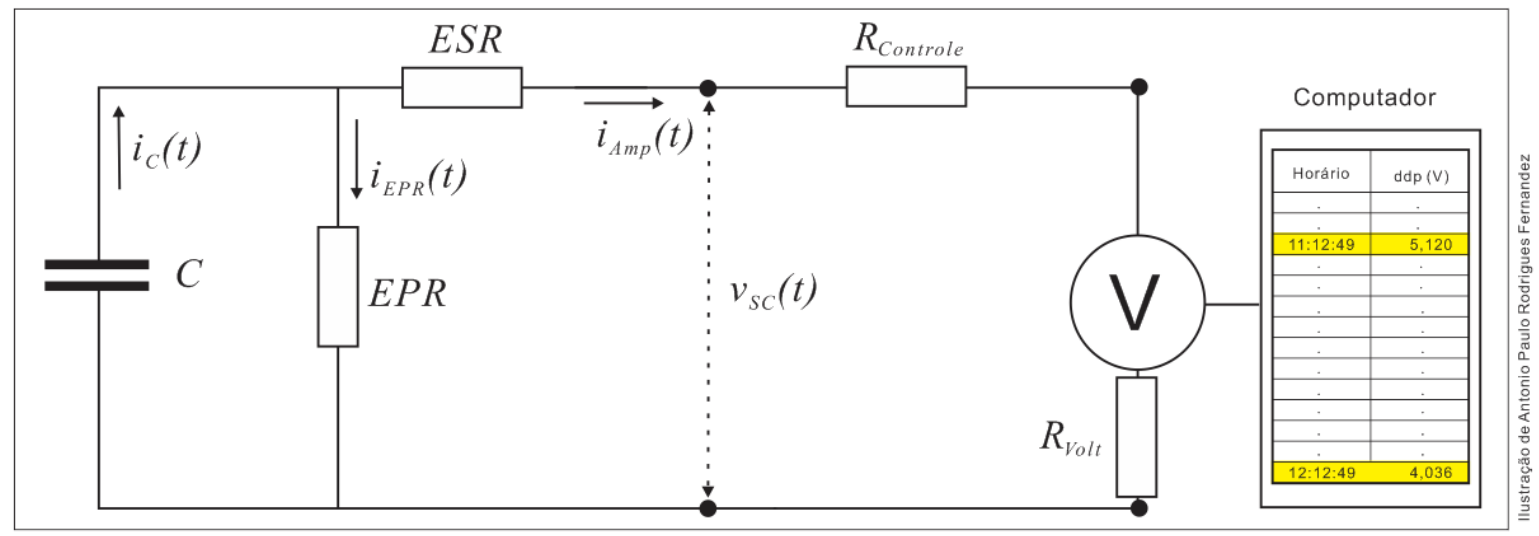

Figura 17 - Circuito representando a autodescarga do supercapacitor. 
A equação que determina o valor de $i_{E P R}(t)$ por meio de auto descarga é apresentada a seguir.

$$
E P R_{(\mathrm{Dep})}=\frac{R_{\text {volt }}+E S R_{(I n s t)}}{\left(R_{\text {volt }}+E S R_{(I n s t)}\right) \frac{C_{(D C)}}{(t f)} \ln \left(\frac{v_{\text {volt }}(0)}{v_{\text {volt }}(t f)}\right)-1}
$$

Sendo que:

$$
\begin{aligned}
& \operatorname{EPR}_{(\text {Dep })} \quad=\text { Valor da resistência em paralelo equivalente obtido pelo } \\
& \text { método dependente; } \\
& C_{(D C)}=\text { Valor da capacitância do supercapacitor obtido pelo método } \\
& \text { da corrente contínua; } \\
& E S R_{(I n s t)} \quad=\text { Valor da resistência em série equivalente obtido pelo método da } \\
& \text { interrupção de corrente; } \\
& R_{\text {volt }} \quad=\text { Valor da resistência interna do voltímetro; } \\
& \text { If } \quad=\text { Valor do tempo de referência para avaliação do potencial } \\
& \text { apresentado pelo voltímetro após o início do processo de } \\
& \text { autodescarga; } \\
& v_{\text {volt }}(0)=\text { Valor do potencial apresentado pelo voltímetro ao inicio do } \\
& \text { processo de autodescarga; e } \\
& v_{\text {volt }}(t)=\text { Valor do potencial apresentado pelo voltímetro a cada instante } \\
& \text { após o início do processo de autodescarga. }
\end{aligned}
$$

\subsection{Resistência em série equivalente obtida pelo método da interrupção de corrente - $E S R_{(I n s t)}$.}

$\mathrm{O}$ ato de carregar e descarregar um supercapacitor está ligado ao movimento de portadores de cargas (íons) presentes no eletrólito, e que se movem através do separador elétrico em direção a estrutura porosa dos eletrodos. Nos processos de carga e descarga ocorre redução do valor de corrente elétrica em relação ao valor teoricamente esperado devido aos efeitos de difusão e dificuldade de mobilidade dos íons em penetrar ou sair da estrutura porosa dos eletrodos. Tal redução de corrente pode ser pensada como se fosse oriunda de uma resistência em série com o capacitor ideal que se encontra dentro da célula que constitui o supercapacitor. Portanto a $E S R_{(I n s t)}$, pode ser pensada como uma resistência puramente ôhmica a título de cálculos e previsão de comportamento do valor de corrente de carga e descarga (Mussoi \& Villaça, 2000). 
O valor da resistência em série equivalente ESR pode ser calculado a partir do valor instantâneo da queda de potencial produzido pela interrupção de corrente auxiliada por uma corrente de descarga constante (corrente controlada), ou seja: após o capacitor estar carregado faz-se uma alteração instantânea no valor de corrente de descarga livre por meio de uma chave comutadora ou gatilho eletrônico, o que permite que uma corrente de, por exemplo, décimos de microampère passe a ser de algumas centenas de microampère durante alguns milésimos de segundos, o que caracteriza uma queda abrupta de potencial. A corrente de descarga livre é uma corrente de valor extremamente baixo que circula devido à presença dos equipamentos de medição que já se fazem presentes no circuito de análise e ficam ligados contínua e diretamente ao supercapacitor, como por exemplo, o osciloscópio e/ou voltímetro. Tais equipamentos tipicamente possuem valores de resistência interna na casa dos megaohms, o que propicia a circulação de uma corrente extremamente baixa, a qual deve ser computada a título de aumento de precisão de resultados quando da obtenção do valor da $E S R_{(I n s t)}$.

No método em que se faz uso de um resistor variável para manter a corrente de descarga controlada constante é necessário que o resistor seja ajustado para permitir a passagem de uma corrente em acordo com o desejado. $\mathrm{O}$ valor de corrente de descarga deve ser ajustado em acordo com as recomendações da IEC. Nas etapas experimentais desta dissertação foi utilizada corrente de descarga de $1 \mathrm{~mA}$. O valor foi escolhido não pela aplicação do supercapacitor, mesmo porque não se sabe qual é a mesma, mas sim pelo fato de tentar evitar a inserção de qualquer variável, além da energia térmica, que pudesse vir a acarretar mudança nos parâmetros elétricos avaliados.

Outra ferramenta importante para obter o valor da $E S R_{(I n s t)}$ é o osciloscópio que deve ter as divisões de tempo e de potencial ajustados adequadamente.

Utilizando o método de descarga controlada com resistor variável faz-se uma ligação em série entre este, o amperímetro e o capacitor carregado, lembrando que é necessário manter inicialmente um dos terminais do capacitor em aberto. Em seguida procede-se com a ligação do osciloscópio em paralelo, o qual tem resistência interna da ordem de dezenas de $\mathrm{M} \Omega$, portanto a corrente de descarga livre do supercapacitor através do osciloscópio deverá ser da ordem de décimos de microampères. Para efetuar o fechamento do circuito de descarga controlada pode ser utilizado um gatilho eletrônico (trigger) ou uma chave comutadora tipo botão pulsador. 
Por meio da figura 18 demonstra-se o arranjo dos componentes do circuito para avaliar o valor da $\operatorname{ESR}_{(\text {Inst })}$.

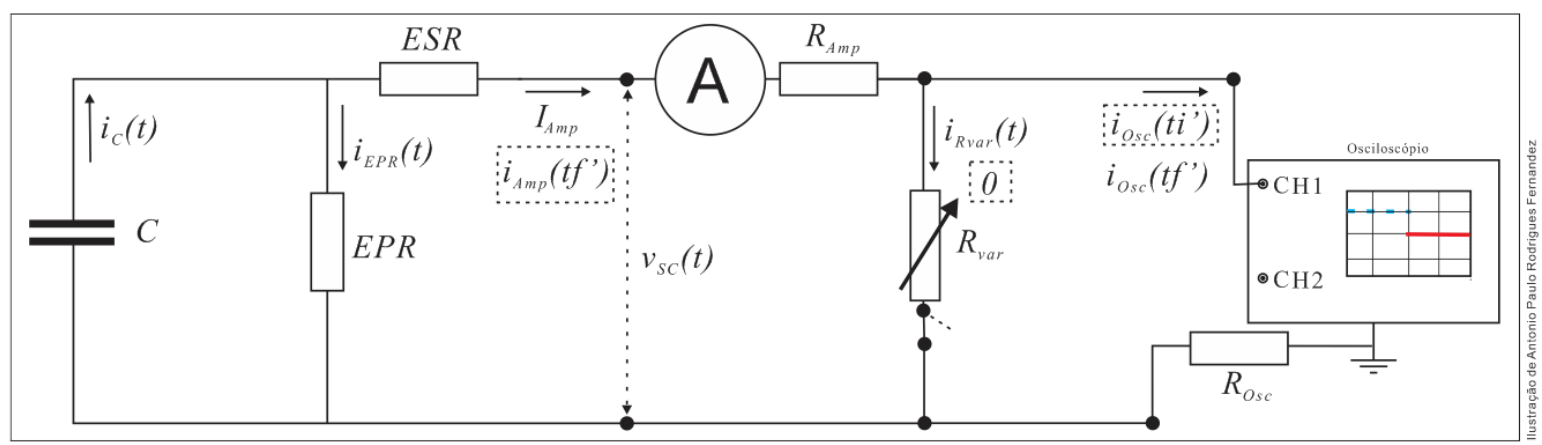

Figura 18 - Arranjo dos componentes para obtenção de $E S R_{(I n s t)}$.

Estando o circuito montado em acordo com o exemplificado por meio da figura 18, o capacitor carregado, o resistor variável e o osciloscópio ajustados, procede-se com o fechamento da chave comutadora.

O resultado instantâneo do fechamento da chave comutadora será a interrupção da corrente e consequente queda instantânea do valor do potencial devido ao início do processo de descarga, conforme exemplificado por meio da figura 19, que representa a forma de sinal visto na tela do osciloscópio.

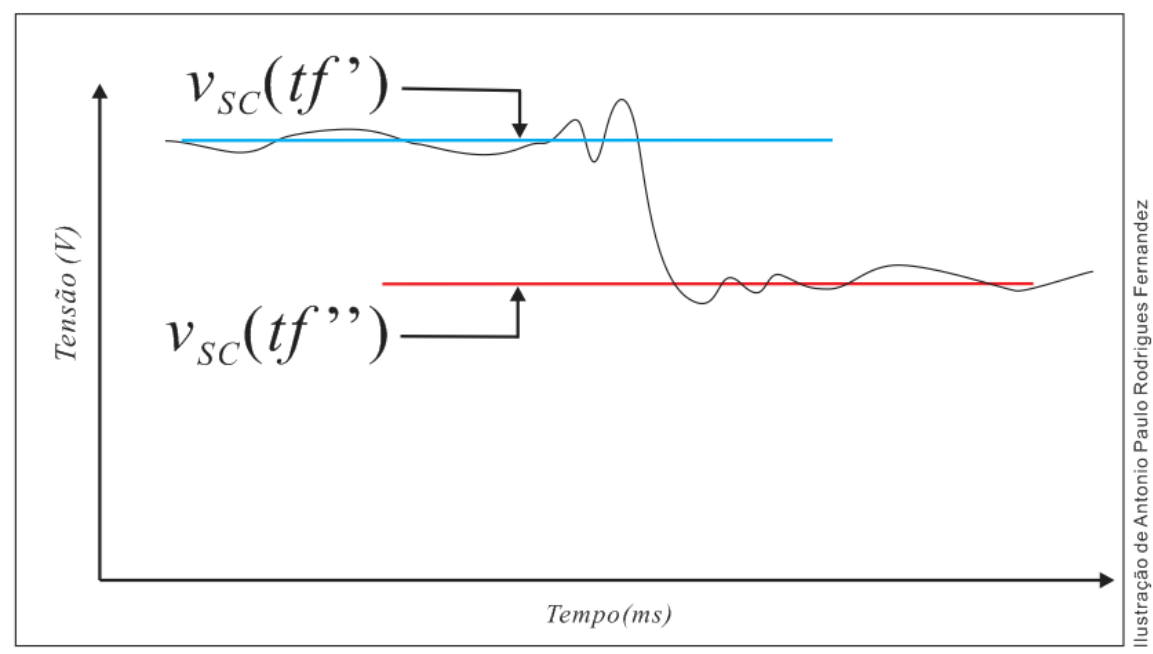

Figura 19 - Obtenção da $E S R_{(I n s t)}$ por meio da queda instantânea do potencial.

Para obter o valor da $\operatorname{ESR}_{(I n s t)}$ é necessário explicitar duas equações: uma que determine o valor do potencial do supercapacitor a cada instante no processo de descarga livre através dos equipamentos de medição e outra para determinar o valor do 
potencial do supercapacitor a cada instante no processo de descarga controlada que ocorre por meio do resistor variável.

A equação (23) determina o valor do potencial do capacitor ideal existente no circuito de modelamento do supercapacitor a cada instante no processo de carga livre, sendo obtida pela análise do circuito (diagrama elétrico) apresentado por meio da figura 20 .

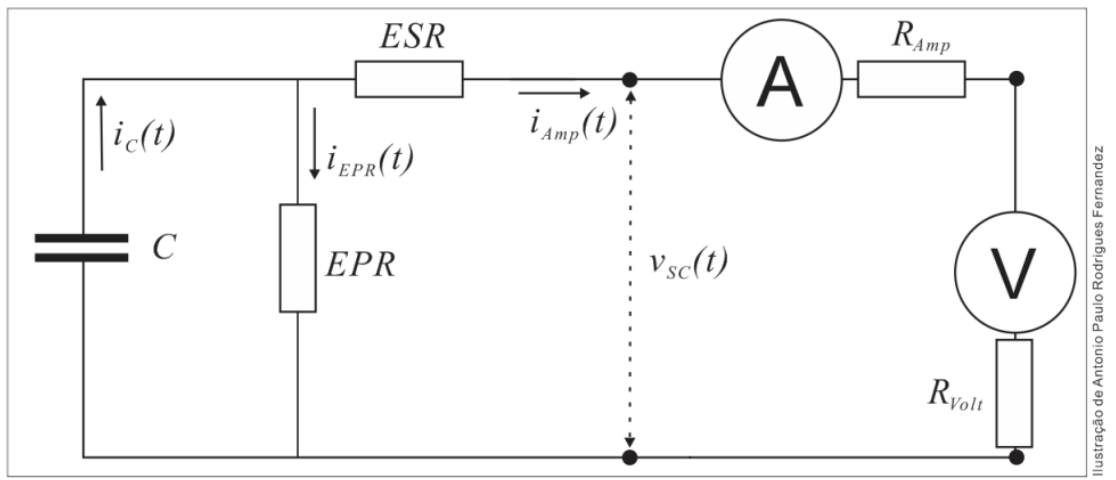

Figura 20 - Processo de descarga livre do supercapacitor.

$$
v_{C}\left(t f^{\prime}\right)=i_{A m p}\left(t f^{\prime}\right) E S R-i_{A m p}\left(t f^{\prime}\right) R_{A m p}+v_{C}\left(t i^{\prime}\right) e^{-\frac{E P R+R_{a m p}+R_{v o l t}+E S R}{C(E P R)\left(R_{\text {anp }}+R_{\text {vol }}+E S R\right)^{\prime}}\left(t f^{\prime}-t i^{\prime}\right)} .
$$

A equação (24) determina o valor do potencial do capacitor ideal existente no circuito de modelamento do supercapacitor a cada instante no processo de descarga controlada, sendo obtida por meio da análise do circuito apresentado pela figura 21.

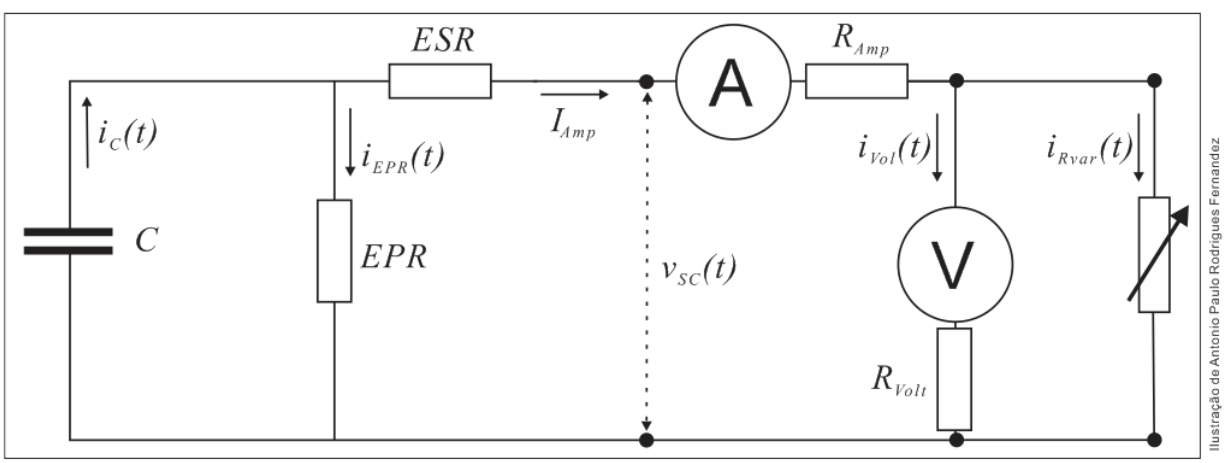

Figura 21 - Circuito utilizado para determinar $v_{C}\left(t f^{\prime \prime}\right)$. 


$$
v_{C}\left(t f^{\prime \prime}\right)=I_{A m p} E S R-I_{A m p} E P R-I_{A m p} R_{a m p}+\left(v_{C}\left(t i^{\prime}\right) e^{-\frac{E P R+R_{a m p}+R_{\text {vol }}+E S R}{C(E P R)\left(R_{\text {amp }}+R_{\text {vol }}+E S R\right)^{\left(t f^{\prime}-t i^{\prime}\right)}}+I_{\text {Amp }} E P R}\right) e^{-\frac{\left(t f^{\prime \prime}-t t^{\prime \prime}\right)}{C R_{k k}}}
$$

Utilizando a expressão para $V_{\text {Fall }}$ (equação (25)) e as equações (23) e (24) obtém-se a equação (26) que determina o valor de ESR pelo método da interrupção de corrente.

Se

$$
V_{\text {Fall }}=v_{S C}\left(t f^{\prime}\right)-v_{S C}\left(t f^{\prime \prime}\right)
$$

tem-se que:

$$
\operatorname{ESR}_{(I n s t)}=\frac{V_{F a l l}+i_{A m p}\left(t f^{\prime}\right) R_{A m p}-I_{A m p} R_{a m p}}{i_{A m p}\left(t f^{\prime}\right)-I_{A m p}}
$$

Sendo que:

$$
\begin{aligned}
& E S R_{(I n s t)}= \begin{array}{l}
\text { Valor da Resistência em Série Equivalente obtida pelo método da } \\
\text { interrupção de corrente; }
\end{array} \\
& i_{A m p}\left(t f^{\prime}\right)= \begin{array}{l}
\text { Valor da corrente de descarga livre do supercapacitor através do } \\
\text { osciloscópio; }
\end{array} \\
& I_{A m p}=\begin{array}{l}
\text { Valor da corrente de descarga controlada do supercapacitor através da } \\
\text { resistência variável; }
\end{array} \\
& V_{\text {Fall }=} \begin{array}{l}
\text { Valor da diferença entre o potencial ao término do processo de } \\
\text { descarga livre e ao início do processo de descarga controlada; }
\end{array}
\end{aligned}
$$

$\mathrm{O}$ valor da $E S R_{(I n s t)}$ determina várias propriedades dos supercapacitores e portanto permite prever alguns comportamentos relacionados ao tempo de carga e descarga e aquecimento por efeito termo iônico, pois a ESR limita os picos de carga ou descarga assim como o tempo mínimo de carga ou descarga. 
O valor da ESR juntamente com o da capacitância origina a constante de tempo intrínseca $\tau_{\text {int }}$ do supercapacitor, a qual determina, em condição de curto circuito, o menor tempo de descarga.

$$
\tau=R_{i} C
$$

A ESR obtida por meio de corrente contínua não deve ser confundida com a ESR obtida por meio de corrente alternada, normalmente especificada para capacitores comerciais. Ao ler o datasheet de supercapacitores comerciais deve-se verificar qual tipo de ESR é abordada no mesmo. O valor da ESR obtido em corrente alternada é mensurado em frequência de $1 \mathrm{kHz}$, sendo que seu valor é tipicamente muitas vezes maior que o da ESR obtido por meio de corrente contínua. O valor da ESR obtido por corrente alternada não é relevante para calcular correntes de irrupção (corrente de transitório $D C$ ) ou outros tipos de correte de pico, enquanto que o valor da $E S R$ obtido em $D C$ não é relevante para análise de defasagem de fase e efeitos de histerese.

\subsection{Capacitância obtida pelo método da corrente contínua - $C_{(D C)}$.}

Para determinar o valor da capacitância pelo método da corrente continua deve-se aplicar ao supercapacitor um valor de potencial nominal de carregamento por meio de uma fonte de tensão com ajuste de valor de corrente. A partir do momento em que o potencial do supercapacitor for igual ao da fonte deve-se manter um tempo de carregamento de no mínimo 30 minutos para que os íons solvatados adentrem nos pontos do material dos eletrodos. $\mathrm{O}$ aumento do potencial poderia fazer com que os íons penetrassem mais dentro dos poros, reduzindo assim o tempo de carga, contudo não se pode ultrapassar o valor de potencial nominal, pois se isto ocorrer o separador elétrico pode ser rompido e o capacitor ser permanentemente danificado.

Após o capacitor ser carregado o próximo passo é descarregá-lo com um valor de corrente contínuo e constante, o que pode ser feito com um resistor variável. Recomenda-se que o início da contagem do tempo de descarga ( $t i)$ se dê a $80 \%$ do valor de potencial de carregamento e o término do tempo de contagem de descarga (tf) se dê a $40 \%$ do valor de potencial de carregamento. 
A equação (28) foi utilizada para determinar o valor da capacitância pelo método da corrente contínua, sendo obtida por meio da análise das correntes e tensões presentes no circuito apresentado por meio da figura 22.

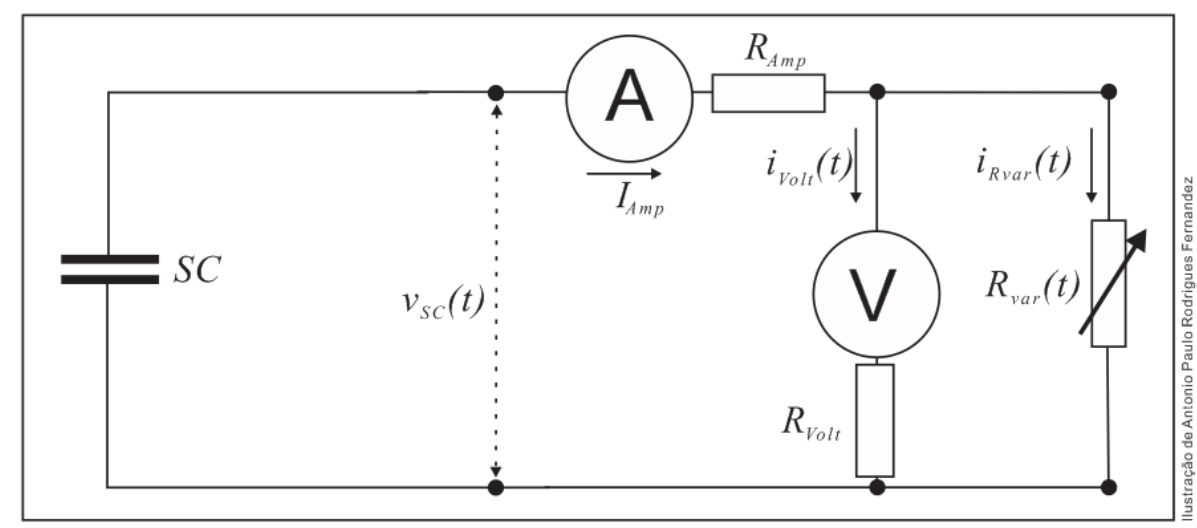

Figura 22 - Circuito utilizado para determinar a capacitância do supercapacitor.

$$
C_{(D C)_{s C}}=I_{a m p} \frac{(t f-t i)}{v_{v o l t}(t f)-v_{v o l t}(t i)}
$$

Onde:

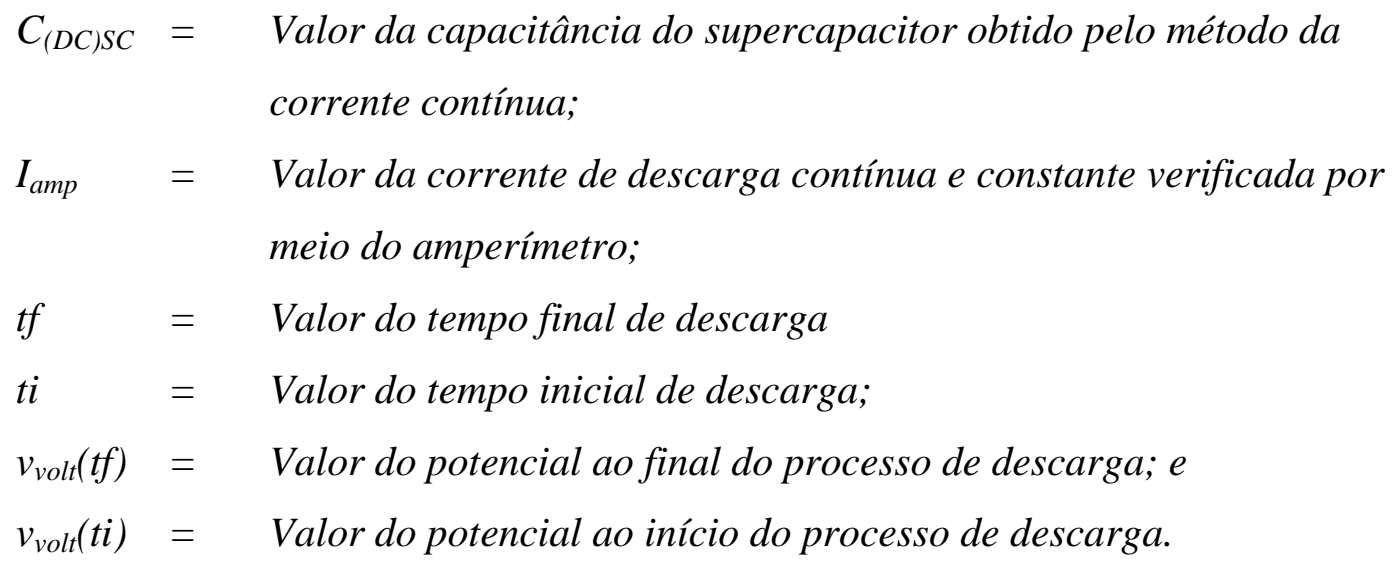


Os valores de corrente de descarga são determinados em acordo com a aplicação do supercapacitor. A International Electrotechnical Commission (IEC) define quatro classes a saber:

Classe 1 - Backup de memória para computadores:

$$
I_{\text {descarga }}=0,2 m A / F V \text { ou } I_{\text {descarga }}=1 m A / F .
$$

Exemplo: Para um capacitor de 1 Farad e potencial nominal de 5,0 Volts, tem-se que a corrente de descarga (ou carga) deve ser de no máximo $1 \mathrm{~mA}$.

Classe 2 - Armazenamento de energia:

$$
I_{\text {descarga }}=0,4 m A / F V
$$

Classe 3 - Sistemas de potência, sendo que:

$$
I_{\text {descarga }}=4 m A / F V
$$

Classe 4 - Sistemas de potência instantânea:

$$
I_{\text {descarga }}=40 \mathrm{~mA} / F V
$$

\subsection{Capacitância obtida pelo método da voltametria cíclica $-C_{(V C)}$.}

Dos vários métodos de análise dinâmicos em eletroquímica, a voltametria cíclica pode ser considerada uma das mais versáteis. Tal versatilidade combinada com a facilidade de obtenção de valores de parâmetros de interesse faz com que a mesma seja largamente utilizada na avaliação de baterias e supercapacitores (Namisnyk, 2003; Júnior, 2014).

A voltametria cíclica é utilizada para investigar o comportamento capacitivo e a estabilidade de supercapacitores com diferentes materiais ativos e diferentes eletrólitos em diferentes faixas de potenciais (Huang, 2013).

A voltametria cíclica $(V C)$ é uma técnica eletroanalítica versátil para o estudo de espécies eletroativas. A $V C$ consiste na aplicação de um potencial, variável e cíclico no tempo, em um eletrodo que é imerso em um eletrólito enquanto se mede a corrente resultante (corrente de resposta). A correlação entre potencial aplicado e corrente de resposta gera o voltamograma, que é um gráfico da corrente versus potencial em que a direção do potencial é revertida ao final da varredura. A $V C$ é uma ferramenta poderosa para a determinação do potencial formal redox, detecção de reações químicas que precedem ou seguem reações eletroquímicas e avaliação da cinética de transferência de elétrons (Gujar, Kim, Puspitasari, Jung, \& Joo, 2007). De forma geral é possível dizer que 
a voltametria cíclica consiste no escaneamento do potencial de um eletrodo de trabalho o qual está imerso em uma solução iônica, medindo-se o valor da corrente elétrica ao longo do tempo (Namisnyk, 2003; Júnior, 2014).

O voltamograma, que é o registro gráfico de dados obtidos por voltametria cíclica, sendo de simples e rápida interpretação quantitativa em termos cinéticos permitindo em um relance, para os mais experientes, por simples comparativa, saber se houve ou não mudanças nos parâmetros elétricos de um componente eletroeletrônico, ou mudanças em uma reação eletroquímica (Namisnyk , 2003).

A voltametria cíclica pode ser considerada como um método de medição dinâmica do potencial eletroquímico. Na voltametria cíclica o potencial varia em acordo com um valor constante no tempo, ou seja: o potencial é diferençável no tempo, aumentando ou diminuindo em acordo com uma função linear de coeficiente angular predefinido. Para que o potencial se mantenha crescendo linearmente é necessário que a corrente varie não linearmente.

O potencial aplicado entre o eletrodo de trabalho e um eletrodo de referência pode ser considerado como sendo um sinal de excitação e a corrente como sendo um sinal de resposta.

$\mathrm{Na}$ avaliação do valor da capacitância por voltametria cíclica $C_{(V C)}$, toma-se como referência a área da curva de voltametria cíclica. A área produzida é integrada fornecendo o produto i. $U$, que é posteriormente dividido pelo produto entre a janela de potencial pela velocidade de variação do potencial (dV/dt) (Namisnyk , 2003).

A voltametria cíclica fornece uma medida de resposta de carga de supercapacitores em relação a um potencial variável no tempo (crescente e decrescente), sendo portanto um possível meio de avaliar a capacitância de maneira simples e eficaz (Namisnyk , 2003).

Para realizar um experimento em voltametria cíclica, a varredura de potencial linear é revertida quando se atinge certo potencial. A corrente de resposta como uma função do potencial é armazenada durante os processos de carga e descarga (Huang, 2013).

O procedimento para obtenção de um voltamograma, que é o gráfico obtido da variação da corrente em função da variação do potencial, requer o uso de um analisador do voltametria cíclica digital programável controlado por computador.

Utilizando um circuito RC teórico, contendo um supercapacitor ideal com uma capacitância idêntica em todas tensões, quando a taxa de varredura $d V / d t$ é constante, então 
a corrente $i(t)=d Q / d t=C d V / d t$ também será constante. O voltamograma cíclico para este caso será perfeitamente retangular, conforme apresentado por meio da figura 23 (a). No entanto, na realidade, existem vários fatores que podem causar desvios no que seria considerado um voltamograma oriundo de um capacitor ideal. A resistência em série equivalente é introduzida em série com a capacitância ideal e definida principalmente pela resistência do eletrodo e do eletrólito, levando um período de tempo para atingir uma corrente capacitiva estável, chamado de constante de tempo Tau $(\tau)$, sendo que $\tau=R C$. Antes de atingir a corrente capacitiva estável, a corrente aumenta vagarosamente até o início da varredura positiva e varredura reversa, como apresentado por meio da figura 23 (b), sendo que ESR refere-se a resistência em série equivalente. Outro tipo de resistência é chamada de resistência de fuga (tratada por resistência em paralelo equivalente), relativa a reações redox indesejadas ou de autodescarga no interior do supercapacitor, estando a mesma em paralelo com a capacitância. Se a resistência de fuga tende a valor infinito, o capacitor permanece na condição de ideal, isto é, se a resistência em série equivalente for nula. $\mathrm{O}$ efeito da resistência de fuga (resistência em paralelo equivalente - EPR) sobre o voltamograma pode ser visto por meio da figura 23 (c). A resistência de fuga pode ser calculada pela inclinação da varredura positiva ou negativa. A combinação dos efeitos da resistência em série e da resistência em paralelo sobre o voltamograma de um capacitor ideal pode ser vista por meio da figura 23 (d). Existem outros vários fatores que afetam a forma do voltamograma cíclico, tais como, por exemplo, a distribuição dos poros em eletrodos porosos (Huang, 2013). 


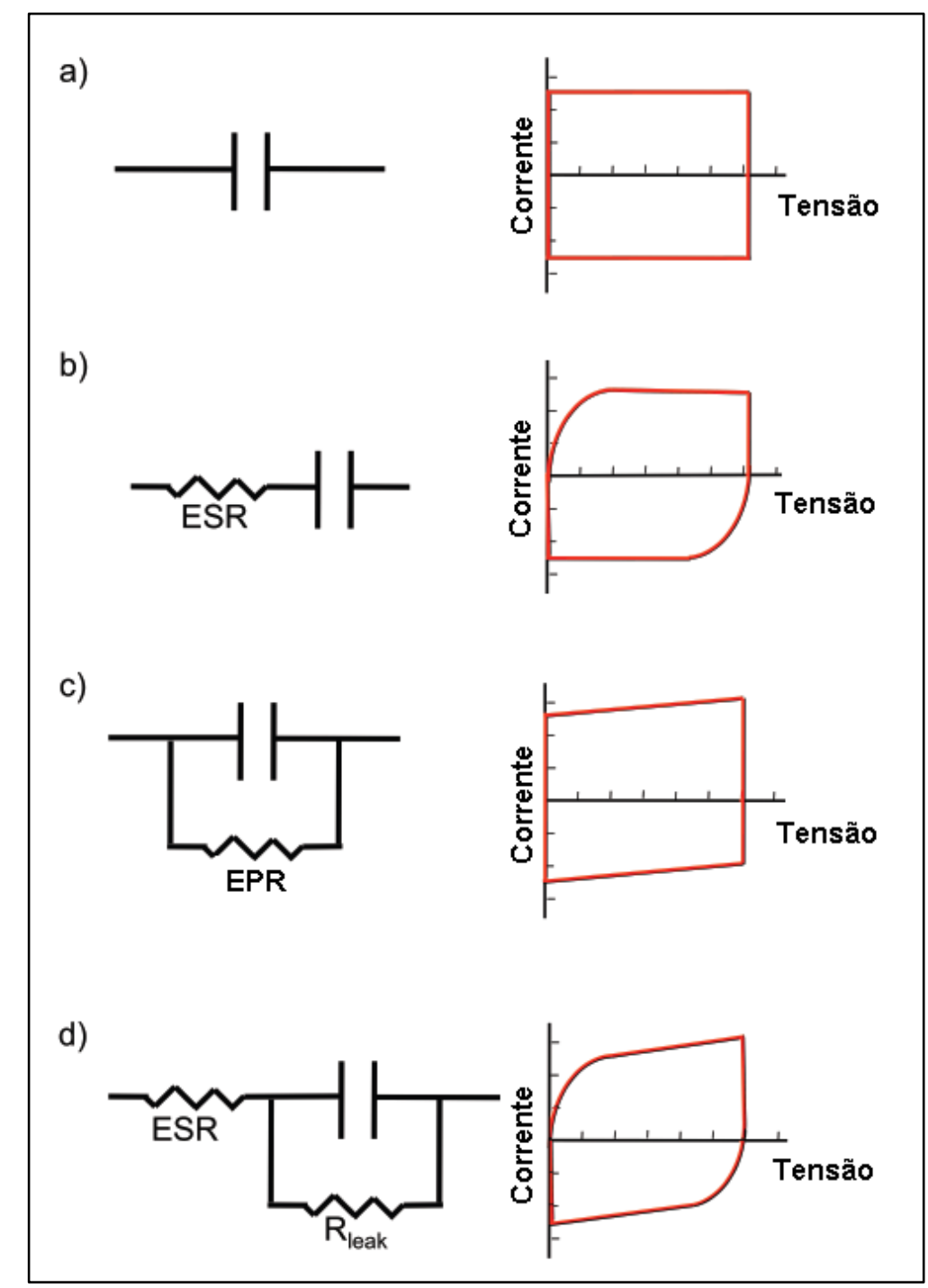

Figura 23 - Voltamograma cíclico de um supercapacitor ideal (a), da combinação entre um supercapacitor ideal e de um resistor em série (b), de um supercapacitor ideal em paralelo com um resistor (c) e de um resistor em série com um resistor em paralelo com um capacitor (d) (Huang, 2013).

Na $V C$ uma varredura com o potencial mudando com uma taxa constante em relação ao tempo é aplicada à célula de interesse. A resposta do potencial de saída ao longo do tempo é dada pela equação (29), onde $U(t)$ é o potencial de saída (resposta), $U_{0}$ o potencial de entrada, $t$ o tempo decorrente (valor instantâneo do tempo) e $v$ a taxa de variação do potencial no tempo (dV/dt) (Huang, 2013).

$$
U(t)=U_{0}+v t
$$

O teste de voltametria cíclica baseia-se em uma série de potenciais de carga e descarga com uma taxa de varredura constante (variação crescente ou decrescente do 
potencial aplicado à uma taxa constante - $d V / d t$ ) que é aplicada no componente eletroeletrônico de interesse, sendo a corrente instantânea (que é a resposta) armazenada e correlacionada ao potencial instantâneo (Namisnyk , 2003).

A capacitância por voltametria cíclica $C_{(V C)}$ pode ser calculada por meio da equação (30), onde $i(t)$ é a corrente instantânea e $v$ é a velocidade de varredura, ou taxa de variação do potencial no tempo, em Volts por segundo.

$$
C_{(V C)}=\frac{i(t)}{v}
$$

Um capacitor ideal - sem resistências - (sem ESR e EPR) - irá gerar um voltamograma cíclico retangular, ao passo que supercapacitores reais irão gerar voltamogramas cíclicos na forma de paralelogramos com picos irregulares, conforme exemplificado por meio da figura 24. Picos proeminentes que ocorrem dentro de janelas estreitas de potencial normalmente evidenciam um comportamento pseudocapacitivo.

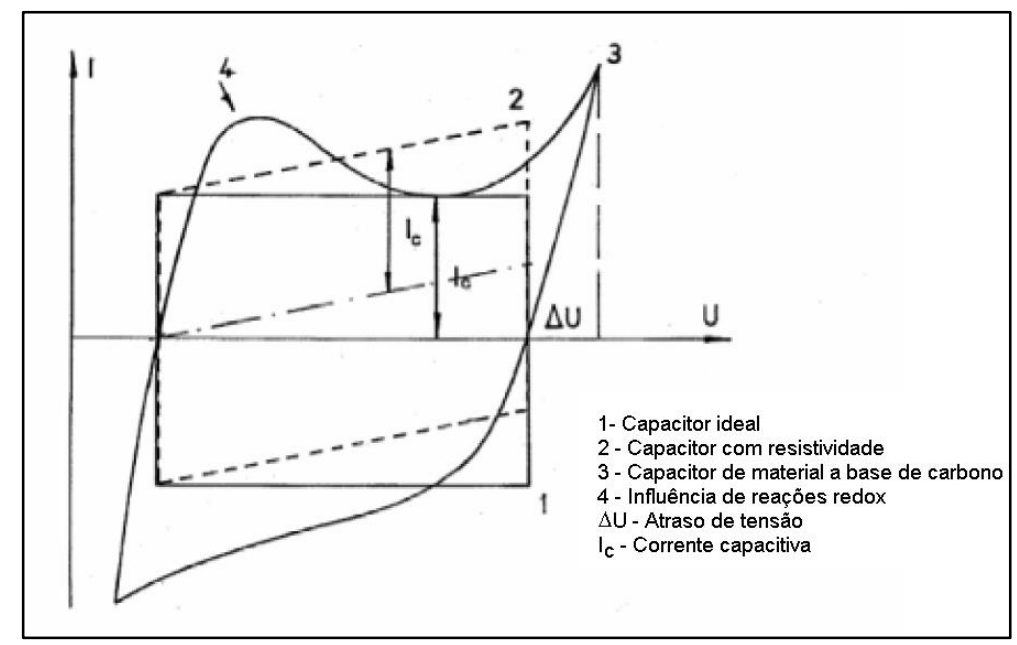

Figura 24 - Comparação entre voltamogramas cíclicos de um capacitor ideal e de capacitores reais (Namisnyk, 2003).

Taxas de varredura mais rápidas correspondem à carga e descarga com maior nível de potência. Vários voltamogramas cíclicos obtidos pelo aumento das taxas de varredura são muitas vezes apresentados em um mesmo gráfico para demonstrar os efeitos dos níveis de potência na carga, conforme exemplificado por meio da figura 25. A partir de tais gráficos torna-se evidente que a capacitância diminui à medida que as taxas de varredura tornam-se mais altas, o que é evidenciado pela redução da área plotada (Namisnyk , 2003). 


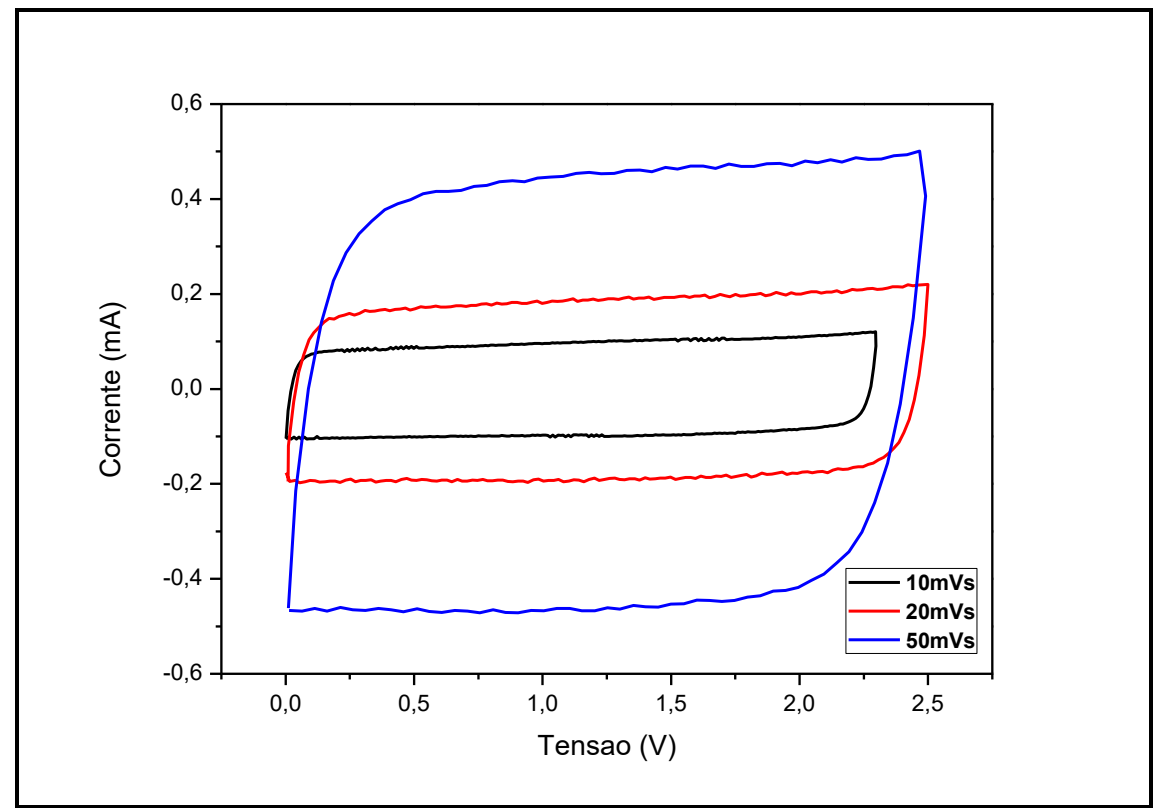

Figura 25 - Comparação entre voltamogramas cíclicos de um supercapacitor com comportamento próximo ao ideal (Cortesia de Tayara Correia Gonsalves). 


\subsubsection{Capacitância obtida pelo método da área do voltamograma cíclico - $C_{(A V C)}$.}

Existem várias formas de se obter o valor da capacitância por voltametria cíclica, sendo uma destas a que considera a área do voltamograma produzida por um ciclo completo, conforme disposto pela equação (31).

$$
C_{(A V C)}=\frac{\int_{V i}^{V f} i(V) d V}{2 v(V f-V i)} .
$$

Onde:

$$
\begin{aligned}
& C_{(A V C)}=\text { Valor capacitância obtido pelo método da área do voltamograma } \\
& V f=\text { cíclico; } \\
& V i=\text { Maior valor de potencial da janela de potencial } \\
& i(V)=\text { Função geratriz da corrente (função potencial } \\
& v=\text { Velocidade de varredura (o mesmo que taxa de varredura) em Volts } \\
& \text { por segundo. } \\
& \text { O termo } \int_{V i}^{V f} i(V) d V \text { resulta em um produto (área) em que as grandezas possuem }
\end{aligned}
$$
dimensões de potencial e potencial por resistência elétrica, sendo suas respectivas unidades $V$ e $A$.

Caso haja dificuldade em obter a função geratriz é possível obter a área total do voltamograma por soma sucessiva de pequenas áreas ou então fazer uso do programa Origin que fornece o valor absoluto da área. 


\subsubsection{Capacitância obtida pelo método da média dos valores da corrente elétrica de resposta em módulo - $C_{(V C i M)}$.}

Os valores de capacitância podem ser obtidos por voltametria cíclica utilizando o método da média dos valores da corrente elétrica de resposta em módulo, sendo a equação (32) utilizada para determinar o valor da capacitância $C_{(V C)}$ por meio do método da média dos valores em módulo da corrente elétrica de resposta.

$$
C_{(V C i M)}=\frac{|i(\bar{V})|}{v},|i(\bar{V})|=\frac{\left|i_{1}(V)\right|+\left|i_{2}(V)\right|+\left|i_{3}(V)\right|+\ldots+\left|i_{n}(V)\right|}{n}=\frac{1}{n} \sum_{a=1}^{n}\left|i_{a}(V)\right|
$$

Onde:

$C_{(V C i M)} \quad=$ Valor da capacitância obtido pelo método da média dos valores da corrente elétrica de resposta em módulo;

$|i(\vec{V})|=$ Valor médio simples dos valores de corrente elétrica de resposta em módulo;

$v \quad=$ Velocidade de varredura (o mesmo que taxa de varredura $d V / d t$ ) em Volts por segundo. 


\subsubsection{Capacitância obtida pelo método da média dos valores de corrente elétrica de resposta oriundos dos menores valores de potencial (potencial tendendo a zero) $-C_{(V C V \rightarrow 0)}$.}

Outro método utilizado para gerar valores de capacitância obtidos por meio de voltametria cíclica faz uso apenas de valores de corrente elétrica de resposta em módulo do ciclo voltamétrico em que o potencial aplicado correspondente seja o menor possível (tenda a zero).

A equação (33) é utilizada no método da média dos valores de corrente elétrica de resposta para valores de potencial igual ou muito próximos de zero.

$$
C_{(V C V \rightarrow 0)}=\frac{\left|\overline{i\left(V^{\prime}\right)}\right|}{v}, V^{\prime}=\lim _{(V \rightarrow 0)} V, \therefore\left|i\left(\bar{V}^{\prime}\right)\right|=\frac{\left|i_{1}\left(V^{\prime}\right)\right|+\left|i_{2}\left(V^{\prime}\right)\right|+\ldots+\left|i_{n}\left(V^{\prime}\right)\right|}{n}=\frac{1}{n} \sum_{a=1}^{n}\left|i_{a}\left(V^{\prime}\right)\right|
$$

Sendo que:

$$
\begin{aligned}
C_{(V C V \rightarrow 0)}= & \begin{array}{l}
\text { Valor da capacitância obtido pelo método da média dos valores } \\
\text { de corrente elétrica de resposta oriundos de valores de potencial } \\
\text { tendendo a zero; }
\end{array} \\
V \rightarrow 0 & \text { Menor valor de potencial (potencial tendendo a zero); } \\
\left|i\left(V^{\prime}\right)\right|= & \text { Valor médio simples dos valores de corrente elétrica de resposta } \\
v & \text { em módulo oriundo de valores de potencial tendendo a zero; e }
\end{aligned}
$$




\section{RESULTADOS.}

\subsection{Considerações gerais.}

Foram utilizados quatro supercapacitores para obtenção dos valores dos parâmetros elétricos em diferentes temperaturas e tempos de exposição. Tais capacitores serão chamados de capacitores de referência, recebendo as siglas $\mathrm{S} 1$ (exposto a $50^{\circ} \mathrm{C}$ ), $\mathrm{S} 2$ (exposto a $75^{\circ} \mathrm{C}$ ), $\mathrm{S} 3$ (exposto a $100^{\circ} \mathrm{C}$ ) e $\mathrm{S} 4$ (exposto a $125^{\circ} \mathrm{C}$ ).

Os valores do erro de medição dos parâmetros elétricos foram obtidos à temperatura ambiente utilizando um único supercapacitor, o qual nunca foi exposto a temperaturas além daquelas presentes à temperatura ambiente. $\mathrm{O}$ valor do erro de medição foi obtido por meio de dez medições consecutivas, tentando sempre manter as mesmas condições iniciais de medição.

Os valore de tolerância dos parâmetros elétricos foram obtidos à temperatura ambiente utilizando dez supercapacitores que nunca foram expostos a temperaturas além daquelas presentes à temperatura ambiente. Procurou-se sempre manter as mesmas condições iniciais de medição, sendo as medições realizadas consecutivamente.

O valor de cada parâmetro elétrico para cada eletrodo foi estimado supondo cada supercapacitor contém quatro eletrodos idênticos em massa, fato este comprovado por desmontagem e pesagem dos mesmos. Dado o fato de que cada supercapacitor possui supostamente quatro eletrodos idênticos em massa é fato que o valor da capacitância por eletrodo será igual a quatro vezes (4X) a da capacitância total do capacitor e que os valores de $E S R_{(I n s t)}$ e $E P R_{(D e p)}$ por eletrodo serão de um quarto $(0,25 \mathrm{X})$ do valor encontrado no supercapacitor.

Os valores de capacitância específica $\left[\mathrm{Fg}^{-1}\right]$, não importando o modelo adotado, foram calculados estimando-se que cada um dos quatro eletrodos que compõem o supercapacitor possui massa média determinada de aproximadamente 90mg; descontado $5 \%$ de ligante.

Os valores do erro de medição da $E P R_{(D e p)}$, da tolerância do parâmetro elétrico $E P R_{(D e p)}$ e da $E P R_{(D e p)}$ para os quatro supercapacitores de referência foram obtidos a 80 horas de autodescarga. 
A equação (34) foi utilizada para obtenção da incerteza padrão, sendo tal valor utilizado para gerar o valor percentual do erro da medição e também para determinar o valor percentual da tolerância de lote.

$$
s=\sqrt{\frac{\sum_{i=1}^{N}\left(x_{i}-\bar{x}\right)^{2}}{N-1}} .
$$

O valor percentual da incerteza da medida obtido pela raiz quadrada da soma entre o quadrado do erro percentual de medição e o quadrado do valor porcentual da tolerância.

\subsection{Avaliação da resistência em paralelo equivalente obtida pelo método do valor dependente $-E P R_{(D e p)}$.}

\subsubsection{Valor do erro de medição da $E P R_{(D e p)}$.}

Inicialmente foi tomando um único supercapacitor como referência e realizada a avaliação do erro da medição na obtenção do valor do $E P R_{(D e p)}$ à temperatura ambiente para um intervalo de tempo de 80 horas de autodescarga. Para obtenção de tal parâmetro foram realizadas dez medições do valor da $E P R_{(D e p)}$, sendo encontrado um erro relacionado a medição de $\pm 34,16 \mathrm{k} \Omega$ em ralação ao valor médio absoluto de $649,94 \mathrm{k} \Omega$ obtido a partir dos dados da Tabela 2. O valor percentual do erro de medição do valor da $\operatorname{EPR}_{(\text {Dep })}$, utilizando a equação 34 , foi calculado em $\pm 5,26 \%$. 
Tabela 2 - Dados utilizados na obtenção do valor do erro de medição da $E P R_{(D e p)}$

\begin{tabular}{ccc}
\hline $\begin{array}{c}\text { Número da medição } \\
\text { (Avaliações realizadas } \\
\text { à temperatura } \\
\text { ambiente) }\end{array}$ & $\begin{array}{c}\text { Valor da } E P R_{(D e p)} \text { a } 80 \text { horas } \\
{[\mathrm{k} \Omega]}\end{array}$ & $\begin{array}{c}\text { Valor estimado da } \\
E P R_{(D e p)} \text { a } 80 \text { horas por } \\
\text { eletrodo }[\mathrm{k} \Omega] .\end{array}$ \\
\hline 1 & & \\
2 & & 156,67 \\
3 & 626,69 & 172,12 \\
4 & 688,47 & 163,76 \\
5 & 655,03 & 179,96 \\
6 & 719,83 & 159,93 \\
7 & 639,73 & 160,27 \\
8 & 641,07 & 162,57 \\
9 & 650,27 & 163,34 \\
10 & 653,37 & 157,31 \\
\hline
\end{tabular}

\subsubsection{Valor da tolerância para a $\operatorname{EPR}_{(D e p)}$.}

O primeiro passo da parte experimental desta dissertação foi encontrar, dentro de um lote de 10 unidades de supercapacitores, 4 unidade que ofertassem valor de $E P R_{(D e p)}$ semelhante e, a partir deste ponto iniciar o processo de avaliação dos parâmetro elétricos em diferentes temperaturas.

Aproveitando o ensaio para a escolha dos 4 supercapacitores semelhantes em termos de $E P R_{(D e p}$ foi avaliada a tolerância do lote referente ao parâmetro elétrico $E P R_{(D e p)}$.

O valor da $E P R_{(D e p)}$ de cada um dos dez supercapacitores avaliados é apresentado na Tabela 3, que por meio de tais valores foi constatada uma tolerância de $\pm 17,39 \%$ para o parâmetro elétrico $E P R_{(D e p)}$. Este foi o maior valor de tolerância encontrado nos parâmetros elétricos avaliados. 
Tabela 3 - Dados utilizados na obtenção do valor da tolerância referente à $E P R_{(D e p)}$

\begin{tabular}{ccc}
\hline Número da amostra & $\begin{array}{c}\text { Valor da } E P R_{(\text {Dep })} \text { a } 80 \text { horas } \\
{[\mathrm{k} \Omega]}\end{array}$ & $\begin{array}{c}\text { Valor estimado da } \\
E P R_{(D e p)} \text { a } 80 \text { horas por } \\
\text { (Avaliações realizadas à } \\
\text { temperatura ambiente) }\end{array}$ \\
\hline 1 & & \\
\hline 2 & $827,91 \pm 43,55$ & $206,97 \pm 10,89$ \\
3 & $743,93 \pm 39,13$ & $185,98 \pm 9,78$ \\
4 & $898,52 \pm 47,26$ & $224,63 \pm 11,82$ \\
5 & $714,86 \pm 37,60$ & $178,71 \pm 9,40$ \\
6 & $1080,93 \pm 56,86$ & $270,23 \pm 14,21$ \\
7 & $719,67 \pm 37,85$ & $179,92 \pm 9,46$ \\
8 & $675,45 \pm 35,53$ & $168,86 \pm 8,88$ \\
9 & $671,30 \pm 35,31$ & $167,82 \pm 8,83$ \\
10 & $653,68 \pm 34,38$ & $163,42 \pm 8,60$ \\
\hline
\end{tabular}

\subsubsection{Valores de $\operatorname{EPR}_{(D e p)}$ (a 80 horas de autodescarga) obtidos por meio da avaliação de quatro supercapacitores de referência em diferentes temperaturas e tempos de exposição.}

Os valores da $\operatorname{EPR}_{(D e p)}$ em diferentes temperaturas e diferentes intervalos de tempo para cada um dos supercapacitores de referência (S1, S2, S3 e S4) são apresentados na figura 26 onde é possível observar os efeitos do acúmulo de energia térmica. Por meio da figura 26 evidenciam-se graficamente os efeitos do acúmulo da energia térmica, sendo gerada a partir dos dados da Tabela 4 .

O valor percentual da incerteza da medida da Tabela 4 foi calculado em $\pm 18,17 \%$. 
Tabela 4 - Valores da $E P R_{(D e p)}$ para cada um dos supercapacitores de referência em diferentes temperatura e diferentes tempos de exposição

\begin{tabular}{ccccc}
\hline $\begin{array}{c}\text { Tempo } \\
(\mathrm{h})\end{array}$ & $\mathrm{S} 1: \mathrm{T}=50^{\circ} \mathrm{C}$ & $\mathrm{S} 2: \mathrm{T}=75^{\circ} \mathrm{C}$ & $\mathrm{S} 3: \mathrm{T}=100^{\circ} \mathrm{C}$ & $\mathrm{S} 4: \mathrm{T}=125^{\circ} \mathrm{C}$ \\
& $E S R_{(I n s t)}[\mathrm{M} \Omega]$ & $E S R_{(\text {Inst })}[\mathrm{M} \Omega]$ & $E S R_{(I n s t)}[\mathrm{M} \Omega]$ & $E S R_{(I n s t)}[\mathrm{M} \Omega]$ \\
\hline 168 & $0,67 \pm 0,12$ & $0,67 \pm 0,12$ & $0,65 \pm 0,11$ & $0,69 \pm 0,12$ \\
336 & $0,67 \pm 0,12$ & $0,63 \pm 0,11$ & $0,63 \pm 0,11$ & $0,35 \pm 0,06$ \\
504 & $0,66 \pm 0,12$ & $0,61 \pm 0,11$ & $0,64 \pm 0,12$ & $0,28 \pm 0,05$ \\
672 & $0,67 \pm 0,12$ & $0,60 \pm 0,11$ & $0,63 \pm 0,11$ & ---- \\
\hline
\end{tabular}

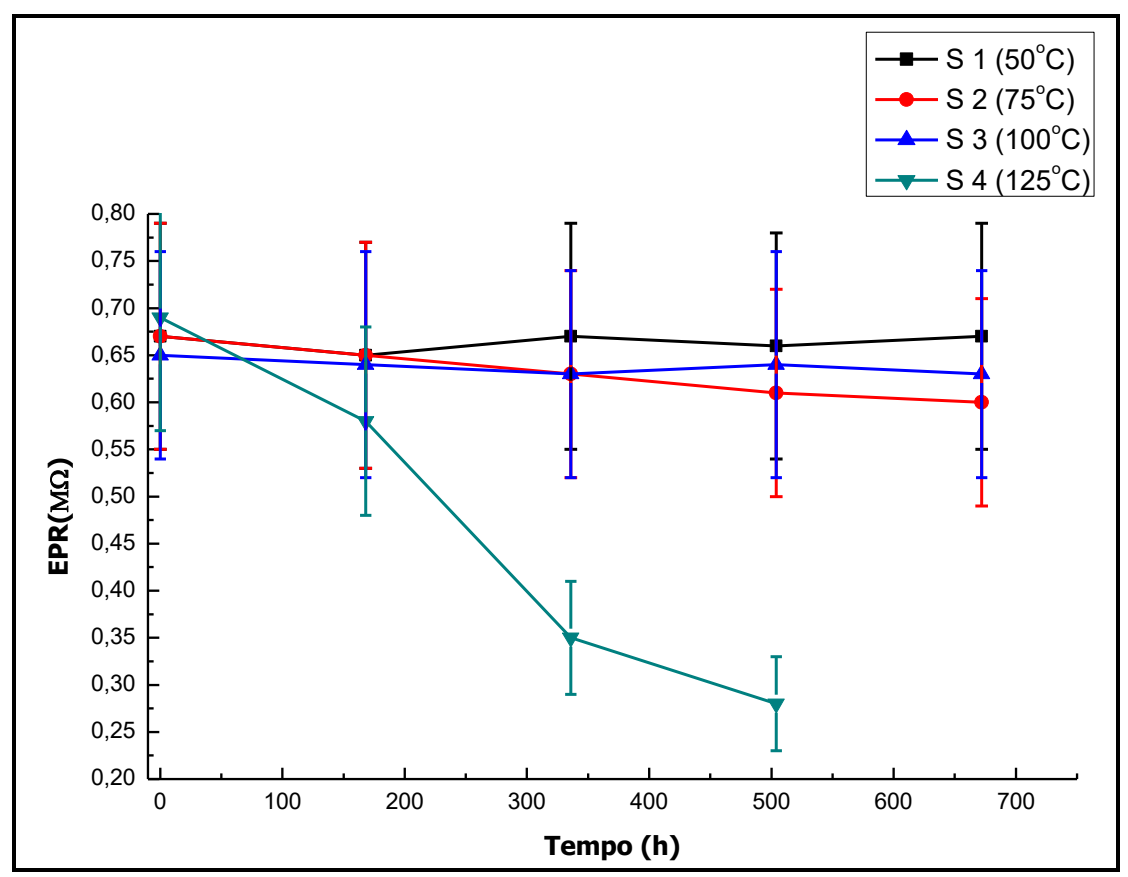

Figura 26 - Variação do valor da EPR(Dep) com o tempo para supercapacitores expostos à diferentes temperaturas.

Nota-se que a exposição à temperatura de $125^{\circ} \mathrm{C}$ influenciou significativamente o valor da $E P R_{(D e p)}$, e portanto o comportamento da $E P R_{(D e p)}$, pois à mediada que o supercapacitor 4 foi sendo submetido a maiores tempos de exposição a tal temperatura o valor de $E P R_{(D e p)}$ caiu consideravelmente. O supercapacitor 4, que foi submetido à temperatura de $125^{\circ} \mathrm{C}$, parou de apresentar propriedades elétricas após 672 horas de exposição, pois o eletrólito acabou por vazar. 
Por meio da figura 27 observa-se as curvas de variação do potencial geradas no processo de autodescarga do supercapacitor 4 (S4), sendo que o mesmo sofreu maior degradação devido a exposição à maior quantia de energia térmica. Nota-se uma mudança no comportamento da autodescarga à medida que o tempo de exposição aumenta.

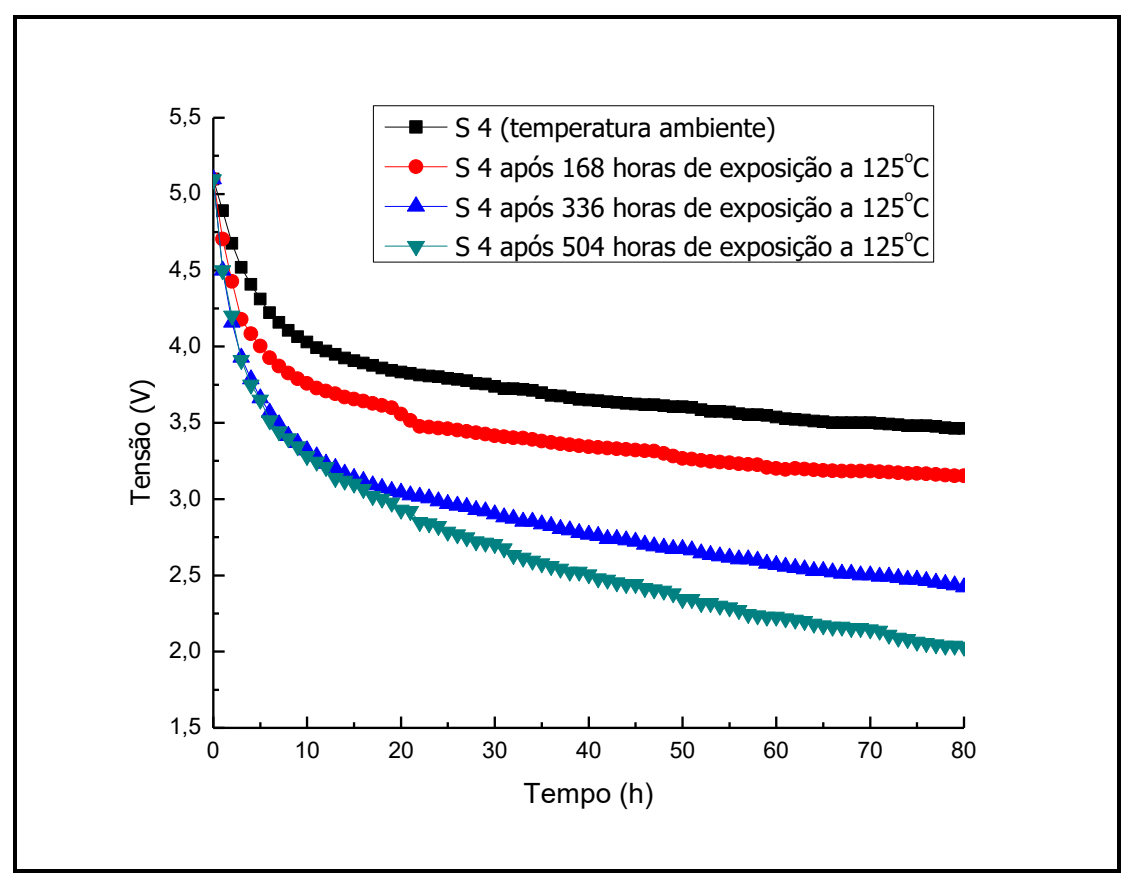

Figura 27 - Variação do potencial durante o processo de auto descarga a $125^{\circ} \mathrm{C}$.

Tem sido relatado que, desde que as taxas de autodescarga são dependentes das taxas de transporte iônico, espera-se que a autodescarga tornar-se mais rápida à medida que temperatura do capacitor for aumentando (Diab, Venet, Gualous, \& Rojat, 2009).

Na figura 28 são apresentados valores da $E P R_{(D e p)}$ obtidos com um tempo de auto descarga de 3, 8, 24, 48, 72 e 80 horas para o supercapacitor 3 (S3) na condição de exposição à temperatura ambiente e depois de quatro semanas exposto a temperatura de $100^{\circ} \mathrm{C}$. O objetivo da Figura 28 é evidenciar que os valores da $E P R_{(D e p)}$ mudam com o tempo de auto descarga, portanto a análise dos valores da EPR devem ser sempre atrelados ao tempo. Devido a uma tendência assintótica por parte do potencial em relação ao tempo quando de valores de tempo muito altos é de se saber que a $E P R_{(D e p)}$ poderá atingir centenas, quem sabe milhares de Megaohms. 


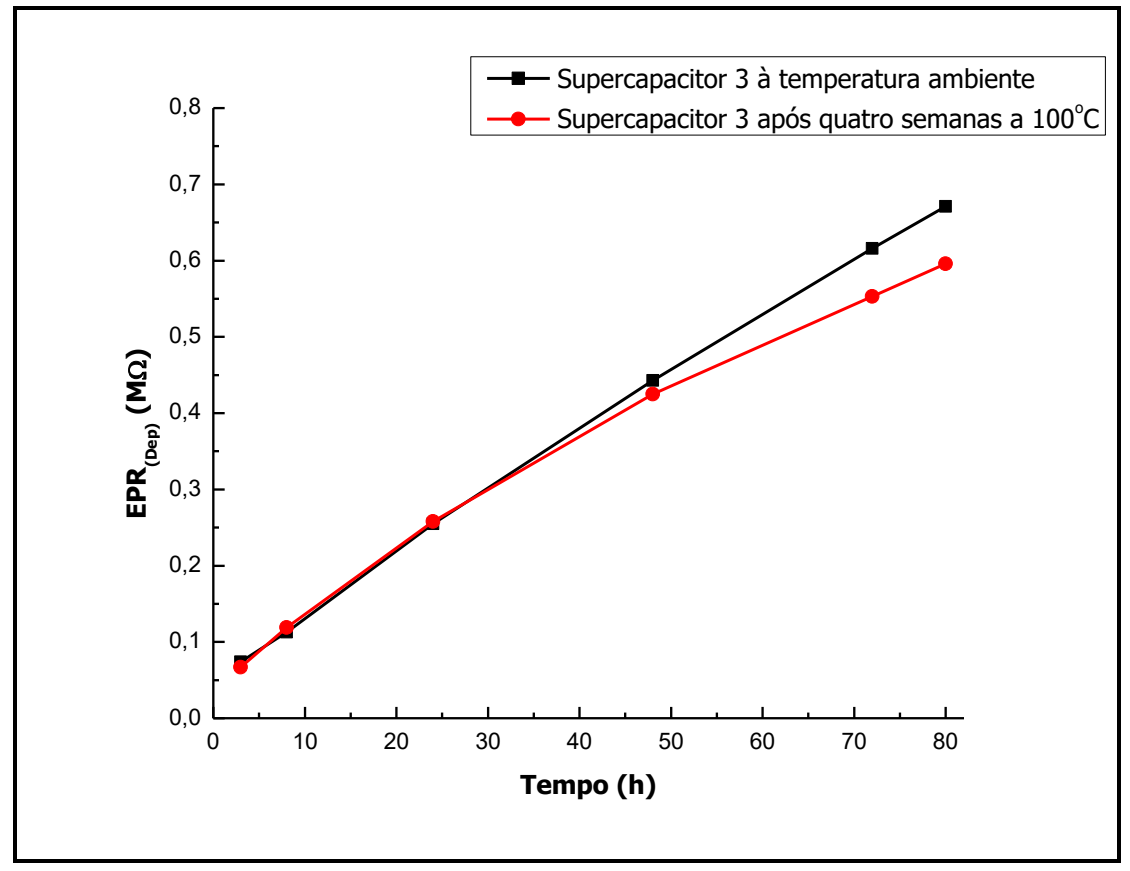

Figura 28 - Variação do valor da $\mathrm{EPR}_{(\mathrm{Dep})}$ em acordo com o tempo de autodescarga. 


\subsection{Avaliação da resistência em série equivalente obtida pelo método da interrupção de corrente $-\boldsymbol{E S R}_{(\text {Inst) }}$.}

\subsubsection{Valor do erro da medição da $E S R_{(I n s t)}$.}

Por meio da figura 29 é possível verificar uma curva típica de variação instantânea do valor de potencial obtida por meio do método da interrupção de corrente vista em um osciloscópio. A curva foi obtida a partir da leitura da queda instantânea do potencial com uso de um osciloscópio com atenuação de sonda de 10X, ajustado com divisão de tempo em $10,00 \mathrm{~ms}$ e divisão de potencial em $10,00 \mathrm{mV}$, sendo a resistência do amperímetro de $540 \Omega$ para escala de microampères e, tendo a corrente de descarga livre valor de $0,3 \mu \mathrm{A}$ e a corrente de descarga controlada de $686 \mu \mathrm{A}$.

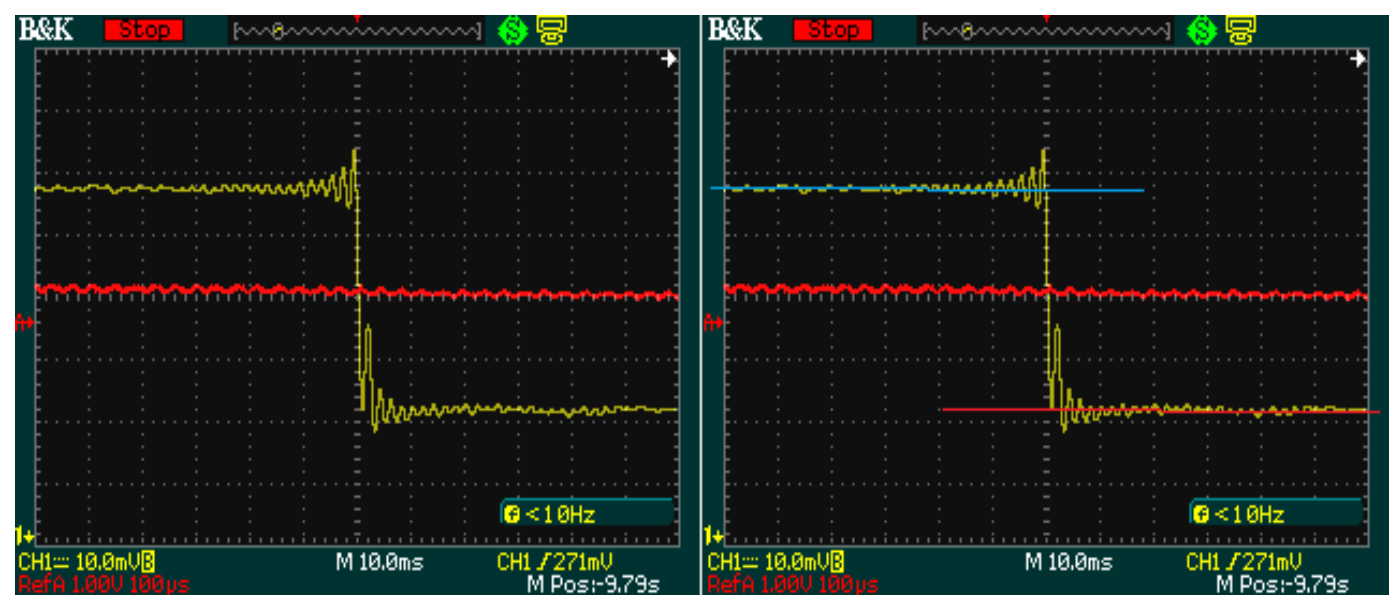

Figura 29 - Avaliação de ESR pelo método da interrupção de corrente.

Com base nos dados apresentados no parágrafo anterior e fazendo uso da equação que determina o valor da $E S R$ pelo método da interrupção de corrente obtém-se um valor aproximado de $29,6 \Omega$ de $E S R_{(I n s t)}$, pois, em acordo com a figura 29 a queda instantânea de potencial foi de $350,00 \mathrm{~m} V$, portanto:

$$
E S R_{(I n s t)}=\frac{350 m V+0,3 \mu A \cdot 540 \Omega-686 \mu A \cdot 540 \Omega}{0,3 \mu A-686 \mu A} \cong 29,57 \Omega
$$

Para obtenção do valor do erro de medição da $E P R_{(D e p)}$ foram realizadas dez medições de tal parâmetro elétrico por meio de um único capacitor, sendo encontrado um erro relacionado a medição de $\pm 13,66 \%$, obtido por meio dos dados da Tabela 5 . 
Tabela 5 - Dados utilizados na obtenção do valor do erro de medição dos valores da $\operatorname{ESR}_{(\text {Inst })}$

\begin{tabular}{ccc}
\hline $\begin{array}{c}\text { Número da medição } \\
\text { (Avaliações realizadas à } \\
\text { temperatura ambiente) }\end{array}$ & Valor da $\operatorname{ESR}_{(\text {Inst })}[\Omega]$ & $\begin{array}{c}\text { Valor da } \operatorname{ESR}_{(\text {Inst })} \\
\text { estimado por eletrodo } \\
{[\Omega]}\end{array}$ \\
\hline 1 & & 5,61 \\
2 & 22,43 & 5,61 \\
3 & 22,44 & 6,02 \\
4 & 24,06 & 6,33 \\
5 & 25,33 & 6,72 \\
6 & 26,86 & 7,25 \\
7 & 29,00 & 7,65 \\
8 & 30,60 & 7,80 \\
9 & 31,21 & 7,99 \\
10 & 31,95 & 6,01 \\
\hline
\end{tabular}

\subsubsection{Valor da tolerância para a $\operatorname{ESR}_{(I n s t)}$.}

A avaliação da tolerância da $E S R_{(\text {(Inst) }}$ foi realizada à temperatura ambiente, tomando como referência os mesmos dez supercapacitores utilizados para avaliar a tolerância da $E P R_{(D e p)}$. Salienta-se que não houve procura de similaridade de valores iniciais para tal parâmetro, pois o parâmetro de referência inicialmente escolhido foi a $E P R_{(D e p)}$, sendo assim os valores iniciais para os demais parâmetros passaram a ser consequência do mesmo, portanto irrelevantes.

Na Tabela 6 apresenta-se os dados coletados referente à variação do valor da $E S R_{(\text {Inst) }}$ para um lote de dez supercapacitores, sendo encontrada uma tolerância de $\pm 11,93 \%$ para tal parâmetro elétrico. 
Tabela 6 - Dados utilizados na obtenção do valor da tolerância referente à $E S R_{(I n s t)}$

\begin{tabular}{ccc}
\hline $\begin{array}{c}\text { Número da amostra } \\
\text { (Avaliações realizadas à } \\
\text { temperatura ambiente) }\end{array}$ & Valor da $E S R_{(\text {Inst })}$ & $\begin{array}{c}\text { Valor estimado da } \\
\operatorname{ESR}_{(\text {Inst })} \text { por eletrodo }[\Omega]\end{array}$ \\
\hline 1 & {$[\Omega]$} & \\
2 & $22,43 \pm 3,06$ & $5,61 \pm 0,77$ \\
3 & $22,44 \pm 3,07$ & $5,61 \pm 0,77$ \\
4 & $24,05 \pm 3,29$ & $6,01 \pm 0,82$ \\
5 & $26,85 \pm 3,67$ & $6,71 \pm 0,92$ \\
6 & $27,17 \pm 3,71$ & $6,79 \pm 0,93$ \\
7 & $22,93 \pm 3,13$ & $5,73 \pm 0,78$ \\
8 & $18,58 \pm 2,54$ & $4,65 \pm 0,63$ \\
9 & $25,89 \pm 3,54$ & $6,47 \pm 0,88$ \\
10 & $27,49 \pm 3,76$ & $6,87 \pm 0,94$ \\
\hline
\end{tabular}

5.3.3 Valores de $\boldsymbol{E S R}($ Inst) obtidos pela avaliação de quatro supercapacitores de referência em diferentes temperaturas e diferentes tempos de exposição.

Os valores da ESR obtidos pelo método da interrupção de corrente para os supercapacitores avaliados na coleta de dados experimentais podem ser vistos na Tabela 7 . 
Tabela 7 - Valores da $\boldsymbol{E S R}_{(\boldsymbol{I n s t})}$ para cada um dos supercapacitores de referência em diferentes temperatura e diferentes tempos de exposição.

\begin{tabular}{ccccc}
\hline $\begin{array}{c}\text { Tempo } \\
(\mathrm{h})\end{array}$ & $\mathrm{S} 1: \mathrm{T}=50^{\circ} \mathrm{C}$ & $\mathrm{S} 2: \mathrm{T}=75^{\circ} \mathrm{C}$ & $\mathrm{S} 3: \mathrm{T}=100^{\circ} \mathrm{C}$ & $\mathrm{S} 4: \mathrm{T}=125^{\circ} \mathrm{C}$ \\
& $E S R_{(\text {Inst })}[\Omega]$ & $E S R_{(\text {Inst })}[\Omega]$ & $E S R_{(\text {Inst })}[\Omega]$ & $E S R_{(\text {Inst })}[\Omega]$ \\
\hline 0 & $24,14 \pm 4,38$ & $24,04 \pm 4,36$ & $28,67 \pm 5,20$ & $23,87 \pm 4,33$ \\
168 & $24,05 \pm 4,36$ & $27,37 \pm 4,96$ & $30,57 \pm 5,54$ & $24,88 \pm 4,51$ \\
336 & $23,04 \pm 4,18$ & $25,05 \pm 4,54$ & $25,59 \pm 4,64$ & $20,67 \pm 3,75$ \\
504 & $28,57 \pm 5,18$ & $24,03 \pm 4,36$ & $21,26 \pm 3,86$ & $23,08 \pm 4,19$ \\
672 & $30,68 \pm 5,56$ & $27,77 \pm 5,04$ & $27,66 \pm 5,02$ & ---- \\
\hline
\end{tabular}




\subsection{Avaliação da capacitância obtida pelo método da corrente contínua} $\left(C_{(D C)}\right)$ à uma corrente constante de descarga de $1 \mathrm{~mA}$.

\subsubsection{Valor do erro da medição da $C_{(D C)}$ a uma corrente constante de descarga de $\operatorname{lm} A$.}

O erro percentual relacionado à medição da $C_{(D C)}$ a uma corrente constante de $1 \mathrm{~mA}$ foi obtido por meio de dez medições de tal parâmetro elétrico em um mesmo supercapacitor, sendo constatado um valor percentual de erro de medição de $\pm 5,36 \%$. Por meio da Tabela 8 são apresentados os valores que foram utilizados na determinação do valor do erro da medição da $C_{(D C)}$.

Tabela 8 - Dados utilizados na obtenção do valor do erro de medição da $C_{(D C)} a \operatorname{lm} A$

\begin{tabular}{|c|c|c|}
\hline $\begin{array}{l}\text { Número da medição } \\
\qquad \begin{array}{c}\text { (Avaliações } \\
\text { realizadas à } \\
\text { temperatura } \\
\text { ambiente) }\end{array}\end{array}$ & $\begin{array}{c}\text { Valor da } C_{(D C)} \\
\qquad[\mathrm{F}]\end{array}$ & $\begin{array}{c}\text { Valor estimado da } C_{(D C)} \text { por } \\
\text { eletrodo }\left[\mathrm{Fg}^{-1}\right]\end{array}$ \\
\hline 1 & 1,07 & 47,56 \\
\hline 2 & 1,18 & 52,44 \\
\hline 3 & 1,25 & 55,56 \\
\hline 4 & 1,12 & 49,78 \\
\hline 5 & 1,06 & 47,11 \\
\hline 6 & 1,07 & 47,56 \\
\hline 7 & 1,12 & 49,78 \\
\hline 8 & 1,16 & 51,56 \\
\hline 9 & 1,08 & 48,00 \\
\hline 10 & 1,09 & 48,44 \\
\hline
\end{tabular}




\subsubsection{Valor da tolerância para a $C_{(D C)}$ a uma corrente constante de descarga de $\operatorname{lm} A$.}

O valor da tolerância para o parâmetro elétrico capacitância obtida pelo método da corrente contínua utilizando valor de corrente constante de $1 \mathrm{~mA}$ foi de $\pm 10,98 \%$, sendo que os valores apurados que levaram a tal resultado podem ser verificados por meio da Tabela 9.

Tabela 9 - Dados utilizados na obtenção do valor da tolerância referente à $C_{(D C)} a \operatorname{lm} A$

\begin{tabular}{|c|c|c|}
\hline $\begin{array}{l}\text { Número da amostra } \\
\qquad \begin{array}{c}\text { (Avaliações } \\
\text { realizadas à } \\
\text { temperatura } \\
\text { ambiente) }\end{array}\end{array}$ & Valor da $C_{(D C)}[\mathrm{F}]$ & $\begin{array}{c}\text { Valor estimado da } C_{(D C)} \\
\text { específica }\left[\mathrm{Fg}^{-1}\right]\end{array}$ \\
\hline 1 & $1,27 \pm 0,07$ & $56,44 \pm 3,03$ \\
\hline 2 & $1,06 \pm 0,06$ & $47,11 \pm 2,53$ \\
\hline 3 & $0,90 \pm 0,05$ & $40,00 \pm 2,14$ \\
\hline 4 & $1,12 \pm 0,06$ & $49,77 \pm 2,67$ \\
\hline 5 & $0,91 \pm 0,05$ & $40,44 \pm 2,17$ \\
\hline 6 & $1,13 \pm 0,06$ & $50,22 \pm 2,69$ \\
\hline 7 & $1,19 \pm 0,06$ & $52,44 \pm 2,83$ \\
\hline 8 & $1,17 \pm 0,06$ & $52,00 \pm 2,79$ \\
\hline 9 & $1,21 \pm 0,06$ & $53,77 \pm 2,88$ \\
\hline 10 & $1,15 \pm 0,06$ & $51,11 \pm 2,74$ \\
\hline
\end{tabular}




\subsubsection{Valore da $C_{(D C)}$ a uma corrente constante de $1 m A$ obtidos por meio da avaliação de quatro supercapacitores de referência em diferentes temperaturas e diferentes tempos de exposição.}

Os valores da $C_{(D C)}$, de descarga com corrente constante a $1 \mathrm{~mA}$, para os supercapacitores avaliados na coleta de dados experimentais são apresentados por meio da na Tabela 10, e por meio da Tabela 11 verifica-se o valor estimado de $C_{(D C)}$ específica, considerando um valor de incerteza de $12,22 \%$.

Tabela 10 - Valores da $C_{(D C)}$, obtida com uma corrente constante de $1 \mathrm{~mA}$, para cada um dos supercapacitores de referência em diferentes tempos e temperaturas

\begin{tabular}{ccccc}
\hline $\begin{array}{c}\text { Tempo } \\
\text { (h) }\end{array}$ & $\begin{array}{c}\mathrm{S} 1: \mathrm{T}=50^{\circ} \mathrm{C} \\
C_{(D C)}[\mathrm{F}]\end{array}$ & $\begin{array}{c}\mathrm{S} 2: \mathrm{T}=75^{\circ} \mathrm{C} \\
C_{(D C)}[\mathrm{F}]\end{array}$ & $\begin{array}{c}\mathrm{S} 3: \mathrm{T}=100^{\circ} \mathrm{C} \\
C_{(D C)}[\mathrm{F}]\end{array}$ & $\begin{array}{c}\mathrm{S} 4: \mathrm{T}=125^{\circ} \mathrm{C} \\
C_{(D C)}[\mathrm{F}]\end{array}$ \\
\hline 0 & $1,18 \pm 0,14$ & $1,21 \pm 0,15$ & $1,16 \pm 0,14$ & $1,14 \pm 0,14$ \\
168 & $1,18 \pm 0,14$ & $1,12 \pm 0,14$ & $1,13 \pm 0,14$ & $1,10 \pm 0,13$ \\
336 & $1,18 \pm 0,14$ & $1,08 \pm 0,13$ & $1,09 \pm 0,13$ & $1,14 \pm 0,14$ \\
504 & $1,17 \pm 0,14$ & $1,12 \pm 0,14$ & $1,10 \pm 0,13$ & $1,17 \pm 0,14$ \\
672 & $1,18 \pm 0,14$ & $1,11 \pm 0,14$ & $1,14 \pm 0,14$ & --- \\
\hline
\end{tabular}

Tabela 11 - Valores estimados da $C_{(D C)}$ específica, obtida com uma corrente constante de $1 \mathrm{~mA}$, em diferentes tempos e temperaturas de exposição para cada um dos supercapacitores de referência

\begin{tabular}{ccccc}
\hline $\begin{array}{c}\text { Tempo } \\
\text { (h) }\end{array}$ & $\begin{array}{c}\mathrm{S} 1: \mathrm{T}=50^{\circ} \mathrm{C} \\
C_{(D C)}\left[\mathrm{Fg}^{-1}\right]\end{array}$ & $\begin{array}{c}\mathrm{S} 2: \mathrm{T}=75^{\circ} \mathrm{C} \\
C_{(D C)}\left[\mathrm{Fg}^{-1}\right]\end{array}$ & $\begin{array}{c}\mathrm{S} 3: \mathrm{T}=100^{\circ} \mathrm{C} \\
C_{(D C)}\left[\mathrm{Fg}^{-1}\right]\end{array}$ & $\begin{array}{c}\mathrm{S} 4: \mathrm{T}=125^{\circ} \mathrm{C} \\
C_{(D C)}\left[\mathrm{Fg}^{-1}\right]\end{array}$ \\
\hline 0 & $55,20 \pm 6,55$ & $56,61 \pm 7,02$ & $54,27 \pm 6,55$ & $53,33 \pm 6,55$ \\
168 & $55,20 \pm 6,55$ & $52,40 \pm 6,55$ & $52,87 \pm 6,55$ & $51,46 \pm 6,08$ \\
336 & $55,20 \pm 6,55$ & $50,53 \pm 6,08$ & $50,99 \pm 6,08$ & $53,33 \pm 6,55$ \\
504 & $54,74 \pm 6,55$ & $52,40 \pm 6,55$ & $51,46 \pm 6,08$ & $54,74 \pm 6,55$ \\
672 & $55,20 \pm 6,55$ & $51,93 \pm 6,55$ & $53,33 \pm 6,55$ & ---- \\
\hline
\end{tabular}




\subsection{Avaliação da capacitância obtida pelo método da área do voltamograma cíclico - $C_{(A V C)}$.}

\subsubsection{Valor do erro da medição da $C_{(A V C)}$ para as velocidades de varredura de $25 \mathrm{mV} / \mathrm{s}, 50 \mathrm{mV} / \mathrm{s}, 75 \mathrm{mV} / \mathrm{s}$ e $100 \mathrm{mV} / \mathrm{s}$.}

O valor do erro de medição da capacitância obtida pelo método da área do voltamograma cíclico $\left(C_{(A V C)}\right)$ foi obtido por meio de dez repetições de leitura para cada uma das quatro taxas de varredura adotadas utilizando um único capacitor. Por meio da Tabela 12 são apresentados os dados que foram utilizados para determinar o erro da medição da capacitância obtida pelo método da área do voltamograma cíclico para as taxas de varredura de $25 \mathrm{mV} / \mathrm{s}, 50 \mathrm{mV} / \mathrm{s}, 75 \mathrm{mV} / \mathrm{s}$ e $100 \mathrm{mV} / \mathrm{s}$.

Tabela 12 - Dados utilizados para determinar o valor do erro de medição da $C_{(A V C)}$ obtido por meio de dez medições de um único capacitor

\begin{tabular}{ccccc}
\hline Número da & $\mathrm{T}=$ Ambiente & $\mathrm{T}=$ Ambiente & $\mathrm{T}=$ Ambiente & $\mathrm{T}=$ Ambiente \\
medição & $25 \mathrm{mV} / \mathrm{s}$ & $50 \mathrm{mV} / \mathrm{s}$ & $75 \mathrm{mV} / \mathrm{s}$ & $100 \mathrm{mV} / \mathrm{s}$ \\
(Avaliações & $C_{(A V C)}[\mathrm{F}]$ & $C_{(A V C)}[\mathrm{F}]$ & $C_{(A V C)}[\mathrm{F}]$ & $C_{(A V C)}[\mathrm{F}]$ \\
realizadas à & & & & \\
temperatura & & & & \\
ambiente) & & & & \\
\hline \multirow{2}{*}{1} & 0,88 & 0,77 & 0,66 & 0,57 \\
2 & 0,88 & 0,78 & 0,65 & 0,56 \\
3 & 0,88 & 0,76 & 0,66 & 0,57 \\
4 & 0,88 & 0,77 & 0,67 & 0,57 \\
5 & 0,88 & 0,77 & 0,67 & 0,57 \\
6 & 0,89 & 0,76 & 0,66 & 0,56 \\
7 & 0,89 & 0,77 & 0,67 & 0,57 \\
8 & 0,89 & 0,77 & 0,65 & 0,57 \\
9 & 0,89 & 0,77 & 0,65 & 0,57 \\
10 & 0,89 & 0,77 & 0,65 & 0,57 \\
\hline
\end{tabular}


Referente ao erro de medição da $\boldsymbol{C}_{(\boldsymbol{A} V \boldsymbol{C})}$ foi encontrado um erro percentual de $\pm 1,14 \%$ para a taxa de varredura de $25 \mathrm{mV} / \mathrm{s}, \pm 1,05 \%$ para a taxa de varredura de $50 \mathrm{mV} / \mathrm{s}$, $\pm 0,96 \%$ para a taxa de varredura de $75 \mathrm{mV} / \mathrm{s}$ e $\pm 0,88 \%$ para a taxa de varredura de $100 \mathrm{mV} / \mathrm{s}$.

\subsubsection{Valor da tolerância para a $C_{(A V C)}$.}

O valor da tolerância para o parâmetro elétrico capacitância obtida pelo método da área do voltamograma cíclico foi $\pm 10,25 \%$ para a taxa de varredura de $25 \mathrm{mV} / \mathrm{s}, \pm 9,95 \%$ para a taxa de varredura de $50 \mathrm{mV} / \mathrm{s}, \pm 9,32 \%$ para a taxa de varredura de $75 \mathrm{mV} / \mathrm{s}$ e $\pm 11,49 \%$ para a taxa de varredura de $100 \mathrm{mV} / \mathrm{s}$. Os valores que geraram tais resultados podem ser verificados na Tabela 13.

Tabela 13 - Dados utilizados para determinar o valor da tolerância da $C_{(A V C)}$ para um lote de dez unidades de supercapacitores

\begin{tabular}{|c|c|c|c|c|}
\hline $\begin{array}{l}\text { Número da } \\
\text { amostra } \\
\text { (Avaliações } \\
\text { realizadas à } \\
\text { temperatura } \\
\text { ambiente) }\end{array}$ & $\begin{array}{c}\mathrm{T}=\text { Ambiente } \\
25 \mathrm{mV} / \mathrm{s} \\
C_{(A V C)}[\mathrm{F}]\end{array}$ & $\begin{array}{c}\mathrm{T}=\text { Ambiente } \\
50 \mathrm{mV} / \mathrm{s} \\
C_{(A V C)}[\mathrm{F}]\end{array}$ & $\begin{array}{c}\mathrm{T}=\text { Ambiente } \\
75 \mathrm{mV} / \mathrm{s} \\
C_{(A V C)}[\mathrm{F}]\end{array}$ & $\begin{array}{c}\mathrm{T}=\text { Ambiente } \\
100 \mathrm{mV} / \mathrm{s} \\
C_{(A V C)}[\mathrm{F}]\end{array}$ \\
\hline 1 & $0,88 \pm 0,01$ & $0,77 \pm 0,01$ & $0,66 \pm 0,01$ & $0,59 \pm 0,01$ \\
\hline 2 & $1,00 \pm 0,01$ & $0,86 \pm 0,01$ & $0,76 \pm 0,01$ & $0,70 \pm 0,01$ \\
\hline 3 & $0,89 \pm 0,01$ & $0,78 \pm 0,01$ & $0,65 \pm 0,01$ & $0,57 \pm 0,01$ \\
\hline 4 & $0,99 \pm 0,01$ & $0,87 \pm 0,01$ & $0,71 \pm 0,01$ & $0,64 \pm 0,01$ \\
\hline 5 & $0,78 \pm 0,01$ & $0,68 \pm 0,01$ & $0,63 \pm 0,01$ & $0,50 \pm 0,00$ \\
\hline 6 & $0,89 \pm 0,01$ & $0,78 \pm 0,01$ & $0,71 \pm 0,01$ & $0,61 \pm 0,01$ \\
\hline 7 & $1,02 \pm 0,01$ & $0,89 \pm 0,01$ & $0,77 \pm 0,01$ & $0,66 \pm 0,01$ \\
\hline 8 & $0,76 \pm 0,01$ & $0,67 \pm 0,01$ & $0,58 \pm 0,01$ & $0,50 \pm 0,00$ \\
\hline 9 & $0,82 \pm 0,01$ & $0,73 \pm 0,01$ & $0,61 \pm 0,01$ & $0,53 \pm 0,00$ \\
\hline 10 & $0,85 \pm 0,01$ & $0,73 \pm 0,01$ & $0,65 \pm 0,01$ & $0,56 \pm 0,00$ \\
\hline
\end{tabular}




\subsubsection{Valores da $C_{(A V C)}$ obtidos por meio da avaliação de quatro supercapacitores de referência em diferentes temperaturas e diferentes tempos de exposição.}

Por meio da figura 30 apresenta-se um conjunto de voltamogramas do supercapacitor de referência, sendo obtidos por meio das velocidades de varredura de $25 \mathrm{mV} / \mathrm{s}, 50 \mathrm{mV} / \mathrm{s}, 75 \mathrm{mV} / \mathrm{s}$ e $100 \mathrm{mV} / \mathrm{s}$. O supercapacitor de referência não foi exposto a energias térmicas além daquelas presentes à temperatura ambiente.

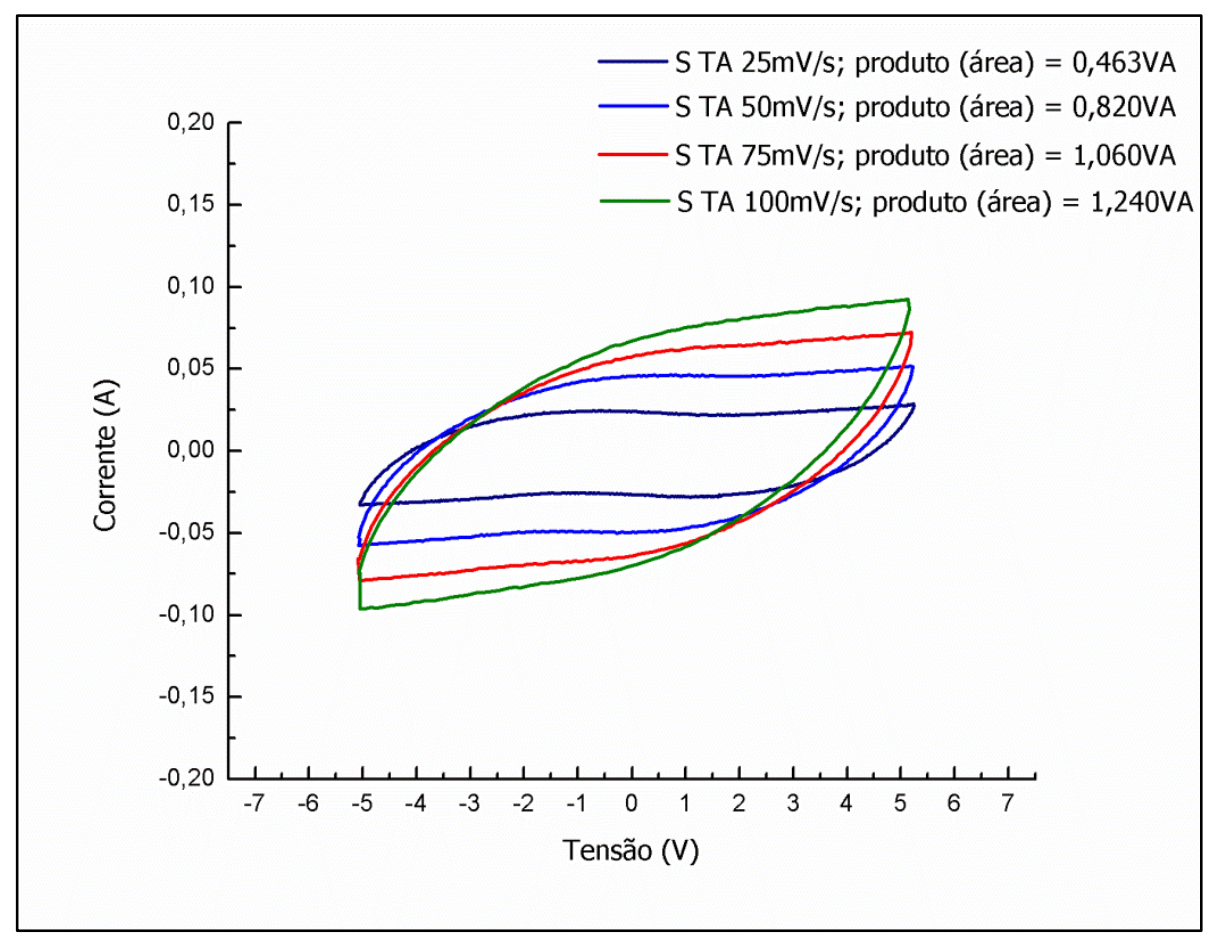

Figura 30 - Voltamogramas cíclicos do supercapacitor de referência - não exposto à energia térmica.

Por meio da figura 31 observa-se as curvas geradas na voltametria cíclica do supercapacitor 1 , o qual foi exposto à temperatura de $50^{\circ} \mathrm{C}$ durante quatro semanas. 


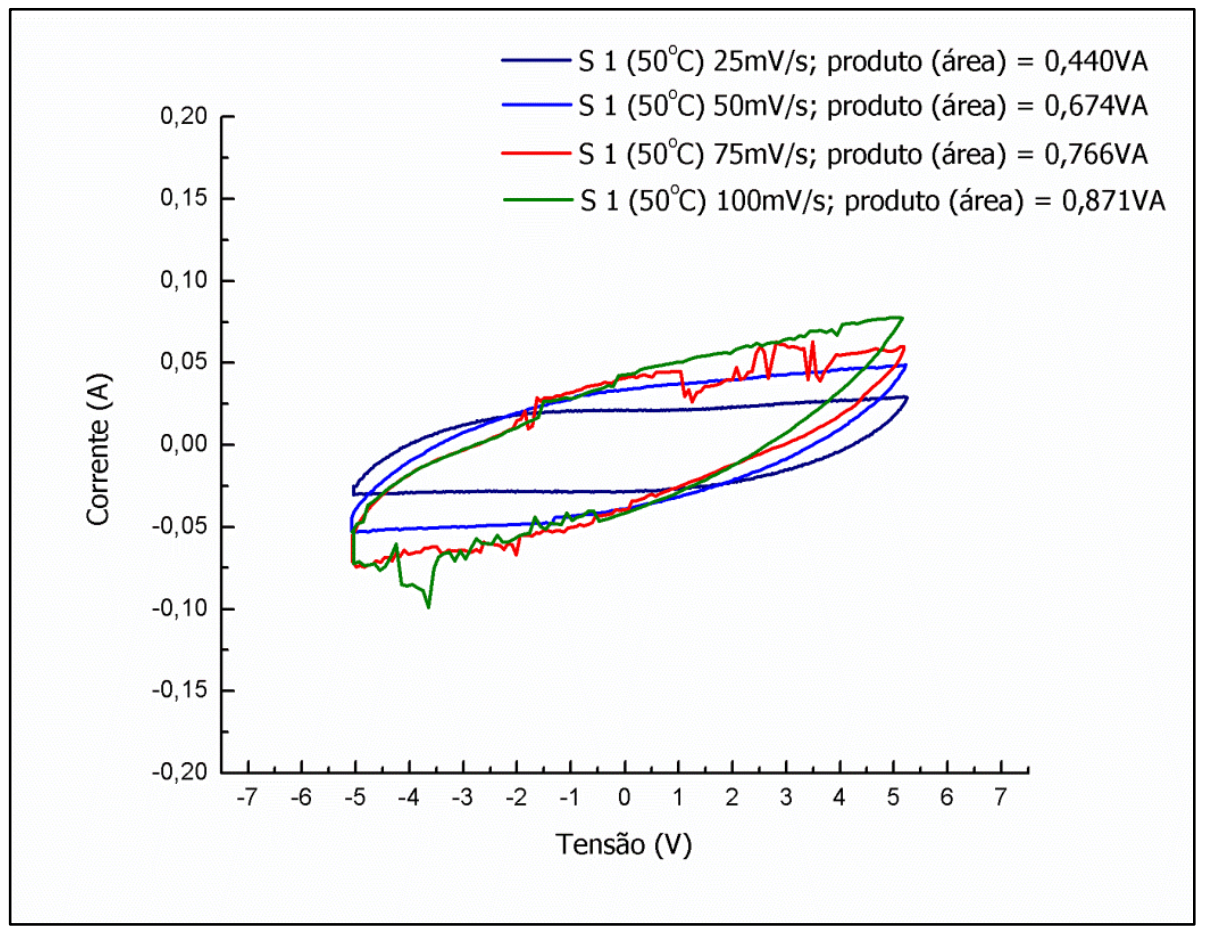

Figura 31 - Voltamogramas cíclicos do supercapacitor 1 exposto por quatro semanas a $50^{\circ} \mathrm{C}$.

Na figura 32 são apresentados os voltamogramas cíclicos do supercapacitor 2 que foi exposto a temperatura de $75^{\circ} \mathrm{C}$ durante quatro semanas.

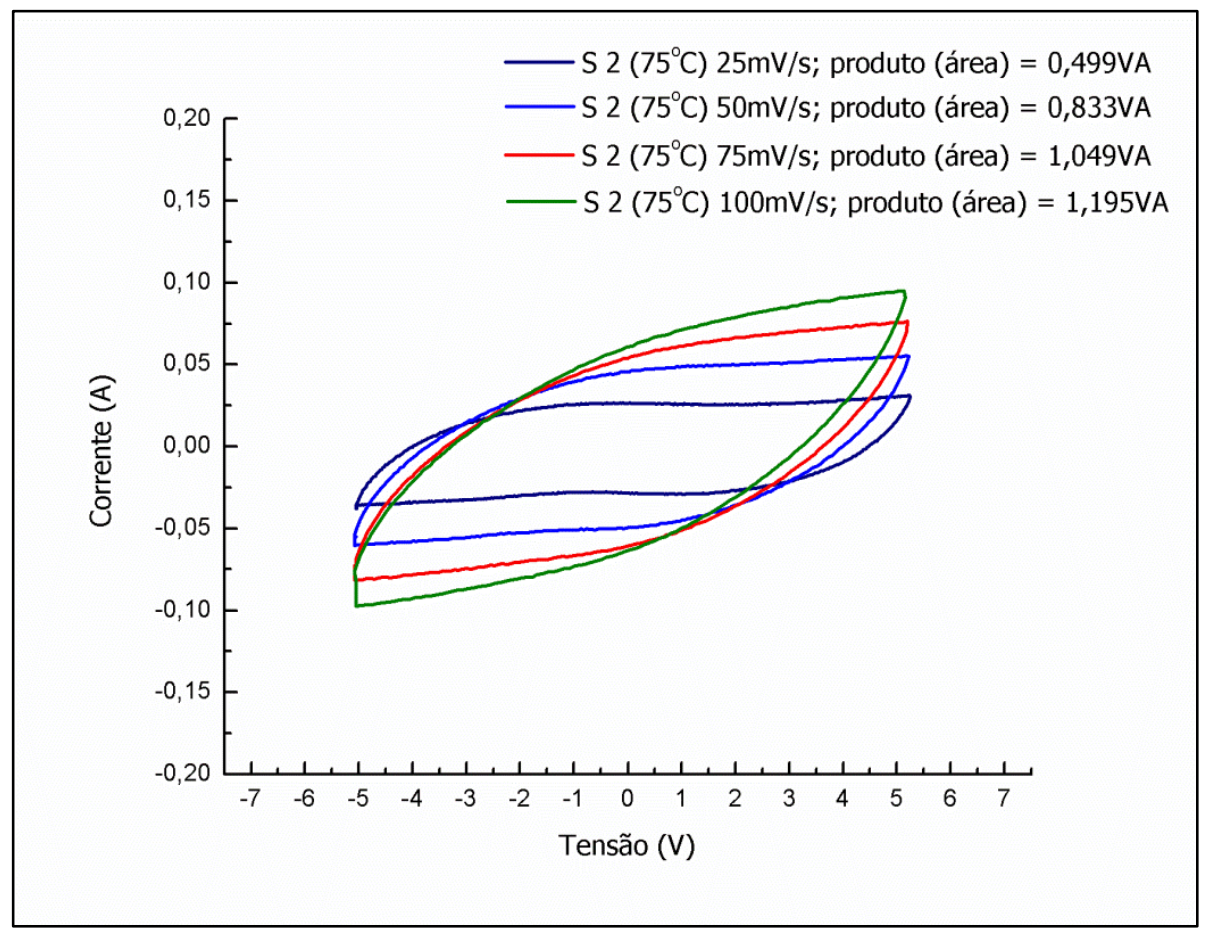

Figura 32 - Voltamogramas cíclicos do supercapacitor 2 exposto por quatro semanas a $75^{\circ} \mathrm{C}$. 
Por meio da figura 33 são apresentados os voltamogramas cíclicos do supercapacitor 3 que foi exposto a temperatura de $100^{\circ} \mathrm{C}$ durante quatro semanas.

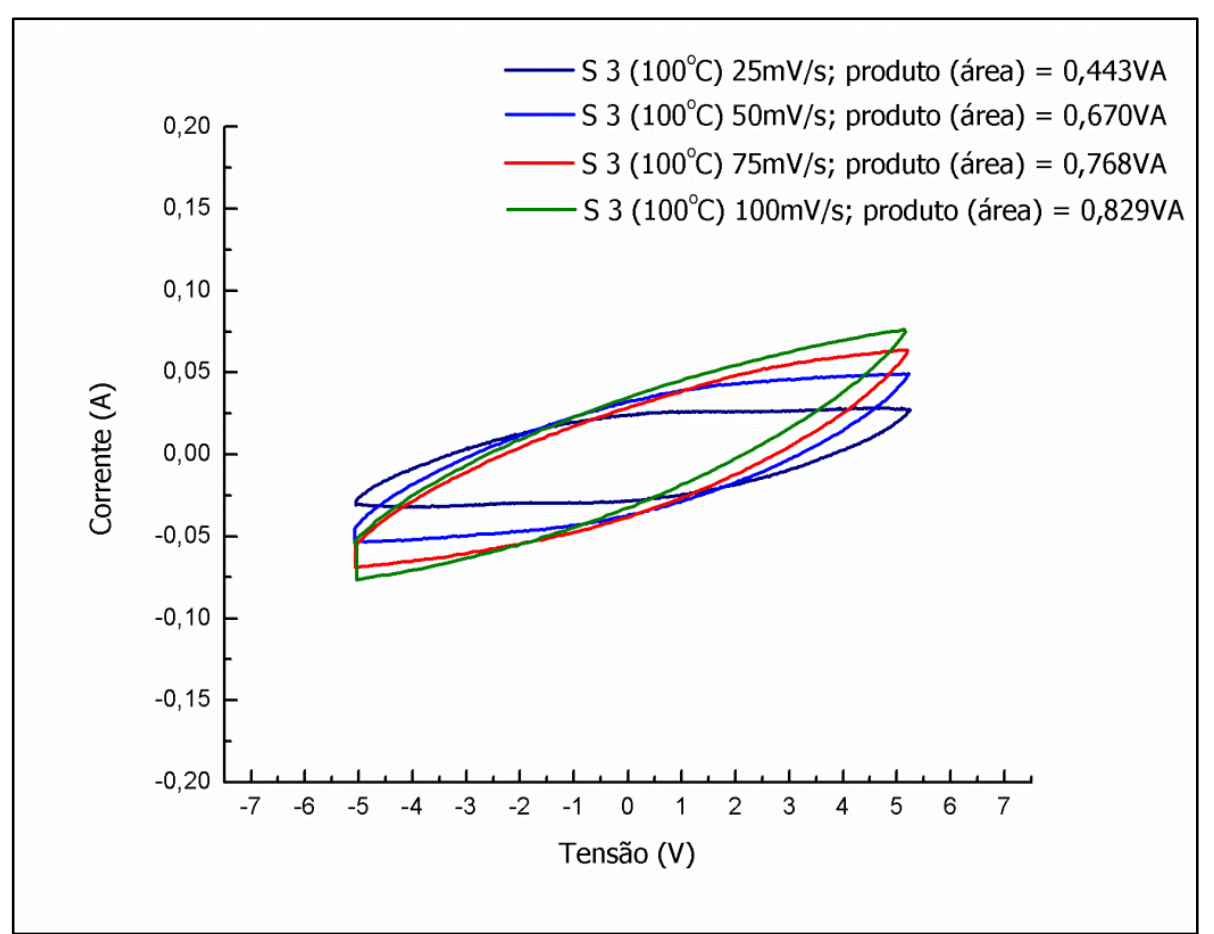

Figura 33 - Voltamogramas cíclicos do supercapacitor 3 exposto por quatro semanas a $100^{\circ} \mathrm{C}$.

Os valores da $C_{(A V C)}$ para os 4 supercapacitores avaliados na coleta de dados experimentais são apresentados na Tabela 14, na qual foi considerado um valor de incerteza de $\pm 14,20 \%$ para taxa de varredura de $25 \mathrm{mV} / \mathrm{s}, \pm 11,10 \%$ para a taxa de varredura de $50 \mathrm{mV} / \mathrm{s}, \pm 8,52 \%$ para a taxa de varredura de $75 \mathrm{mV} / \mathrm{s}$ e $\pm 8,57 \%$ para a taxa de varredura de $100 \mathrm{mV} / \mathrm{s}$.

Na Tabela 15 são apresentados os valores estimados da $C_{(A V C)}$ específica. 
Tabela 14 - Valores da $C_{(A V C)}$ em diferentes taxas de varredura para um supercapacitor não exposto (S0) e para os supercapacitores de referência S1, S2 e S3 expostos em diferentes temperatura e tempo de exposição de 672 horas

\begin{tabular}{|c|c|c|c|c|}
\hline $\begin{array}{c}\mathrm{dV} / \mathrm{dt} \\
{[\mathrm{mV} / \mathrm{s}]}\end{array}$ & $\begin{array}{c}\mathrm{S} 1: \mathrm{T}= \\
\text { Ambiente } \\
C_{(A V C)}(F)\end{array}$ & $\begin{array}{c}\mathrm{S} 2: \mathrm{T}=50^{\circ} \mathrm{C} \\
C_{(A V C)}(F)\end{array}$ & $\begin{array}{c}\mathrm{S} 3: \mathrm{T}=75^{\circ} \mathrm{C} \\
C_{(A V C)}(F)\end{array}$ & $\begin{array}{c}\mathrm{S} 4: \mathrm{T}=100^{\circ} \mathrm{C} \\
C_{(A V C)}(F)\end{array}$ \\
\hline 25 & $0,93 \pm 0,13$ & $0,88 \pm 0,12$ & $1,00 \pm 0,14$ & $0,89 \pm 0,13$ \\
\hline 50 & $0,82 \pm 0,09$ & $0,67 \pm 0,07$ & $0,83 \pm 0,09$ & $0,67 \pm 0,07$ \\
\hline 75 & $0,71 \pm 0,06$ & $0,51 \pm 0,04$ & $0,70 \pm 0,06$ & $0,51 \pm 0,04$ \\
\hline 100 & $0,62 \pm 0,05$ & $0,43 \pm 0,04$ & $0,60 \pm 0,05$ & $0,41 \pm 0,03$ \\
\hline
\end{tabular}

Tabela 15 - Valores estimados da $C_{(V C)}$ específica em diferentes taxas de varredura para um supercapacitor não exposto (S0) e para os supercapacitores de referência $S 1, S 2$ e $S 3$ expostos em diferentes temperatura e tempo de exposição de 672 horas.

\begin{tabular}{ccccc}
\hline $\begin{array}{c}\mathbf{d V} / \mathbf{d t} \\
{[\mathbf{m V} / \mathbf{s}]}\end{array}$ & $\begin{array}{c}\mathrm{T}=\text { Ambiente } \\
C_{(A V C)}\left[\mathrm{Fg}^{-1}\right]\end{array}$ & $\begin{array}{c}\mathrm{T}=50^{\circ} \mathrm{C} \\
C_{(A V C)}\left[\mathrm{Fg}^{-1}\right]\end{array}$ & $\begin{array}{c}\mathrm{T}=75^{\circ} \mathrm{C} \\
C_{(A V C)}\left[\mathrm{Fg}^{-1}\right]\end{array}$ & $\begin{array}{c}\mathrm{T}=100^{\circ} \mathrm{C} \\
C_{(A V C)}\left[\mathrm{Fg}^{-1}\right]\end{array}$ \\
\hline 25 & $43,51 \pm 6,18$ & $41,17 \pm 5,85$ & $46,78 \pm 6,64$ & $41,64 \pm 5,91$ \\
50 & $38,36 \pm 4,26$ & $31,35 \pm 3,48$ & $38,83 \pm 4,31$ & $31,35 \pm 3,48$ \\
75 & $33,22 \pm 2,83$ & $23,86 \pm 2,03$ & $32,75 \pm 2,79$ & $23,86 \pm 2,03$ \\
100 & $29,01 \pm 2,49$ & $20,12 \pm 1,72$ & $28,07 \pm 2,41$ & $19,18 \pm 1,64$ \\
\hline
\end{tabular}




\subsection{Avaliação da capacitância obtida pelo método da média dos valores da corrente elétrica de resposta em módulo - $C_{(V C i M)}$.}

\subsubsection{Valor do erro de medição da $C_{(V C i M)}$ para as velocidade de varredura de $25 \mathrm{mV} / \mathrm{s}, 50 \mathrm{mV} / \mathrm{s}, 75 \mathrm{mV} / \mathrm{s}$ e $100 \mathrm{mV} / \mathrm{s}$.}

O valor do erro de medição da capacitância obtida pelo método da média dos valores da corrente elétrica de resposta em módulo $\left(C_{(V C i M)}\right)$ foi adquirido por meio de dez leituras de tal parâmetro elétrico para cada taxa de varredura adotada utilizando um único capacitor. Os dados da Referente ao erro de medição da C(VCiM) foi encontrado um erro percentual de $\pm 0,47 \%$ para a taxa de varredura de $25 \mathrm{mV} / \mathrm{s}, \pm 0,41 \%$ para a taxa de varredura de $50 \mathrm{mV} / \mathrm{s}, \pm 1,11 \%$ para a taxa de varredura de $75 \mathrm{mV} / \mathrm{s}$ e $\pm 1,10 \%$ para a taxa de varredura de $100 \mathrm{mV} / \mathrm{s}$.

Foram utilizadas dez medições para cada uma das velocidades de varredura objetivando determinar o erro de medição do valor da capacitância obtido pelo método $\boldsymbol{C}_{(\text {VCiM })}$ para cada um as taxas de varredura de $25 \mathrm{mV} / \mathrm{s}, 50 \mathrm{mV} / \mathrm{s}, 75 \mathrm{mV} / \mathrm{s}$ e $100 \mathrm{mV} / \mathrm{s}$. 
Tabela 16 - Dados utilizados para determinar o valor do erro de medição da $C_{(V C i M)}$

\begin{tabular}{|c|c|c|c|c|}
\hline $\begin{array}{c}\text { Número da } \\
\text { medição } \\
\text { (Avaliações } \\
\text { realizadas à } \\
\text { temperatura } \\
\text { ambiente) }\end{array}$ & $\begin{array}{c}\mathrm{T}=\text { Ambiente } \\
25 \mathrm{mV} / \mathrm{s} \\
C_{(V C i M)}[\mathrm{F}]\end{array}$ & $\begin{array}{c}\mathrm{T}=\text { Ambiente } \\
50 \mathrm{mV} / \mathrm{s} \\
C_{(V C i M)}[\mathrm{F}]\end{array}$ & $\begin{array}{c}\mathrm{T}=\text { Ambiente } \\
75 \mathrm{mV} / \mathrm{s} \\
C_{(V C i M)}[\mathrm{F}]\end{array}$ & $\begin{array}{c}\mathrm{T}=\text { Ambiente } \\
100 \mathrm{mV} / \mathrm{s} \\
C_{(V C i M)}[\mathrm{F}]\end{array}$ \\
\hline 1 & 0,88 & 0,77 & 0,66 & 0,57 \\
\hline 2 & 0,88 & 0,77 & 0,65 & 0,57 \\
\hline 3 & 0,89 & 0,77 & 0,66 & 0,57 \\
\hline 4 & 0,89 & 0,77 & 0,67 & 0,57 \\
\hline 5 & 0,89 & 0,77 & 0,66 & 0,57 \\
\hline 6 & 0,89 & 0,76 & 0,66 & 0,57 \\
\hline 7 & 0,89 & 0,77 & 0,67 & 0,57 \\
\hline 8 & 0,89 & 0,77 & 0,66 & 0,59 \\
\hline 9 & 0,89 & 0,77 & 0,65 & 0,57 \\
\hline 10 & 0,89 & 0,77 & 0,65 & 0,57 \\
\hline
\end{tabular}

Referente ao erro de medição da $\boldsymbol{C}_{(V C i M)}$ foi encontrado um erro percentual de $\pm 0,47 \%$ para a taxa de varredura de $25 \mathrm{mV} / \mathrm{s}, \pm 0,41 \%$ para a taxa de varredura de $50 \mathrm{mV} / \mathrm{s}$, $\pm 1,11 \%$ para a taxa de varredura de $75 \mathrm{mV} / \mathrm{s}$ e $\pm 1,10 \%$ para a taxa de varredura de $100 \mathrm{mV} / \mathrm{s}$. 


\subsubsection{Valor de tolerância para a $C_{(V C i M)}$.}

O valor da tolerância para o parâmetro elétrico capacitância obtida pelo método da área do voltamograma cíclico foi $\pm 8,85 \%$ para a taxa de varredura de $25 \mathrm{mV} / \mathrm{s}, \pm 10,47 \%$ para a taxa de varredura de $50 \mathrm{mV} / \mathrm{s}, \pm 9,44 \%$ para a taxa de varredura de $75 \mathrm{mV} / \mathrm{s}$ e $\pm 12,33 \%$ para a taxa de varredura de $100 \mathrm{mV} / \mathrm{s}$. Na Tabela 17 são apresentados os valores que foram utilizados para produzir os resultados descritos.

Tabela 17 - Dados utilizados para determinar o valor da tolerância referente a $C_{(\text {VCiM })}$

\begin{tabular}{|c|c|c|c|c|}
\hline $\begin{array}{c}\text { Número da } \\
\text { amostra } \\
\text { (Avaliações } \\
\text { realizadas à } \\
\text { temperatura } \\
\text { ambiente) }\end{array}$ & $\begin{array}{c}\mathrm{T}=\text { Ambiente } \\
25 \mathrm{mV} / \mathrm{s} \\
C_{(V C i M)}[\mathrm{F}]\end{array}$ & $\begin{array}{c}\mathrm{T}=\text { Ambiente } \\
50 \mathrm{mV} / \mathrm{s} \\
C_{(V C i M)}[\mathrm{F}]\end{array}$ & $\begin{array}{c}\mathrm{T}=\text { Ambiente } \\
75 \mathrm{mV} / \mathrm{s} \\
C_{(V C i M)}[\mathrm{F}]\end{array}$ & $\begin{array}{c}\mathrm{T}=\text { Ambiente } \\
100 \mathrm{mV} / \mathrm{s} \\
C_{(V C i M)}[\mathrm{F}]\end{array}$ \\
\hline 1 & $0,87 \pm 0,00$ & $0,76 \pm 0,00$ & $0,68 \pm 0,01$ & $0,57 \pm 0,01$ \\
\hline 2 & $0,98 \pm 0,00$ & $0,88 \pm 0,00$ & $0,73 \pm 0,01$ & $0,72 \pm 0,01$ \\
\hline 3 & $0,87 \pm 0,00$ & $0,77 \pm 0,00$ & $0,63 \pm 0,01$ & $0,55 \pm 0,01$ \\
\hline 4 & $0,94 \pm 0,00$ & $0,88 \pm 0,00$ & $0,74 \pm 0,01$ & $0,66 \pm 0,01$ \\
\hline 5 & $0,77 \pm 0,00$ & $0,67 \pm 0,00$ & $0,65 \pm 0,01$ & $0,52 \pm 0,01$ \\
\hline 6 & $0,88 \pm 0,00$ & $0,77 \pm 0,00$ & $0,70 \pm 0,01$ & $0,60 \pm 0,01$ \\
\hline 7 & $1,00 \pm 0,00$ & $0,88 \pm 0,00$ & $0,74 \pm 0,01$ & $0,65 \pm 0,01$ \\
\hline 8 & $0,78 \pm 0,00$ & $0,66 \pm 0,00$ & $0,55 \pm 0,01$ & $0,51 \pm 0,01$ \\
\hline 9 & $0,82 \pm 0,00$ & $0,74 \pm 0,00$ & $0,60 \pm 0,01$ & $0,51 \pm 0,01$ \\
\hline 10 & $0,86 \pm 0,00$ & $0,75 \pm 0,00$ & $0,66 \pm 0,01$ & $0,55 \pm 0,01$ \\
\hline
\end{tabular}




\subsubsection{Valores da $C_{(V C i M)}$ obtidos pela avaliação de quatro supercapacitores de referência em diferentes temperaturas e diferentes tempos de exposição.}

Os valores da $C_{(V C i M)}$ para os 4 supercapacitores utilizados na coleta experimental de dados são apresentados por meio da Tabela 18, na qual foi considerado um valor de incerteza de $\pm 2,78 \%$ para taxa de varredura de $25 \mathrm{mV} / \mathrm{s}, \pm 2,62 \%$ para a taxa de varredura de $50 \mathrm{mV} / \mathrm{s}, \pm 12,08 \%$ para a taxa de varredura de $75 \mathrm{mV} / \mathrm{s}$ e $\pm 15,85 \%$ para a taxa de varredura de $100 \mathrm{mV} / \mathrm{s}$.

Na Tabela 19 são apresentados os valores estimado da $C_{(V C i M)}$ específica, considerando-se nos cálculos que cada supercapacitor é composto por 4 eletrodos, e cada eletrodo possui massa de aproximadamente $90 \mathrm{mg}$ descontado $5 \%$ de ligante e supondo quatro eletrodos idênticos por dispositivo.

Tabela 18 - Valores da $C_{(V C i M)}$ para um supercapacitor não exposto (S0) e para os supercapacitores de referência S1, S2 e S3 expostos em diferentes temperatura e tempo de exposição de 672 horas

\begin{tabular}{ccccc}
\hline $\mathbf{d V} / \mathbf{d t}$ & $\begin{array}{c}\mathrm{S} 0: \mathrm{T}= \\
\text { Ambiente }\end{array}$ & $\begin{array}{c}\mathrm{S} 1: \mathrm{T}=50^{\circ} \mathrm{C} \\
C_{(V C i M)}[\mathrm{F}]\end{array}$ & $\begin{array}{c}\mathrm{S} 2: \mathrm{T}=75^{\circ} \mathrm{C} \\
C_{(V C i M)}[\mathrm{F}]\end{array}$ & $\begin{array}{c}\mathrm{S} 3: \mathrm{T}=100^{\circ} \mathrm{C} \\
C_{(V C i M)}[\mathrm{F}]\end{array}$ \\
\hline $\mathbf{m V} / \mathbf{s}]$ & $C_{(V C i M)}[\mathrm{F}]$ & $0,86 \pm 0,02$ & $0,97 \pm 0,03$ & $0,86 \pm 0,02$ \\
50 & $0,93 \pm 0,03$ & $0,66 \pm 0,02$ & $0,81 \pm 0,02$ & $0,65 \pm 0,02$ \\
75 & $0,79 \pm 0,02$ & $0,53 \pm 0,06$ & $0,68 \pm 0,08$ & $0,50 \pm 0,06$ \\
100 & $0,69 \pm 0,08$ & $0,43 \pm 0,07$ & $0,59 \pm 0,09$ & $0,40 \pm 0,06$ \\
\hline
\end{tabular}


Tabela 19 - Valores estimados da $C_{(V C i M)}$ específica para um supercapacitor não exposto (S0) e para os supercapacitores de referência S1, S2 e S3 expostos em diferentes temperatura e tempo de exposição de 672 horas.

\begin{tabular}{ccccc}
\hline $\mathbf{d V} / \mathbf{d t}$ & $\begin{array}{c}\mathrm{S} 0: \mathrm{T}= \\
\text { Ambiente }\end{array}$ & $\mathrm{S} 1: \mathrm{T}=50^{\circ} \mathrm{C}$ & $\mathrm{S} 2: \mathrm{T}=75^{\circ} \mathrm{C}$ & $\mathrm{S} 3: \mathrm{T}=100^{\circ} \mathrm{C}$ \\
{$[\mathbf{m V} / \mathbf{s}]$} & $C_{(V C i M)}\left[\mathrm{Fg}^{-1}\right]$ & $C_{(V C i M)}\left[\mathrm{Fg}^{-1}\right]$ & $C_{(V C i M)}\left[\mathrm{Fg}^{-1}\right]$ & $C_{(V C i M)}\left[\mathrm{Fg}^{-1}\right]$ \\
\hline 25 & $43,51 \pm 1,40$ & $40,23 \pm 0,94$ & $45,38 \pm 1,40$ & $40,23 \pm 0,94$ \\
50 & $36,96 \pm 0,94$ & $30,88 \pm 0,94$ & $37,89 \pm 0,94$ & $30,41 \pm 0,94$ \\
75 & $32,28 \pm 3,74$ & $24,80 \pm 2,81$ & $31,81 \pm 3,74$ & $23,39 \pm 2,81$ \\
100 & $28,54 \pm 4,68$ & $20,12 \pm 3,27$ & $27,60 \pm 4,21$ & $18,71 \pm 2,81$ \\
\hline
\end{tabular}

5.7 Avaliação da capacitância obtida pelo método da média dos valores de corrente elétrica de resposta oriundos dos menores valores de potencial (potencial tendendo a zero) - $C_{(V C V \rightarrow 0)}$.

\subsubsection{Valor do erro da medição da $C_{(V C V \rightarrow 0)}$ para velocidades de varredura de $25 \mathrm{mV} / \mathrm{s}, 50 \mathrm{mV} / \mathrm{s}, 75 \mathrm{mV} / \mathrm{s}$ e $100 \mathrm{mV} / \mathrm{s}$.}

O valor do erro de medição da capacitância obtida pelo método da média dos valores da corrente elétrica de resposta oriundo de potencial tendendo a zero $\left(C_{(V C V \rightarrow 0)}\right)$ foi obtido por meio de dez leituras de tal parâmetro elétrico para cada taxa de varredura adotada utilizando um único capacitor. Os dados da Tabela 20 foram utilizados para determinar o valor do erro da medição da $C_{(V C V \rightarrow 0)}$ para as taxas de varredura de $25 \mathrm{mV} / \mathrm{s}$, $50 \mathrm{mV} / \mathrm{s}, 75 \mathrm{mV} / \mathrm{s}$ e $100 \mathrm{mV} / \mathrm{s}$. 
Tabela 20 - Dados utilizados para determinar o valor do erro de medição da $C_{(V C V \rightarrow 0)}$.

\begin{tabular}{ccccc}
\hline Número da & $\mathrm{T}=$ Ambiente & $\mathrm{T}=$ Ambiente & $\mathrm{T}=$ Ambiente & $\mathrm{T}=$ Ambiente \\
medição & $25 \mathrm{mV} / \mathrm{s}$ & $50 \mathrm{mV} / \mathrm{s}$ & $75 \mathrm{mV} / \mathrm{s}$ & $100 \mathrm{mV} / \mathrm{s}$ \\
(Avaliações & $C_{(V C V \rightarrow 0)}[\mathrm{F}]$ & $C_{(V C V \rightarrow 0)}[\mathrm{F}]$ & $C_{(V C V \rightarrow 0)}[\mathrm{F}]$ & $C_{(V C V \rightarrow 0)}[\mathrm{F}]$ \\
realizadas à & & & & \\
temperatura & & & & \\
ambiente) & & & & \\
\hline 1 & 0,96 & 0,84 & 0,71 & 0,64 \\
2 & 0,96 & 0,87 & 0,72 & 0,63 \\
3 & 0,97 & 0,86 & 0,72 & 0,63 \\
4 & 0,97 & 0,86 & 0,72 & 0,64 \\
5 & 0,97 & 0,87 & 0,72 & 0,64 \\
6 & 0,97 & 0,88 & 0,71 & 0,63 \\
7 & 0,97 & 0,86 & 0,72 & 0,64 \\
8 & 0,99 & 0,87 & 0,71 & 0,64 \\
9 & 0,97 & 0,86 & 0,72 & 0,63 \\
10 & 0,97 & 0,86 & 0,72 & 0,64 \\
\hline
\end{tabular}

Referente ao erro de medição da $C_{(V C V \rightarrow 0)}$ foi encontrado um erro percentual de $\pm 0,81 \%$ para a taxa de varredura de $25 \mathrm{mV} / \mathrm{s}, \pm 1,23 \%$ para a taxa de varredura de $50 \mathrm{mV} / \mathrm{s}$, $\pm 0,67 \%$ para a taxa de varredura de $75 \mathrm{mV} / \mathrm{s}$ e $\pm 0,81 \%$ para a taxa de varredura de $100 \mathrm{mV} / \mathrm{s}$. 


\subsubsection{Valor da tolerância para a $C_{(V C V \rightarrow 0)}$.}

O valor da tolerância para o parâmetro elétrico da média dos valores da corrente elétrica de resposta oriundo de potencial tendendo a zero foi de $\pm 7,54 \%$ para a taxa de varredura de $25 \mathrm{mV} / \mathrm{s}, \pm 8,48 \%$ para a taxa de varredura de $50 \mathrm{mV} / \mathrm{s}, \pm 9,58 \%$ para a taxa de varredura de $75 \mathrm{mV} / \mathrm{s}$ e $\pm 12,34 \%$ para a taxa de varredura de $100 \mathrm{mV} / \mathrm{s}$. Por meio da Tabela 21 são apresentados os valores utilizados para produzir os resultados descritos.

Tabela 21 - Dados utilizados para determinar o valor da tolerância da $C_{(V C V \rightarrow 0)}$

\begin{tabular}{|c|c|c|c|c|}
\hline $\begin{array}{l}\text { Número da } \\
\text { amostra } \\
\text { (Avaliações } \\
\text { realizadas à } \\
\text { temperatura } \\
\text { ambiente) }\end{array}$ & $\begin{array}{c}\mathrm{T}=\text { Ambiente } \\
25 \mathrm{mV} / \mathrm{s} \\
C_{(V C V \rightarrow 0)}[\mathrm{F}]\end{array}$ & $\begin{array}{c}\mathrm{T}=\text { Ambiente } \\
50 \mathrm{mV} / \mathrm{s} \\
C_{(V C V \rightarrow 0)}[\mathrm{F}]\end{array}$ & $\begin{array}{c}\mathrm{T}=\text { Ambiente } \\
75 \mathrm{mV} / \mathrm{s} \\
C_{(V C V \rightarrow 0)}[\mathrm{F}]\end{array}$ & $\begin{array}{c}\mathrm{T}=\text { Ambiente } \\
100 \mathrm{mV} / \mathrm{s} \\
C_{(V C V \rightarrow 0)}[\mathrm{F}]\end{array}$ \\
\hline 1 & $0,93 \pm 0,01$ & $0,82 \pm 0,01$ & $0,75 \pm 0,01$ & $0,63 \pm 0,01$ \\
\hline 2 & $1,10 \pm 0,01$ & $0,95 \pm 0,01$ & $0,81 \pm 0,01$ & $0,79 \pm 0,01$ \\
\hline 3 & $0,94 \pm 0,01$ & $0,87 \pm 0,01$ & $0,69 \pm 0,00$ & $0,61 \pm 0,00$ \\
\hline 4 & $1,00 \pm 0,01$ & $0,92 \pm 0,01$ & $0,82 \pm 0,01$ & $0,73 \pm 0,01$ \\
\hline 5 & $0,88 \pm 0,01$ & $0,77 \pm 0,01$ & $0,72 \pm 0,00$ & $0,57 \pm 0,00$ \\
\hline 6 & $0,94 \pm 0,01$ & $0,83 \pm 0,01$ & $0,77 \pm 0,01$ & $0,66 \pm 0,01$ \\
\hline 7 & $1,06 \pm 0,01$ & $0,92 \pm 0,01$ & $0,82 \pm 0,01$ & $0,72 \pm 0,01$ \\
\hline 8 & $0,88 \pm 0,01$ & $0,72 \pm 0,01$ & $0,61 \pm 0,00$ & $0,56 \pm 0,00$ \\
\hline 9 & $0,92 \pm 0,01$ & $0,81 \pm 0,01$ & $0,66 \pm 0,00$ & $0,56 \pm 0,00$ \\
\hline 10 & $0,96 \pm 0,01$ & $0,84 \pm 0,01$ & $0,73 \pm 0,00$ & $0,61 \pm 0,00$ \\
\hline
\end{tabular}




\subsubsection{Valores da $C_{(V C V \rightarrow 0)}$ obtidos pela avaliação de quatro supercapacitores de referência em diferentes temperaturas e diferentes tempos de exposição.}

Os valores da $\boldsymbol{C}_{(V C V \rightarrow 0)}$ para os 4 supercapacitores utilizados na coleta experimental de dados são apresentados por meio da Tabela 22, na qual foi considerado um valor de incerteza de $\pm 5,14 \%$ para taxa de varredura de $25 \mathrm{mV} / \mathrm{s}, \pm 13,86 \%$ para a taxa de varredura de $50 \mathrm{mV} / \mathrm{s}, \pm 4,22 \%$ para a taxa de varredura de $75 \mathrm{mV} / \mathrm{s}$ e $\pm 7,65 \%$ para a taxa de varredura de $100 \mathrm{mV} / \mathrm{s}$.

$\mathrm{Na}$ Tabela 23 são apresentados os valores estimado da $C_{(V C V \rightarrow 0)}$ específica, considerando-se nos cálculos que cada supercapacitor é composto por 4 eletrodos, e cada eletrodo possui massa de aproximadamente $90 \mathrm{mg}$ descontado $5 \%$ de ligante e supondo quatro eletrodos idênticos por dispositivo.

Tabela 22 - Valores da $C_{(V C V \rightarrow 0)}$ para um supercapacitor não exposto (S0) e para os supercapacitores de referência S1, S2 e S3 expostos em diferentes temperatura e tempo de exposição de 672 horas

\begin{tabular}{|c|c|c|c|c|}
\hline $\begin{array}{c}\mathrm{dV} / \mathrm{dt} \\
{[\mathrm{mV} / \mathrm{s}]}\end{array}$ & $\begin{array}{c}\text { S0: } \mathrm{T}=\text { Ambiente } \\
C_{(V C V \rightarrow 0)}[\mathrm{F}]\end{array}$ & $\begin{array}{c}\mathrm{S} 1: \mathrm{T}=50^{\circ} \mathrm{C} \\
C_{(V C V \rightarrow 0)}[\mathrm{F}]\end{array}$ & $\begin{array}{c}\mathrm{S} 2: \mathrm{T}=75^{\circ} \mathrm{C} \\
C_{(V C V \rightarrow 0)}[\mathrm{F}]\end{array}$ & $\begin{array}{c}\mathrm{S} 3: \mathrm{T}=100^{\circ} \mathrm{C} \\
C_{(V C V \rightarrow 0)}[\mathrm{F}]\end{array}$ \\
\hline 25 & $1,00 \pm 0,05$ & $0,99 \pm 0,05$ & $1,05 \pm 0,05$ & $1,05 \pm 0,05$ \\
\hline 50 & $0,95 \pm 0,13$ & $0,73 \pm 0,10$ & $0,95 \pm 0,13$ & $0,70 \pm 0,10$ \\
\hline 75 & $0,80 \pm 0,03$ & $0,85 \pm 0,04$ & $0,77 \pm 0,03$ & $0,45 \pm 0,02$ \\
\hline 100 & $0,68 \pm 0,05$ & $0,42 \pm 0,03$ & $0,83 \pm 0,06$ & $0,34 \pm 0,03$ \\
\hline
\end{tabular}

Tabela 23 - Valores estimados da $C_{(V C V \rightarrow 0)}$ específica para um supercapacitor não exposto (S0) e para os supercapacitores de referência S1, S2 e S3 expostos em diferentes temperatura e tempo de exposição de 672 horas

\begin{tabular}{ccccc}
\hline $\begin{array}{c}\mathbf{d V} / \mathbf{d t} \\
{[\mathbf{m V} / \mathbf{s}]}\end{array}$ & $\begin{array}{c}\mathrm{S} 0: \mathrm{T}=\text { Ambiente } \\
C_{(V C V \rightarrow 0)}\left[\mathrm{Fg}^{-1}\right]\end{array}$ & $\begin{array}{c}\mathrm{S} 1: \mathrm{T}=50^{\circ} \mathrm{C} \\
C_{(V C V \rightarrow 0)}\left[\mathrm{Fg}^{-1}\right]\end{array}$ & $\begin{array}{c}\mathrm{S} 2: \mathrm{T}=75^{\circ} \mathrm{C} \\
C_{(V C V \rightarrow 0)}\left[\mathrm{Fg}^{-1}\right]\end{array}$ & $\begin{array}{c}\mathrm{S} 3: \mathrm{T}=100^{\circ} \mathrm{C} \\
C_{(V C V \rightarrow 0)}\left[\mathrm{Fg}^{-1}\right]\end{array}$ \\
\hline 25 & $44,44 \pm 2,22$ & $44,00 \pm 2,22$ & $46,67 \pm 2,22$ & $46,67 \pm 2,22$ \\
50 & $42,22 \pm 5,78$ & $32,44 \pm 4,44$ & $42,22 \pm 5,78$ & $31,11 \pm 4,44$ \\
75 & $35,56 \pm 1,33$ & $37,78 \pm 1,78$ & $34,22 \pm 1,33$ & $20,00 \pm 0,89$ \\
100 & $30,22 \pm 2,22$ & $18,67 \pm 1,33$ & $36,89 \pm 2,67$ & $15,11 \pm 1,33$ \\
\hline
\end{tabular}




\subsection{Análise química e caracterização dos materiais dos eletrodos.}

Por meio da figura 34 observa-se a micrografia do material do eletrodo, que é constituído na sua essência por carvão ativado. A análise por energia dispersiva de Raios-X dos supercapacitores avaliados mostra que o carbono é o elemento matriz dos eletrodos contendo pequenas impurezas, provavelmente advindas do material que constitui o separador.

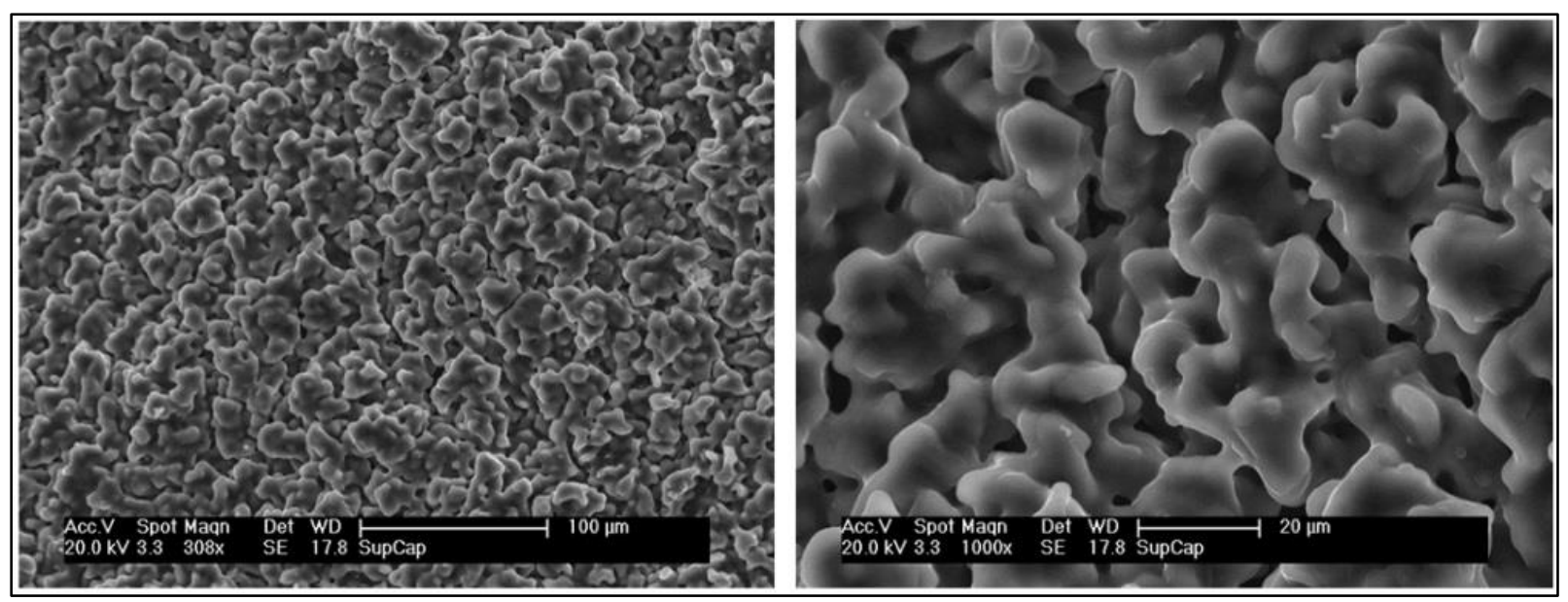

Figura 34 - Microscopia eletrônica de varredura do material do eletrodo composto por carbono.

Por meio da figura 35 verifica-se a ampliação das regiões que contém pequenas impurezas.

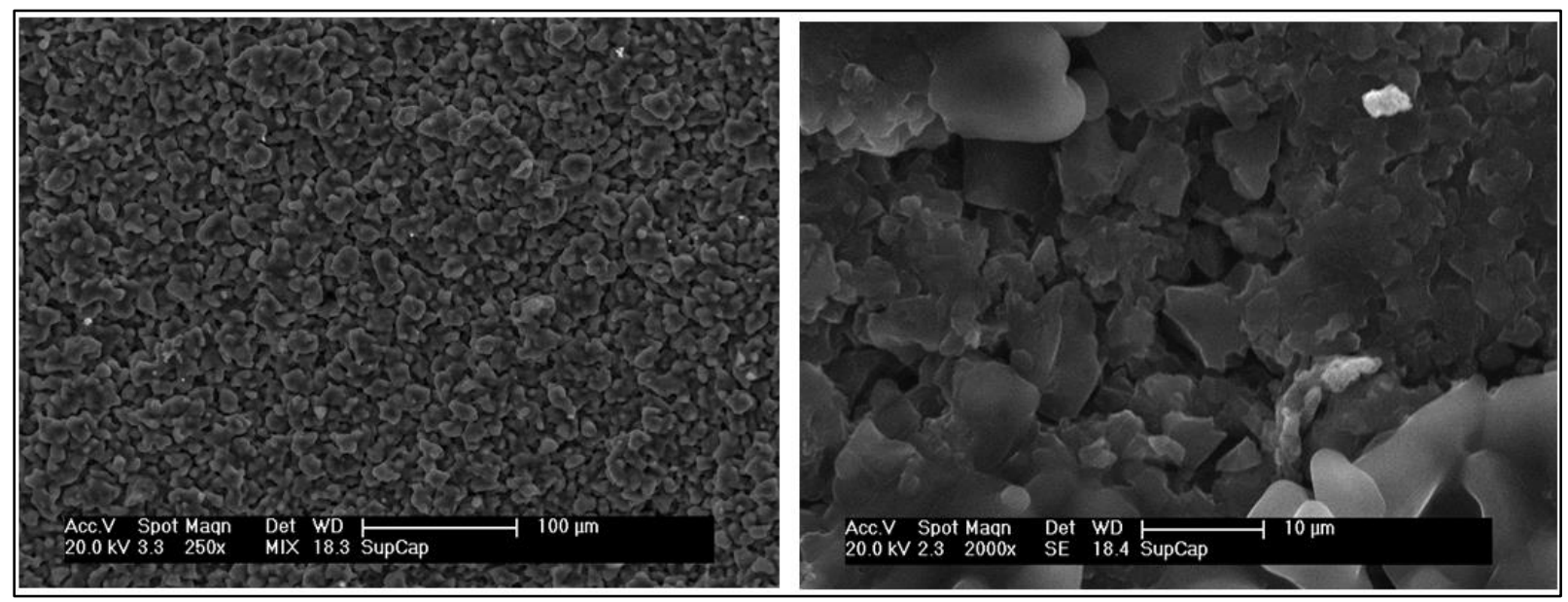

Figura 35 - Microscopia eletrônica de varredura do material do eletrodo com impurezas (pontos brancos). 
O espectro de EDX da região das impurezas apresentou picos que correspondem aos elementos $\mathrm{Fe}$ e $\mathrm{C}$, sendo mostrados por meio da figura 36 e figura 37.

Oxigênio foi detectado, possivelmente devido ao tratamento de ativação para conseguir elevada área superficial do material do eletrodo.

Flúor e estanho também foram detectados na forma de pequena impureza no interior do material de eletrodo, sendo o estanho um dos materiais utilizados na solda entre os terminais e os eletrodos metálicos dos supercapacitores. A presença de flúor tem sido atribuída ao tipo de eletrólito utilizado nestes supercapacitores (Park G., 2010).

Por meio da figura 37 apresenta-se o espectro de fluorescência do material do eletrodo e a análise semiquantitativa é apresentada por meio da Tabela 24. Além de Si e $\mathrm{Fe}$, demonstrado por meio de EDX, também foram detectados $\mathrm{S}, \mathrm{K}, \mathrm{Cu}, \mathrm{Ni}$ e $\mathrm{Zn}$ por meio da técnica de fluorescência de Raios-X.

O espectro de energia dispersiva de Raios-X da região apresentado por meio da figura 34 (lado direito) mostra picos oriundos da região onde estão as pequenas impurezas. Quando a região de análise é ampliada tais picos não são detectados pela proporção em relação ao montante de carbono presente no eletrodo.

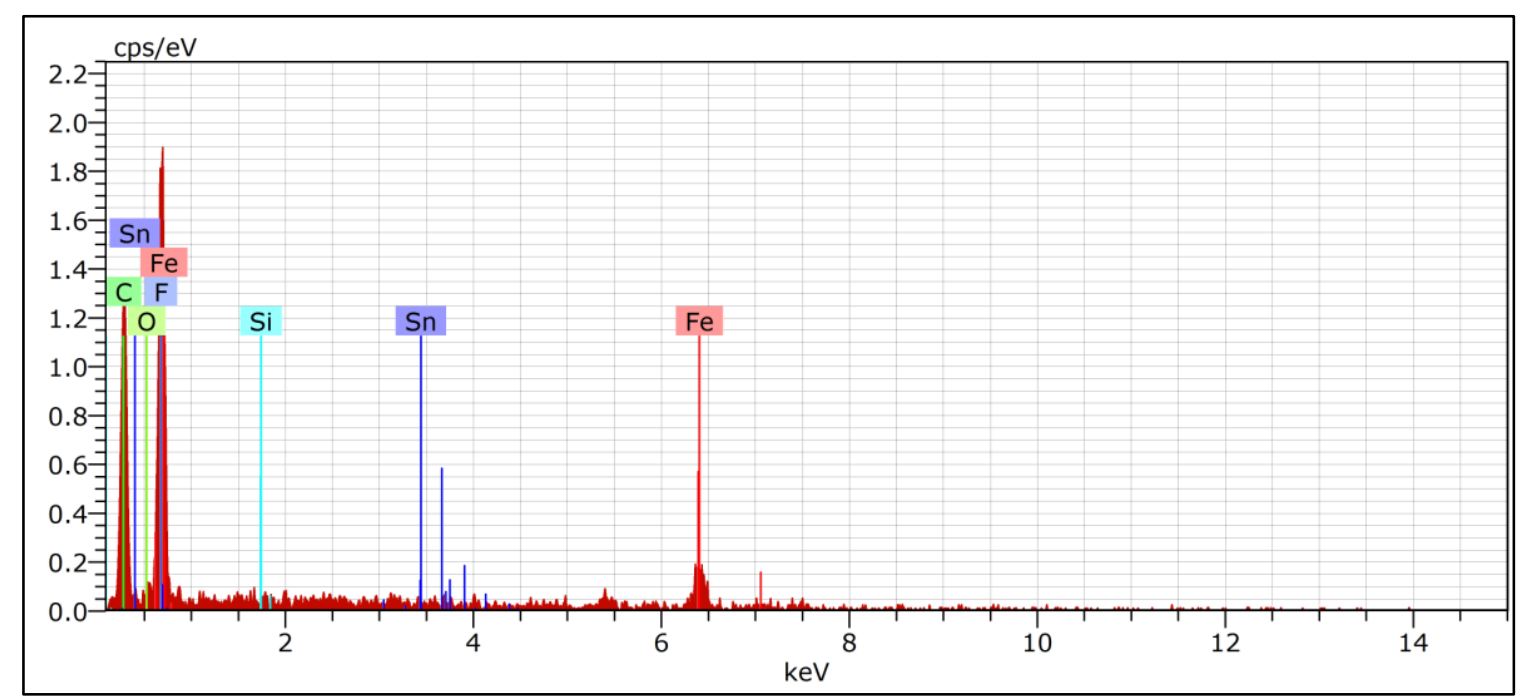

Figura 36 - Espectro de Energia dispersiva de Raio-X das impurezas do material do eletrodo. 


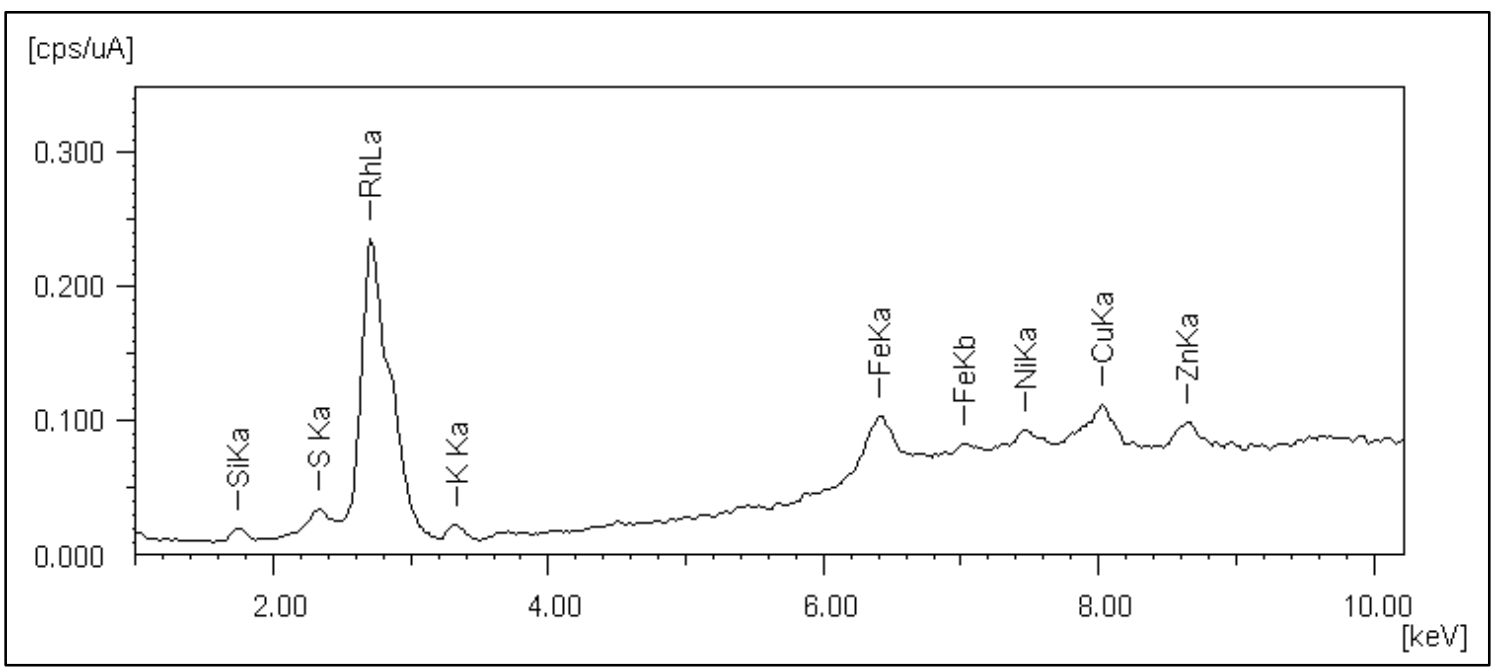

Figura 37 - Espectro de Fluorescência de Raios-X do material do eletrodo de um dos supercapacitores analisados.

Tabela 24 - Análise de fluorescência de Raios-X semiquantitativa do material do eletrodo

\begin{tabular}{cccc}
\hline Elemento & $\begin{array}{c}\text { Quantia } \\
{[\%]}\end{array}$ & Desvio padrão & $\begin{array}{c}\text { Intensidade } \\
{[\mathrm{cps} / \mu \mathrm{A}]}\end{array}$ \\
\hline $\mathrm{Si}$ & 23,96 & 0,59 & 0,036 \\
$\mathrm{~S}$ & 20,11 & 0,43 & 0,070 \\
$\mathrm{~K}$ & 19,35 & 0,73 & 0,032 \\
$\mathrm{Fe}$ & 14,16 & 0,28 & 0,434 \\
$\mathrm{Cu}$ & 9,26 & 0,23 & 0,392 \\
$\mathrm{Ni}$ & 8,33 & 0,28 & 0,253 \\
$\mathrm{Zn}$ & 4,80 & 0,22 & 0,201 \\
\hline
\end{tabular}




\section{ANÁLISE E DISCUSSÕES.}

Considerando que os supercapacitores investigados são compostos por duas células individuais, cada uma composta por dois eletrodos, objetivando atingir o máxima valor de potencial de trabalho de 5,5V, é possível inferir que o valor da $\operatorname{ESR}_{(I n s t)}$ para cada célula, assumindo que as mesmas são idênticas, é metade do valor da $E S R_{(I n s t)}$ apresentado pela Tabela 7. Por outro lado, o valor de capacitância de cada célula será o dobro do apresentado pelas Tabelas 10, 14, 18 e 22, já que as células são ligadas em série. Eletrólitos orgânicos, tais como o empregado nos capacitores estudados, têm uma janela de potencial de energia na faixa de $2,7 \mathrm{~V}$ e o armazenamento pode ser aumentado por um arranjo em série.

Os valores de capacitância só puderam ser comprados entre os métodos apresentados para os supercapacitores $\mathrm{S} 1, \mathrm{~S} 2$ e $\mathrm{S} 3$, expostos, respectivamente às temperaturas de $50^{\circ} \mathrm{C}, 75^{\circ} \mathrm{C}$ e $100^{\circ} \mathrm{C}$ em um montante de 672 horas de exposição, pois o capacitor $\mathrm{S} 4$, expostos a $125^{\circ} \mathrm{C}$ parou de apresentar propriedades elétricas após 504 horas de exposição a tal temperatura.

Em acordo com os dados coletados à temperatura ambiente, por meio dos quais o(s) valore(s) do erro de medição do parâmetro elétrico capacitância foram calculados para cada um dos métodos apresentados, que estão agrupados na Tabela 25, conclui-se que o erro de medição de $\pm 5,36 \%$ obtido pelo método da $C_{(D C)}$ é o de maior valor para tal parâmetro elétrico, sendo o de menor valor de erro de medição o de $\pm 0,41 \%$ apresentado pelo método da $\boldsymbol{C}_{(V C i M)}$ a $50 \mathrm{mV} / \mathrm{s}$. Na média o erro da medição proposto pelos métodos da voltametria cíclica não ultrapassa, em acordo com os dados resumidos na Tabela 25, a $1,00 \%$. Disto conclui-se que o equipamento e métodos que cercam a voltametria cíclica são mais estáveis e, portanto produzem valores mais confiáveis e mais próximos ao real. $\mathrm{O}$ tempo de obtenção dos dados para geração do valor da capacitância por meio da voltametria cíclica, não importando o método adotado, é de aproximadamente 7 minutos para uma taxa de $25 \mathrm{mV} / \mathrm{s}$, sendo esta a taxa mais demorada de obtenção de dados entre as taxas escolhidas, ao passo que a obtenção de dados por meio do método da corrente contínua é de aproximadamente 40 minutos, portanto mais um fator a depor a favor da voltametria cíclica. 
Conclui-se com base nos valores de incerteza expostos por meio da Tabela 25 que o método da $\boldsymbol{C}_{(V C i M)}$ oriundo da voltametria cíclica é mais eficaz para obtenção de valores da capacitância que os métodos $\boldsymbol{C}_{(\boldsymbol{A V C})}, C_{(V C V \rightarrow 0)}$ e $C_{(D C)}$.

Tabela 25 - Valores percentuais do erro de medição da capacitância em acordo com o método adotado

\begin{tabular}{ccc}
\hline Método & $\begin{array}{c}\text { S0: T }=\text { Ambiente } \\
\text { Erro de medição [\%] }\end{array}$ & $\begin{array}{c}\text { S0: T = Ambiente } \\
\text { Erro médio de } \\
\text { medição [\%] }\end{array}$ \\
\hline$C_{(D C)}$ & $\pm 5,36$ & Não se aplica \\
\hline $\boldsymbol{C}_{(A V C)}$ a $25 \mathrm{mV} / \mathrm{s}$ & $\pm 1,14$ & \\
$\boldsymbol{C}_{(A V C)}$ a $50 \mathrm{mV} / \mathrm{s}$ & $\pm 1,05$ & $\pm 1,00$ \\
$\boldsymbol{C}_{(A V C)}$ a $75 \mathrm{mV} / \mathrm{s}$ & $\pm 0,96$ & \\
$\boldsymbol{C}_{(A V C)}$ a $100 \mathrm{mV} / \mathrm{s}$ & $\pm 0,88$ & \\
$\boldsymbol{C}_{(V C i M)}$ a $25 \mathrm{mV} / \mathrm{s}$ & $\pm 0,47$ & \\
$\boldsymbol{C}_{(V C i M)}$ a $50 \mathrm{mV} / \mathrm{s}$ & $\pm 0,41$ & \\
$\boldsymbol{C}_{(V C i M)}$ a $75 \mathrm{mV} / \mathrm{s}$ & $\pm 1,11$ & \\
$\boldsymbol{C}_{(V C i M)}$ a $100 \mathrm{mV} / \mathrm{s}$ & $\pm 1,10$ & \\
$\boldsymbol{C}_{(V C V \rightarrow 0)}$ a $25 \mathrm{mV} / \mathrm{s}$ & $\pm 0,81$ & $\pm 0,88$ \\
$\boldsymbol{C}_{(V C V \rightarrow 0)}$ a $50 \mathrm{mV} / \mathrm{s}$ & $\pm 1,23$ & \\
$\boldsymbol{C}_{(V C V \rightarrow 0)}$ a $75 \mathrm{mV} / \mathrm{s}$ & $\pm 0,67$ & \\
$\boldsymbol{C}_{(V C V \rightarrow 0)}$ a $100 \mathrm{mV} / \mathrm{s}$ & $\pm 0,81$ & \\
\hline
\end{tabular}

É possível notar por meio dos valores de capacitância apresentados na Tabela 26, descontado o valor da incerteza, que há similaridade de valores de capacitância entre o método da corrente contínua e os métodos oriundos da voltametria cíclica apenas para as taxas de $25 \mathrm{mV} / \mathrm{s}$, onde a taxa de potência instantânea de transferência de energia é a menor de todas. 
Tabela 26 - Valores da capacitância após 672 horas de exposição em acordo com o método adotado

\begin{tabular}{|c|c|c|c|}
\hline Método & $\begin{array}{c}\mathrm{S} 1: \mathrm{T}=50^{\circ} \mathrm{C} \\
C[\mathrm{~F}]\end{array}$ & $\begin{array}{c}\mathrm{S} 2: \mathrm{T}=75^{\circ} \mathrm{C} \\
C[\mathrm{~F}]\end{array}$ & $\begin{array}{c}\mathrm{S} 3: \mathrm{T}=100^{\circ} \mathrm{C} \\
C[\mathrm{~F}]\end{array}$ \\
\hline$C_{(D C)}$ & $1,18 \pm 0,14$ & $1,11 \pm 0,14$ & $1,14 \pm 0,14$ \\
\hline$C_{(A V C)} \mathrm{a}$ & & $1,00 \pm 0,14$ & $1,05 \pm 0,05$ \\
\hline $25 \mathrm{mV} / \mathrm{s}$ & $0,88 \pm 0,12$ & & \\
\hline$C_{(A V C)} \mathrm{a}$ & & $0,83 \pm 0,09$ & $0,70 \pm 0,10$ \\
\hline $50 \mathrm{mV} / \mathrm{s}$ & $0,67 \pm 0,07$ & & \\
\hline$C_{(A V C)} \mathrm{a}$ & & $0,70 \pm 0,06$ & $0,45 \pm 0,02$ \\
\hline $75 \mathrm{mV} / \mathrm{s}$ & $0,51 \pm 0,04$ & & \\
\hline$C_{(A V C)} \mathrm{a}$ & & $0,60 \pm 0,05$ & $0,34 \pm 0,03$ \\
\hline $100 \mathrm{mV} / \mathrm{s}$ & $0,43 \pm 0,04$ & & \\
\hline $\begin{array}{c}\boldsymbol{C}_{(\text {VCiM })} \mathrm{a} \\
25 \mathrm{mV} / \mathrm{s}\end{array}$ & $0,86 \pm 0,02$ & $0,97 \pm 0,03$ & $0,86 \pm 0,02$ \\
\hline $\begin{array}{c}C_{(V C i M)} \text { a } \\
50 \mathrm{mV} / \mathrm{s}\end{array}$ & $0,66 \pm 0,02$ & $0,81 \pm 0,02$ & $0,65 \pm 0,02$ \\
\hline $\begin{array}{c}\boldsymbol{C}_{(\text {VCiM })} \mathrm{a} \\
75 \mathrm{mV} / \mathrm{s}\end{array}$ & $0,53 \pm 0,06$ & $0,68 \pm 0,08$ & $0,50 \pm 0,06$ \\
\hline $\begin{array}{l}C_{(V C i M)} \text { a } \\
100 \mathrm{mV} / \mathrm{s}\end{array}$ & $0,43 \pm 0,07$ & $0,59 \pm 0,09$ & $0,40 \pm 0,06$ \\
\hline $\begin{array}{c}C_{(V C V \rightarrow 0)} \mathrm{a} \\
25 \mathrm{mV} / \mathrm{s}\end{array}$ & $0,99 \pm 0,05$ & $1,05 \pm 0,05$ & $1,05 \pm 0,05$ \\
\hline $\begin{array}{c}C_{(V C V \rightarrow 0)} \mathrm{a} \\
50 \mathrm{mV} / \mathrm{s}\end{array}$ & $0,73 \pm 0,10$ & $0,95 \pm 0,13$ & $0,70 \pm 0,10$ \\
\hline $\begin{array}{c}C_{(V C V \rightarrow 0)} \mathrm{a} \\
75 \mathrm{mV} / \mathrm{s}\end{array}$ & $0,85 \pm 0,04$ & $0,77 \pm 0,03$ & $0,45 \pm 0,02$ \\
\hline $\begin{array}{c}C_{(V C V \rightarrow 0)} \mathrm{a} \\
100 \mathrm{mV} / \mathrm{s}\end{array}$ & $0,42 \pm 0,03$ & $0,83 \pm 0,06$ & $0,34 \pm 0,03$ \\
\hline
\end{tabular}

A

figura 38 foi gerada a partir dos dados referentes à capacitância específica do supercapacitor exposto a temperatura de $50^{\circ} \mathrm{C}$ durante 672 horas, tem por objetivo propor uma maneira de comparar graficamente os valores da capacitância específica em acordo 
com o método adotado e velocidade de varredura adotada (taxa de varredura adotada), ou no caso da $C_{(D C)}$, que utilizou corrente de descarga constante de $1 \mathrm{~mA}$, a intensidade da corrente de descarga, evidenciando a dependência entre resultados do valor de capacitância e velocidade de varredura $(d V / d t)$ ou intensidade de corrente adotados.

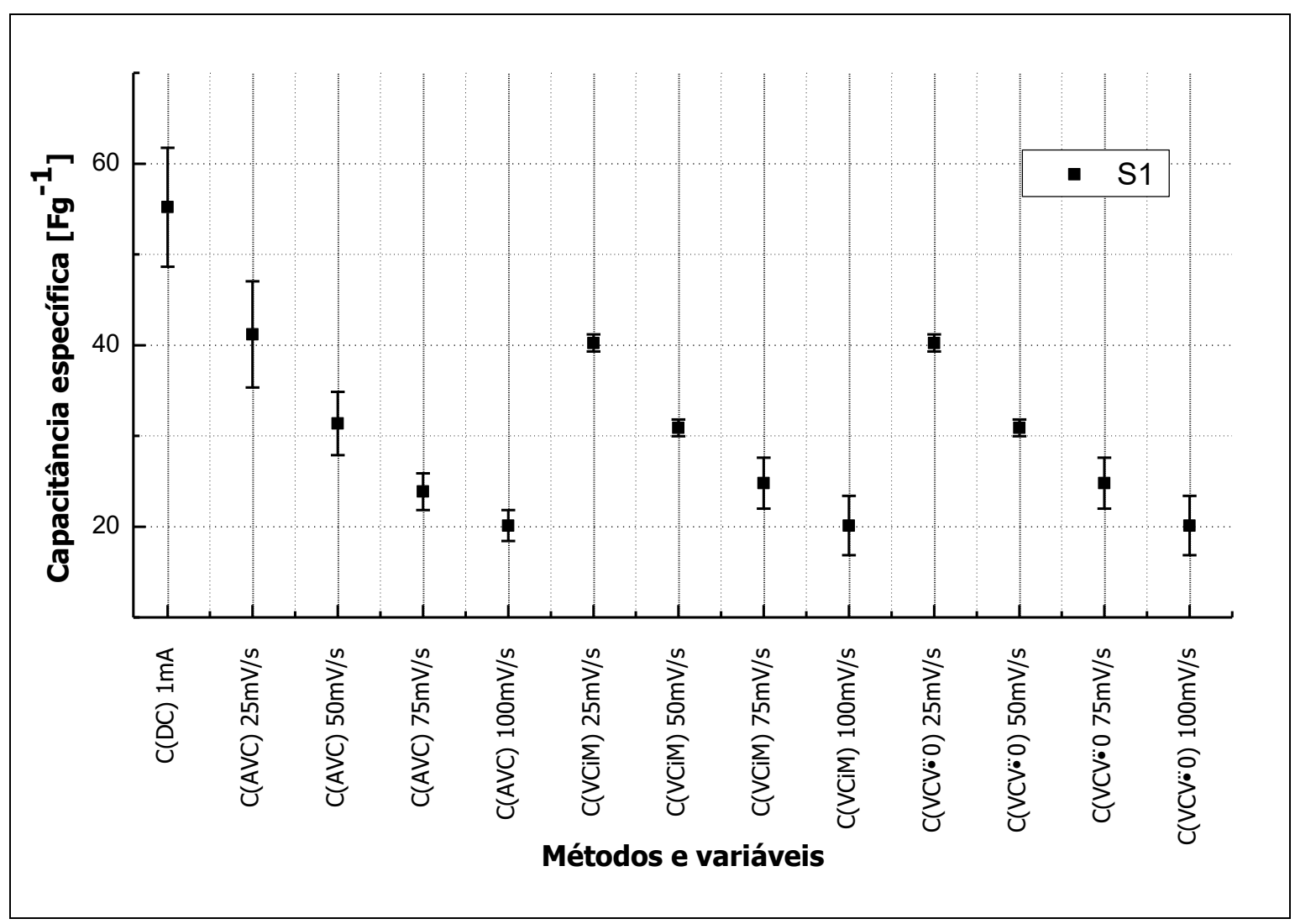

Figura 38 - Valores da capacitância em acordo com o método e velocidade de varredura adotada ou intensidade de corrente de descarga $\left(\mathrm{C}_{(\mathrm{DC})}\right)$.

Não só na voltametria cíclica, em acordo com a taxa de varredura em volts e, portanto indiretamente em acordo com a taxa de varredura em ampères que os valores de capacitância mudam.

Se diferentes valores de corrente de descarga constante forem utilizados, o valor da capacitância obtido pelo método DC apresentará diferença de valores como evidenciado na figura 34 , em que os valores foram obtidos por meio dos procedimentos adotados para obtenção do valor de capacitância CD anteriormente descritos, fazendo-se uso do supercapacitor S0. Ressalta-se que as barras de incerteza apresentadas na figura 34 são oriundas do valor percentual de tolerância de 10,98\% e do erro de medição de 5,36\% para a corrente de descarga de $1 \mathrm{~mA}, 8,32 \%$ para a corrente de descarga de $10 \mathrm{~mA}, 12,32 \%$ para a corrente de descarga de $20 \mathrm{~mA}$ e de $18,63 \%$ para a corrente de descarga de $40 \mathrm{~mA}$. 
Os valores dos erros de medição foram obtidos por meio de dez medições do valor de capacitância para cada uma das correntes citadas. Observa-se por meio da figura 34 que à medida que a corrente de descarga aumenta o erro de medição e, portanto a incerteza aumenta. Tal aumento no valor do erro de medição ocorre em virtude do método empregado no controle da corrente de descarga que é manual e, portanto à medida que a corrente de descarga aumenta dificuldades de ajuste do resistor variável, que controla a corrente, fazem com que o valor de corrente de descarga divirja do valor esperado; portanto quanto maior o valor de corrente de descarga maior a incerteza. Isto não ocorre quando se utiliza o analisador digital ARBIN BT -4.

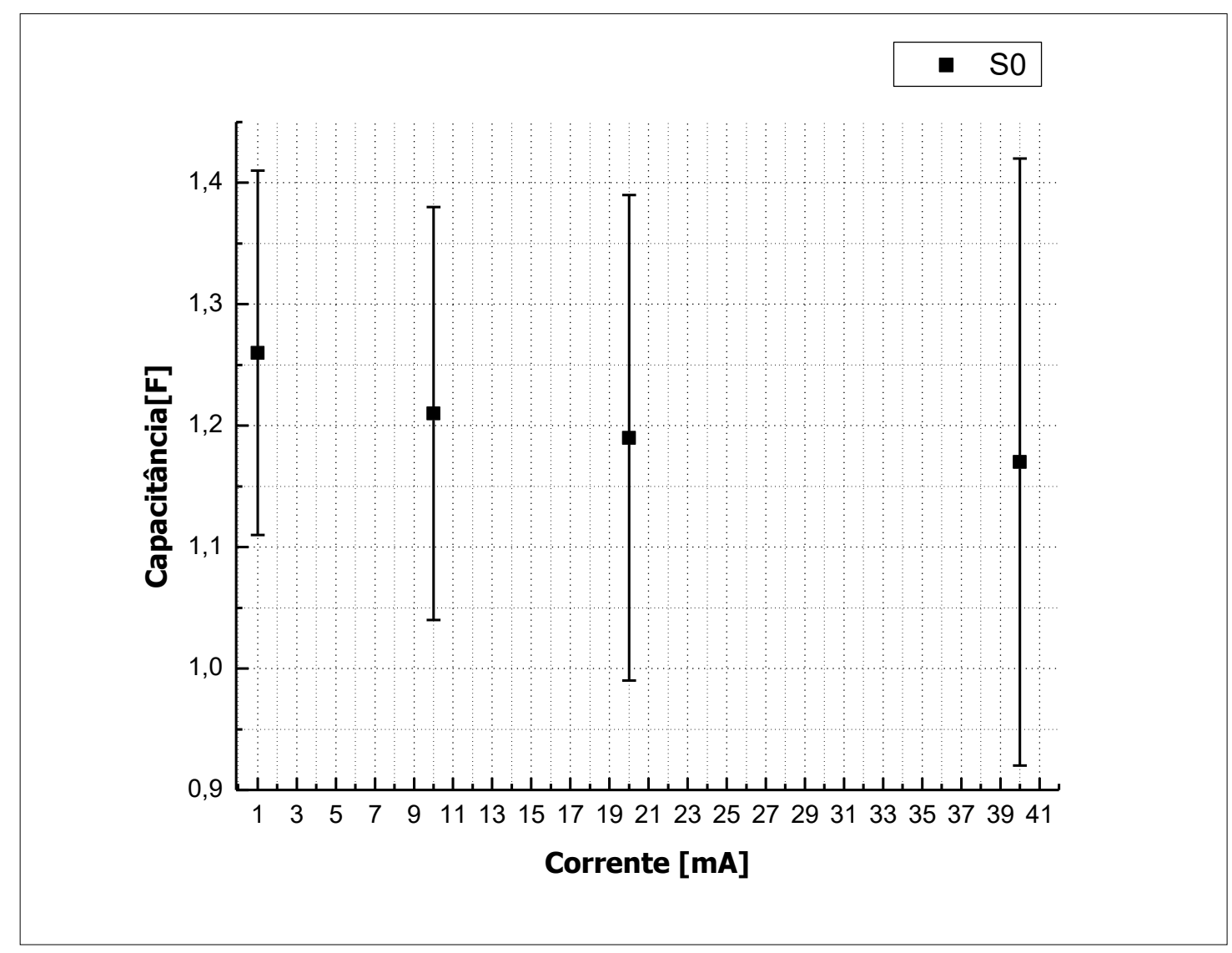

Figura 39 - Valores da capacitância em acordo com o método e velocidade de varredura adotada ou intensidade de corrente de descarga $\left(\mathrm{C}_{(\mathrm{DC})}\right)$.

Conclui-se desta maneira que ao medir os valores de capacitância, independentemente do método adotado, deve-se estar ciente de que variações propostas nos parâmetros de entrada irão alterar os valores de saída de tal parâmetro elétrico, pois, conclusivamente, a capacitância de supercapacitores sempre será diferenciáveis em relação às condições e métodos de medição. 
Outras causas da degradação dos supercapacitores foram estudadas a partir de várias fontes, incluindo algumas patentes e podem ser resumidos como segue (Kurzweil P., 2008):

- O oxigênio e impurezas metálicas também têm sido atribuídos ao dano do eletrodo e aumento da resistência em série.

- A redução da corrente de carga e descarga tem sido associada à presença de grupos ácidos na superfície de carvão ativado.

- A água presente no solvente do eletrólito orgânico reduz a janela do potencial influenciando no envelhecimento de supercapacitores e produzindo gases com degradação do desempenho eletroquímico, bloqueando os poros do carvão ativado do eletrodo e do separador, aumentando desta forma a resistência em série equivalente. Gases são normalmente gerados para potencial superior a $2,5 \mathrm{~V}$ por célula.

- A corrente de fuga tem sido associada à presença de grupos ácidos na superfície de carvão ativado, o que é decorrente de falhas no processo de limpeza da superfície dos eletrodos após produção de porosidade no carvão ativado.

- O ligante utilizado na junção dos grãos de carvão ativado, ou fibra de carbono, ou lâminas de grafeno, tem sido suspeito de ser uma das causas da diminuição da capacitância e aumento da $E S R_{(I n s t)}$.

- O ligante também pode degradar em temperaturas elevadas combinada com o tempo de exposição prolongado, criando espaçamentos entre o material granular do eletrodo, reduzindo assim a $E S R_{(I n s t)}$.

- Altas temperaturas também provocam a evaporação do eletrólito se a selagem das células que constituem o supercapacitor não for suficientemente forte (adequada à aplicação) para resistir ao aumento da pressão. Assim a expectativa de vida útil é reduzida drasticamente com um pequeno aumento da temperatura além da temperatura de funcionamento dos supercapacitores (Rajan \& Rahman, 2014). 


\section{CONCLUSÕES.}

Os resultados mostraram que os valores de capacitância pouco mudam com o acúmulo de energia térmica.

Em longo prazo, a uma temperatura elevada, a $E P R_{(D e p)}$ diminui drasticamente. A autodescarga é o parâmetro mais sensível para avaliar a degradação da $E P R_{(D e p)}$ em supercapacitores.

As taxas de autodescarga aceleraram fortemente com o aumento da temperatura de trabalho.

O parâmetro que mais sofre alteração com a temperatura foi a $E P R_{(D e p)}$. Assim é de se esperar que sejam realizadas pesquisas para melhorar tal parâmetro, principalmente em aplicações veiculares ou nos locais onde os supercapacitores serão expostos a altas temperaturas.

$\mathrm{O}$ valor da $E S R_{(I n s t)}$ pouco muda com a temperatura.

O valor determinado da capacitância DC só tem significado quando é especificada a condição de medida, isto é, corrente de carga e descarga por Farad $\left(\mathrm{mAF}^{-1}\right)$, quando a capacidade nominal do supercapacitor comercial é conhecida, ou então, densidade de corrente $\left(\mathrm{Ag}^{-1}\right)$ quando se mede um supercapacitor produzido com material experimental.

Como observação contundente é de se saber que para a voltametria cíclica, o valor da capacitância, não importando o método do qual este tenha sido oriundo, só fará sentido se estiver atrelado e, portanto diferenciado a uma taxa de varredura. A medida que a taxa de varredura cresce é de se esperar que a capacitância venha a diminuir, já que se requer do capacitor, a cada intervalo de tempo, uma resposta mais rápida para retenção de cargas à medida que o potencial vai crescendo em módulo. Nem todos os capacitores conseguem manter um valor de corrente proporcional ao potencial aplicado, reduzindo desta maneira a quantia de cargas armazenadas. Se um capacitor tem um valor de ESR elevado é de se esperar que ocorra uma elevação do índice de inclinação (slope) na reta cartesiana gerada pelos valores de corrente dependentes de potencial $[\mathrm{i}(\mathrm{t})=\mathrm{f}(\mathrm{V}(\mathrm{t}))]$ à medida que a taxa de varredura aumenta.

A microestrutura do eletrodo, constituído de carvão ativado, mostrou uma característica bastante homogênea, não apresentando regiões porosas obstruídas, regiões vastamente contaminadas e nem fissuras, com um valor médio da maior dimensão dos grãos de aproximadamente 40 micrometros. De forma geral a estrutura do material está 
adequada ao propósito de servir como eletrodo para supercapacitores em acordo com a grande homogeneidade e quantia de poros por volume. A análise de fluorescência de Raios-X semiquantitativa do material do eletrodo mostrou Si, S, K e Fe como principais contaminantes. A análise por energia dispersiva de Raios-X mostrou picos de $\mathrm{Si}$, Sn, e Fe (devido ao baixo número atômico, $\mathrm{C}, \mathrm{F}$ e $\mathrm{O}$ não foram considerados na análise). 


\section{REFERÊNCIAS BIBLIOGRÁFICAS.}

AZAIS, P.; DUCALUX, L.; FLORIAN, P.; MASSIOT, D.; ANGELES, M.; RODENAS, L.; Et Al. Causes of supercapacitors ageing in organic electrolyte. Journal of Power Sources, V 171, p. 1046-1053, 2007.

BAN, S.; ZHANG, J.; LEI, Z.; TSAY, K.; SONG, D.; ZOU, X. Charging and discharging electrochemical supercapacitors in the presence of both parallel leakage process and electrochemical decomposition of solvent. London, ON, Canada N6A 5B7, Canada, 2013.

BRESCANSIN, L. M. Cursos UNICAMP, Curso Regular de Graduação, Primeiro semestre de 2013, Instituto de Física "Gleb Wataghin" Universidade Estadual de Campinas (IFGW Unicamp) - FÍSICA GERAL III - Aula 5 Capacitores e Dielétricos [Filme Cinematográfico], 2013.

CARVALHO, L. L. Construção e caracterização eletroquímica de eletrodos baseados em grafeno - Dissertação apresentada ao Instituto de Química da Universidade de São Paulo para obtenção do título de Mestre em Química, São Paulo, 2014.

CHMIOLA, J. Pore-size ion-size correlations for carbon supercapacitors. Tese apresentada a faculdade de Drexel por John Chmiola como parte dos requisistos para obtenção do grau de Doutor em Filosofia, Philadelphia, USA, 2009.

CONWAY, B. E. In: Electrochemical Supercapacitors: Scientific Fundamentals and Technological Applications (p. 1-8). Ontario: Springer, 1999.

DIAB, Y.; VENET, P.; GUALOUS, H.; ROJAT, G. Self-Discharge Characterization and Modeling of Electrochemical Capacitor Used for Power Electronics Applications. IEEE TRANSACTIONS ON POWER ELECTRONICS, VOL. 24, NO. 2, p. 509-517, 2009.

EDMINISTER, J. A. Circuitos elétricos. São Paulo: Pearson Education, 1991.

FRANCO, J. R. Caracterização Eletroquímica de material ativo de eletrodo de supercapacitor baseado em nanocompósitos de nanotubos de carbono e óxido de níquel. Viçosa, Minas Gerais, Brasil, 2014.

GUJAR, T.; KIM, W. Y.; PUSPITASARI, I.; JUNG, K. D.; JOO, O. S. Electrochemically Deposited Nanograin Ruthenium Oxide as a Pseudocapacitive Electrode. International Eletrochemical Science, p. 668, 2007.

HUANG, P. On-chip micro-supercapacitors based on nano-structured carbon materials. HAL, p. 124, 2013.

JÚNIOR, R. N. F. Baterias Recarregáveis. Introdução aos Materiais e Cálculos. São Paulo: Artliber, 2014. 
KÖTZ, M.; CARLEN, M. Principles and aplications of electrochemical capacitors. Baden, Dättwil, Switzerland, 1999.

KURZWEIL P.; C. M. Electrochemical stability of organic electrolyte in supercapacitors: Spectroscopy and gas ananlysis of decomposition products. Journal of Power Sources, pp. 176, 555, 2008.

KURZWEIL, P.; CHWISTEK, M.; GALLAY, R. Electrochemical and Spectroscopic Studies on Rated Capacitance and Aging Mechanisms of Supercapacitors. 2nd European Symposium on Super Capacitors \& Applications (ESSCAP), 23. Lusanne, 2006

Supercapacitores. Disponível em: www.maxwell.com/products/ultracapacitors. Acessado em dezembro de 2015.

MUSSOI, F. L.; VILLAÇA, M. V. Capacitores, $3^{\text {a }}$ edição. Florianópolis, BRASIL, 2000.

NAMISNYK, A. M. A Survey of Eletrochemical Supercapacitor Technology - Project Submitted for the Degree of Bachelor of Engineering. Sydney, Austrália, 2003.

PANNO, N. F. ELETRÓlITOS À BASE DE LÍQUIDO IÔNICO BMI.BF4 PARA APLICAÇÃO EM CAPACITORES ELETROQUÍMICOS DE NÍQUEL. Dissertação apresentada ao Instituto de Química da Universidade do Rio Grande do Sul como requisito para obtenção do título Químico Industrial. Porto Alegre, RS, Brasil, 2010.

PARK G. Graphite: application to anode and cathode materials for energy storage device. Doctor Thesis, Saga University, p. 19, 2010.

RAJAN, R. S.; RAHMAN, M. Lifetime Analysis of Super Capacitor for Many Power Electronics Applications. IOSR Journal of Electrical and Electronics Engineering (IOSRJEEE), Volume 9, Issue 1 Ver. IV, pp. 55-58, 2014.

SCHINDALL, J. E.; KASSAKIAN, J. G.; KU, D. C.; RICCARDO, S. Electrochemical Double-Layer Capacitors Using Carbon Nanotube Electrode Structures. MIT Open Access Article. Cambridge, Massachusetts, USA, 2016.

WANG, Y. Modeling of Ultracapacitor Short-term and Long-term Dynamic Behavior. A Thesis Present to The Granduate Faculty of The University of Akron. Akron, Ohio, USA, 2008.

Capacitors. Disponível em: www.en.wikipedia.org/wiki/Capacitorm. Acessado em janeiro de 


\section{PUBLICAÇÕES}

Artigos completos apresentados em Conferência Internacional em 2015:

Tenth International Latin American Conference on Powder Technology, 08-11 November, 2015, RJ.

1) Thermal influence on the electric parameter and microstructure of activated powder double layer supercapacitors, Antonio Paulo Rodrigues Fernandez, Eguiberto Galego, Rubens Nunes de Faria Jr., Accepted to be published on the Materials Science Forum in 2016.

2) Supercapacitor application of powder prepared using the hydrogenation disproportionation desorption and recombination (HDDR) process in graphene oxide, Julio Cesar Serafim Casini, Antonio Paulo Rodrigues Fernandez, Rene Ramos de Oliveira, Solange Kazumi Sakata, Rubens Nunes de Faria Jr., Accepted to be published on the Materials Science Forum in 2016. 